US Army Corps

of Engineers ${ }_{\circledast}$

Engineer Research and

Development Center

Development and Testing of the Training Range Environmental Evaluation and Characterization System (TREECS ${ }^{\mathrm{TM}}$ ) for Arctic/Sub-Arctic Conditions

Mark S. Dortch, Jodi L. Ryder, Jeffrey A. Gerald, September 2019 and Billy E. Johnson 
The U.S. Army Engineer Research and Development Center (ERDC) solves the nation's toughest engineering and environmental challenges. ERDC develops innovative solutions in civil and military engineering, geospatial sciences, water resources, and environmental sciences for the Army, the Department of Defense, civilian agencies, and our nation's public good. Find out more at www.erdc.usace.army.mil.

To search for other technical reports published by ERDC, visit the ERDC online library at http://acwc.sdp.sirsi.net/client/default. 


\section{Development and Testing of the Training Range Environmental Evaluation and Characterization System (TREECSTM) for Arctic/Sub-Arctic Conditions}

Mark S. Dortch, Jodi L. Ryder, Jeffrey A. Gerald, and Billy E. Johnson

Environmental Laboratory (EL)

U.S. Army Research and Development Center

3909 Halls Ferry Road

Vicksburg, MS 39180-6199

Final report

Approved for public release; distribution is unlimited.

Prepared for Headquarters, U.S. Army Corps of Engineers

Washington, DC 20314-1000

Under Project number ER-201435 


\section{Abstract}

The Training Range Environmental Evaluation and Characterization System (TREECS ${ }^{\mathrm{TM}}$ ) was developed for the U. S. Army to forecast the fate of and risk from munitions constituents (MC) (e.g., high explosives and metals), within, and transported from, firing/training ranges to surface water and groundwater. The military footprint of the United States (U.S.) in the Arctic region falls within the state of Alaska, where the U.S. Army manages approximately $10 \%$ of all active Army training lands worldwide. Primary recalcitrant contaminants of concern at active and previouslyused training ranges include energetics, high explosives, and heavy metals. There are limited management tools for assessing contaminant fate and transport and identifying risks in Arctic environments. TREECS ${ }^{\mathrm{TM}}$ can handle a wide variety of site conditions and has been applied to a variety of temperate sites. However, previous versions had limitations for application to Arctic conditions. The work reported herein was conducted to overcome these limitations. This report describes the changes implemented in TREECS ${ }^{\mathrm{TM}}$ for handling Arctic conditions as well as application test results.

DISCLAIMER: The contents of this report are not to be used for advertising, publication, or promotional purposes. Citation of trade names does not constitute an official endorsement or approval of the use of such commercial products. All product names and trademarks cited are the property of their respective owners. The findings of this report are not to be construed as an official Department of the Army position unless so designated by other authorized documents. 


\section{Contents}

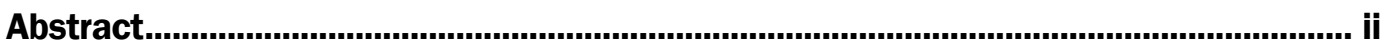

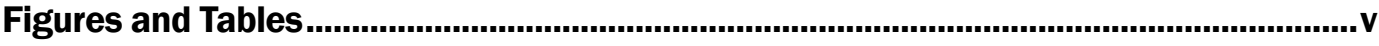

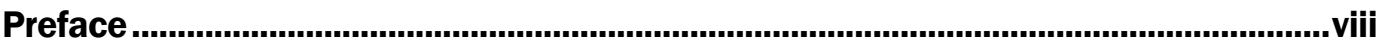

List of Acronyms, Abbreviations, and Symbols ........................................................ ix

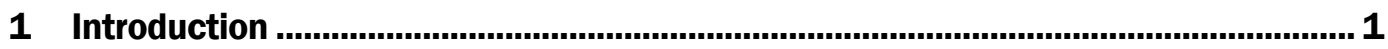

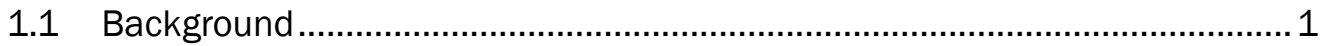

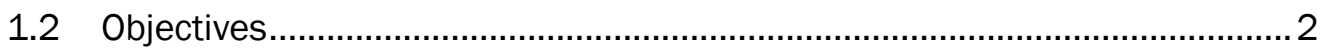

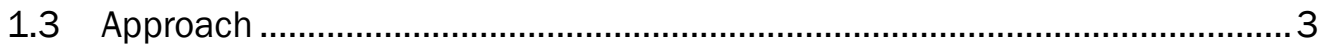

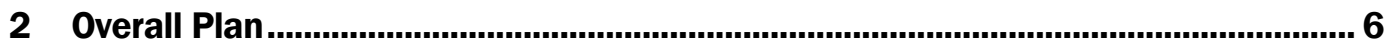

2.1 Surface soil water movement and contaminant $F / T$ with

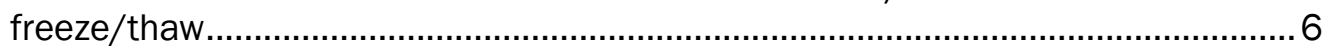

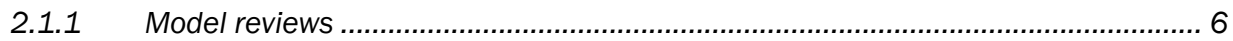

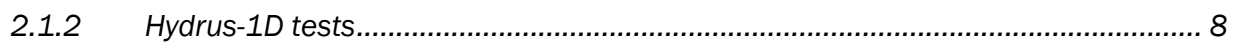

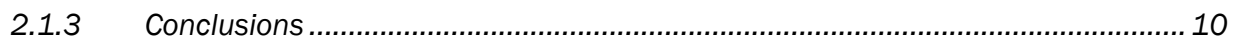

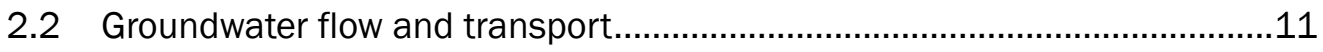

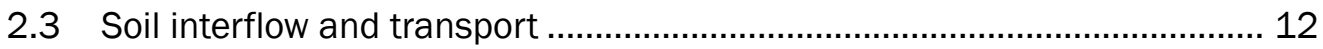

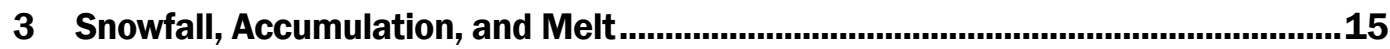

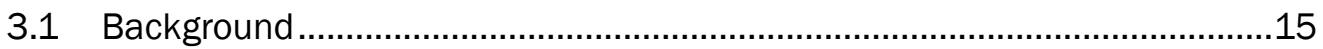

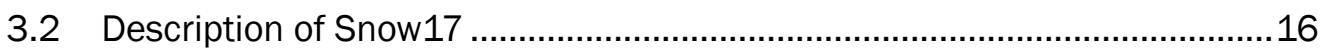

3.3 Conversion of snow cover from SWE to actual depth ................................. 18

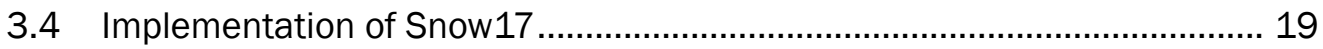

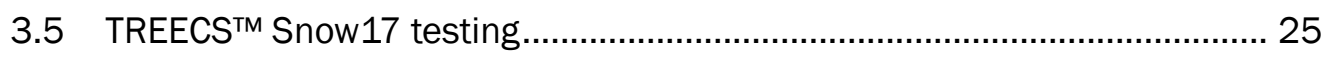

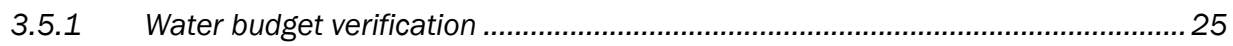

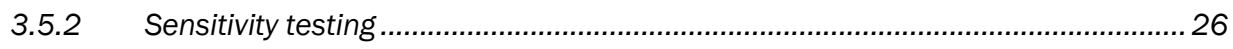

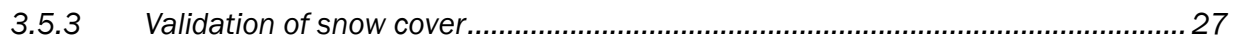

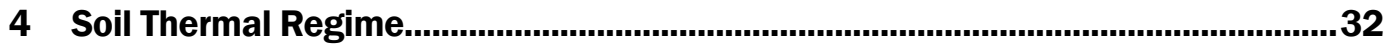

4.1 Implementation of the GIPL model and input............................................. 32

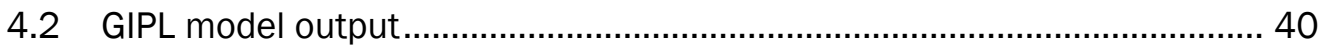

4.3 TREECSTM GIPL verification and validation .......................................... 45

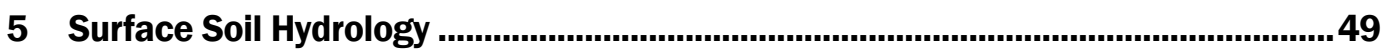

5.1 Description of Arctic surface soil hydrology model.......................................49

5.2 Implementation of the Arctic surface soil hydrology model ........................56

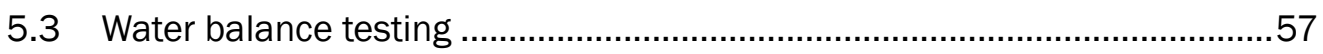

6 Changes to the HGCT

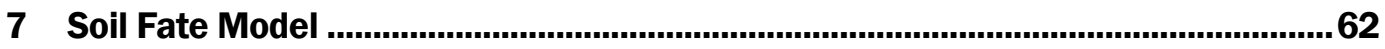


7.1 Description of changes for the Arctic soil fate model................................62 62

7.2 Implementation of the Arctic soil fate model and related processors ........ 65

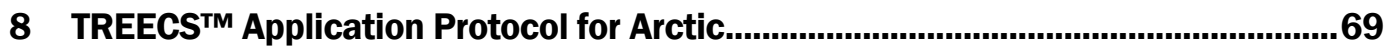

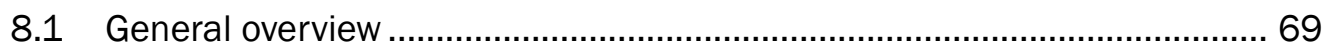

8.2 TREECS ${ }^{\mathrm{TM}}$ application methodology ...................................................... 71

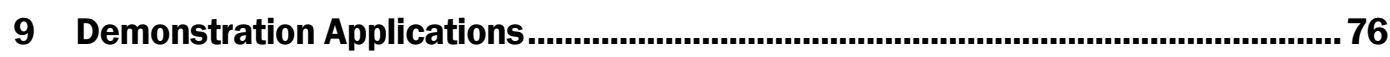

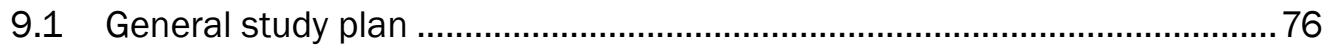

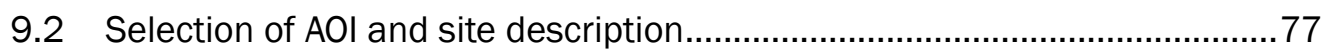

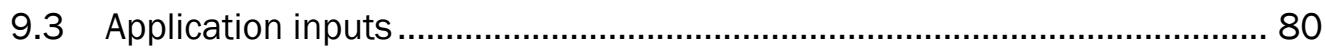

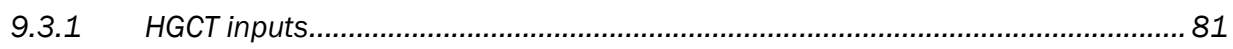

9.3.2 Soil fate model inputs.............................................................................. 82

9.3.3 Vadose zone and aquifer model inputs ............................................................ 83

9.3.4 Soil interflow fate/transport model inputs ....................................................... 84

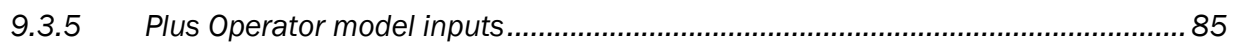

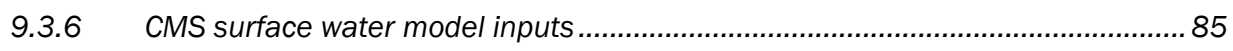

9.4 Model results for base case scenario ....................................................... 86

9.4.1 Soil AOI concentrations and fluxes .................................................................... 87

9.4.2 Soil interflow mass fluxes to surface water.......................................................... 92

9.4.3 Combined mass fluxes to surface water .............................................................. 93

9.4.4 Surface water and sediment concentrations .....................................................94

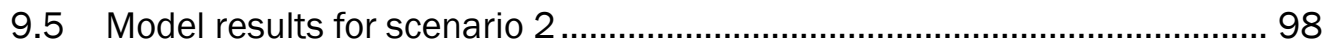

9.5.1 Soil AOl concentrations and fluxes ..................................................................... 98

9.5.2 Vadose zone fluxes and aquifer concentrations ..................................................99

9.5.3 Soil interflow mass fluxes to surface water.........................................................101

9.5.4 Combined mass fluxes to surface water ...........................................................101

9.5.5 Surface water and sediment concentrations ................................................... 102

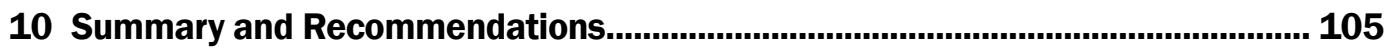

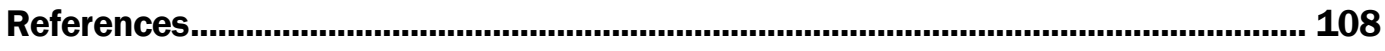

Appendix A: GIPL Input and Output files.......................................................... 113

Report Documentation Page 


\section{Figures and Tables}

\section{Figures}

Figure 1. Schematic of soil profile with permafrost (from https://www.erdc.usace.army.mil/CRREL/Permafrost-Tunnel-Research-Facility/GeneralFacts/).

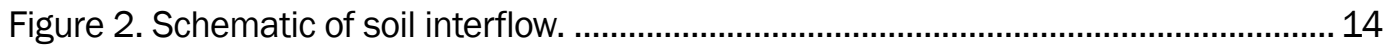

Figure 3. Example of precipitation input file used by TREECS ${ }^{\mathrm{TM}}$ Snow17. ...........................20

Figure 4. Example of air temperature input file used by TREECS ${ }^{\text {TM }}$ Snow17.......................20

Figure 5. TREECS ${ }^{\text {TM }}$ Snow17 model parameters input file,

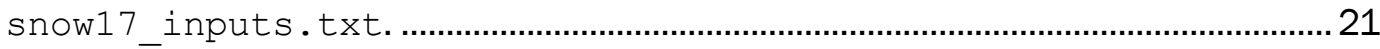

Figure 6. Example of TREECS'M Snow17 output file, snow17_outputs . txt. ............. 24

Figure 7. Example of TREECS ${ }^{\text {TM }}$ Snow17 output file, SnowCoverMeltDepth. txt.

Figure 8. Predicted and observed snow depths vs. days of simulation with $\rho_{0}=$ 0.2 and $k_{s}=0.07,2010-2016$, Fairbanks International Airport, AK.

Figure 9. Predicted vs. observed snow depths with $\rho_{0}=0.2$ and $k_{s}=0.07$ compared with a perfect fit (black line), 2010-2016, Fairbanks International Airport, AK.

Figure 10. Cumulative probably distribution for model-computed and observed snow depths with $\rho_{0}=0.2$ and $k_{s}=0.07,2010-2016$, Fairbanks International Airport, AK.

Figure 11. Example of GIPL processor input tab used to create the control file for TREECSTM GIPL, gipl_config. cfg.

Figure 12. Example of sites input tab used by the TREECSTM GIPL pre-processor to create the in/sites. txt file.

Figure 13. Example of grid input tab used by the TREECSTM GIPL preprocessor to create the in/grid. txt file.

Figure 14. Example of mineral input tab used by TREECSTM GIPL preprocessor to create the in/mineral. txt file.

Figure 15. Example of organic input file used by the TREECSTM GIPL preprocessor to create the in/organic.txt file...

Figure 16. Example of bound input tab used by the TREECSTM GIPL preprocessor to create the in/bound.txt, in/snow.txt, and in/rsnow.txt files.

Figure 17. Example of initial input file used by the TREECSTM GIPL preprocessor to create the in/initial. txt file.

Figure 18. Example of the GIPL_output tab produced by TREECSTM GIPL running in the preprocessor. This tab presents the data in the dump/result. txt file.

Figure 19. Example plots from the GIPL_output tab in the TREECSTM GIPL preprocessor: Part a) shallowest unfrozen node depth time series, Part b) output time series, Part c) input vs. output, and Part d) depth profiles.

Figure 20. Goldstream Histels complex used in validation of TREECSTM GIPL 
Figure 21. Schematic of water pathways at the top of the soil column.............................49

Figure 22. Schematic of Arctic soil hydrologic processes and water balance....................52

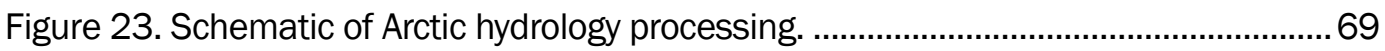

Figure 24. Schematic of TREECS ${ }^{\text {TM }}$ application methodology for Arctic regions................. 70

Figure 25. FRAMES work space within TREECS ${ }^{\text {TM }}$ for case ArcCa se . trp......................73

Figure 26. Map of Alaska showing Forts Wainwright and Richardson and

associated training areas (from CSU 2004b)...................................................................... 77

Figure 27. SCIA of the YTA (modified from CSU 2004b)................................................... 78

Figure 28. Streams of YTA (modified from CSU 2004b)................................................... 78

Figure 29. Artillery impact area of the SCIA (from rendering in Google Earth Pro

$\odot)$.

Figure 30. Computed RDX total concentration vs. year in AOI soil, base case (SCIA1) (continuous permafrost)

Figure 31. Computed RDX pore-water dissolved concentration vs. year in AOI soil, base case (SCIA1) (continuous permafrost).

Figure 32. Rainfall rate vs. year, Fairbanks International Airport, AK................................90

Figure 33. Cumulative rainfall vs. year, Fairbanks International Airport, AK.....................90

Figure 34. Computed RDX adsorbed mass flux from AOI soil to surface water (due to soil erosion) vs. year, base case (SCIA1) (continuous permafrost).

Figure 35. Computed RDX dissolved mass flux from AOI soil to surface water (due to rainfall impact and runoff) vs. year, base case (SCIA1) (continuous permafrost).

Figure 36. Computed RDX dissolved mass flux from AOI soil to soil interflow vs. year, base case (SCIA1) (continuous permafrost).

Figure 37. Computed RDX dissolved mass flux from soil interflow to surface water vs. year, base case (SCIA1) (continuous permafrost).

Figure 38. Computed, combined, total (adsorbed and dissolved) RDX mass flux to surface water (from Plus Operator output) vs. year, base case or SCIA1 (continuous permafrost).

Figure 39. Computed total RDX concentration in sediment vs. year in Stuart Creek at the confluence with South Fork Chena River, base case (SCIA1) (continuous permafrost) with background flow.

Figure 40. Computed total RDX concentration in water column vs. year in Stuart Creek at the confluence with South Fork Chena River, base case (SCIA1) (continuous permafrost) with background flow.

Figure 41. Computed total RDX concentration in sediment vs. year in Stuart Creek at the confluence with South Fork Chena River, base case (SCIA1) (continuous permafrost) without background flow.

Figure 42. Computed total RDX concentration in water column vs. year in Stuart Creek at the confluence with South Fork Chena River, base case (SCIA1) (continuous permafrost) without background flow.

Figure 43. Computed RDX dissolved mass flux from AOI soil to soil interflow vs. year for scenario 2 (SCIA2) (no permafrost).

Figure 44. Computed RDX dissolved mass flux from AOI soil to vadose zone vs. year, scenario 2 (SCIA2) (no permafrost). 
Figure 45. Computed RDX dissolved mass flux through the vadose zone and entering the aquifer vs. year, scenario 2 (SCIA2) (no permafrost).

Figure 46. Computed RDX dissolved concentration at groundwater well vs. year, scenario 2 (SCIA2) (no permafrost).

Figure 47. Computed RDX dissolved mass flux from soil interflow to surface water vs. year, scenario 2 (SCIA2) (no permafrost).

Figure 48. Computed, combined, total (adsorbed and dissolved) RDX mass flux to surface water (from Plus Operator output) vs. year, scenario 2 (SCIA2) (no permafrost).

Figure 49. Computed total RDX concentration in sediment vs. year in Stuart Creek at the confluence with South Fork Chena River, scenario 2 (SCIA2) (no permafrost) with background flow.

Figure 50. Computed total RDX concentration in water column vs. year in Stuart Creek at the confluence with South Fork Chena River, scenario 2 (SCIA2) (no permafrost) with background flow.

\section{Tables}

Table 1. Water flow parameters used in Hydrus-1D tests. 9

Table 2. Description of TREECS ${ }^{\mathrm{TM}}$ Snow17 model parameter inputs.

Table 3. Initial and maximum snow cover density by snow class from Sturm et al. (2010)

Table 4. Description of TREECSTM GIPL input parameters for the

gipl_config.cfg, in/sites.txt, and in/grid.txt files 34

Table 5. Description of TREECS ${ }^{\text {TM }}$ GIPL input parameters...................................................35

Table 6. Description of TREECSTM GIPL output parameters.

Table 7. Permafrost classifications with fraction of surface area coverage (based on various Internet searches). 


\section{Preface}

This study was funded by the U.S. Army's Environmental Quality and Installations (EQI) Research Program under the focus area Military Materials in the Environment. The work was performed under Task 5, under Project Number 0602720A, entitled "Incorporate Field Relevant Numerical Descriptors of Biotic/Abiotic Factors Affecting Contaminant Transformation to Extend the Capabilities of Fate and Transport Models to Characterize Potential Risks for Adaptive Ecosystem Management," of the EQI project "Biogeochemical Processes affecting Military Materials in Arctic/Sub-Arctic Terrestrial Environments."

The study was conducted by LimnoTech, Inc. and the U. S. Army Engineer Research and Development Center (ERDC) Environmental Laboratory (EL) under the general direction of Mr. Mark Noel, Chief, Water Quality and Contaminant Modeling Branch (WQCMB); and Mr. Warren Lorentz, Chief, Environmental Processes and Engineering Division (EPED). Dr. Elizabeth Ferguson, of the ERDC-EL, was the Technical Director of Military Materials in the Environment. Mr. David Ringelberg, ERDC-Cold Regions Research and Engineering Laboratory (CRREL) was the Program Manager, and Dr. Karl Indest, ERDC-EL, was the Principal Investigator for the project. Dr. Jack E. Davis was Deputy Director, and Dr. Ilker R. Adiguzel was the Director of EL.

COL Teresa A. Schlosser was the Commander of ERDC and Dr. David W. Pittman was the Director of ERDC. 


\section{List of Acronyms, Abbreviations, and Symbols}

\section{Acronyms and Abbreviations}

AA

ALT

AALT

AALTmin

AAALT

$\mathrm{AK}$

AOI

ATI

CMS

CRREL

CSU

DERP

decay

DES

DBD

DoD

DTA

EL

EPED

ERDC

ET

FRAMES

FUDS

$\mathrm{F} / \mathrm{T}$

GIPL

$\mathrm{HE}$

HGCT

$\mathrm{MC}$

MEPAS

MUSLE

NCDC

NCEI

NOAA

NWS

PET
Average annual hydrology, a modeling option in TREECS ${ }^{\mathrm{TM}}$

Daily thawed active layer temperature of the soil as

determined by the GIPL model, ${ }^{\circ} \mathrm{C}$

Annual active layer thickness of thawed surface soil, which is the maximum thawed soil layer thickness for the year, $m$

The minimum AALT for the simulation period, $\mathrm{m}$

Average annual active layer thickness of thawed surface soil, $\mathrm{m}$

Alaska

area of interest (e.g., HE impact area)

Antecedent temperature index

Contaminant Model for Streams

Cold Regions Research and Engineering Laboratory

Colorado State University

Defense Environmental Restoration Program

First-order decay rate of new snow transforming into base snow, an input for the TREECSTM Snow17 model, per day

Frames Description file required for all modules in FRAMES

Soil dry bulk density, $\mathrm{g} / \mathrm{cm}^{3}$

Department of Defense

Donnelly Training Area of the Fort Wainwright complex, AK

Environmental Laboratory

Environmental Processes and Engineering Division

Engineer Research and Development Center

Evapotranspiration

Framework for Risk Analysis in Multimedia Environmental Systems

Formerly used defense sites

Fate and transport of contaminants

Geophysical Institute Permafrost Laboratory

high explosives

Hydro-Geo-Characteristics Toolkit within TREECSTM

munitions constituents, such as the HE RDX

Multimedia Environmental Pollutant Assessment System

Modified Universal Soil Loss Equation used in HGCT for daily soil erosion estimates

National Climatic Data Center

National Centers for Environmental Information of NOAA, previously NCDC

National Oceanographic and Atmospheric Administration

National Weather Service, department of NOAA

Potential evapotranspiration 
RDX Royal Demolition Explosive, a high explosive, hexahydro1,3,5-trinitro-1,3,5-triazine

SCS Soil Conservation Service that developed the runoff curve number method

SCIA Stuart Creek Impact Area of Yukon Training Area

SDR Sediment Delivery Ratio, an option in the HGCT soil erosion module for trapping eroded soil within a watershed

Snow17 A snow accumulation and melt model developed by the NWS

SWE Snow water equivalent

TFTA Tanana Flats Training Area of the Fort Wainwright complex, AK

TIPM Antecedent temperature index parameter, an input for the TREECSTM Snow17 model

TNT HE Trinitrotoluene

TR Technical Report

TREECS $^{\text {TM }}$ Training Range Environmental Evaluation and Characterization System

TV Time-varying results driven by daily hydrology, a modeling option in TREECSTM

UI user interface for entering and viewing model inputs

U.S. United States

USACE U.S. Army Corps of Engineers

USGS U.S. Geological Survey

WFF Water Flux File, a standardized FRAMES file containing water and mass fluxes for transfer these fluxes among modules

WQCMB Water Quality and Contaminant Modeling Branch

WSS

Web Soil Survey, a Web-based application developed by U.S. Department of Agriculture for evaluating soil characteristics

YTA Yukon Training Area of the Fort Wainwright complex, AK

1D One-dimensional in space

2D Two-dimensional in space

\section{Symbols}
$d$
Number of days in a particular month
den_o Asymptotic average base snow density, an input for the TREECS ${ }^{\text {TM }}$ Snow17 model, g/cm ${ }^{3}$
$E \quad$ Daily soil erosion rate, $\mathrm{m} /$ day
Fgw TV mass flux exported to groundwater as determined by the soil fate model post processor, $\mathrm{g} / \mathrm{yr}$
$f_{i f} \quad$ Fraction of $\mathrm{Fl}$ exported to soil interflow
Fiw $\quad$ TV mass flux exported to soil interflow as determined by the soil fate model post processor, $\mathrm{g} / \mathrm{yr}$
$F_{l} \quad$ TV mass leaching flux computed by the soil fate model, g/yr 


\begin{tabular}{|c|c|}
\hline$f_{P F}$ & $\begin{array}{l}\text { Fraction of AOI surface area that is underlain with } \\
\text { permafrost }\end{array}$ \\
\hline$f_{t}$ & $\begin{array}{l}\text { Fraction of maximum active soil layer that is thawed in the } \\
\text { soil fate model, }=Z_{b} / Z_{\max }\end{array}$ \\
\hline$H$ & $\begin{array}{l}\text { Thickness of the thawed surface soil layer for conducting } \\
\text { surface soil layer water balance, length (e.g., inches) }\end{array}$ \\
\hline Hini & $\begin{array}{l}\text { Initial actual snow depth on January 1, an input for the } \\
\text { TREECS }{ }^{\mathrm{TM}} \text { Snow17 model, inches }\end{array}$ \\
\hline$H_{\max }$ & $\begin{array}{l}\text { Maximum soil layer thickness for conducting surface soil } \\
\text { layer water balance, length (e.g., cm) }\end{array}$ \\
\hline$H_{\min }$ & $\begin{array}{l}\text { Minimum thickness of the thawed surface soil layer } \\
\text { representing fully frozen soil, }=1.0 \mathrm{~cm}\end{array}$ \\
\hline Hbase & $\begin{array}{l}\text { Depth of base snow for the present day in the model for } \\
\text { converting snow depth in SWE to actual snow depth, inches }\end{array}$ \\
\hline Hbaseo & $\begin{array}{l}\text { Depth of base snow for the previous day in the model for } \\
\text { converting snow depth in SWE to actual snow depth, inches }\end{array}$ \\
\hline$H_{\text {new }}$ & $\begin{array}{l}\text { Depth of new (falling and recently fallen) snow for the } \\
\text { present day in the model for converting snow depth in SWE } \\
\text { to actual snow depth, inches }\end{array}$ \\
\hline$H_{\text {newo }}$ & $\begin{array}{l}\text { Depth of new (falling and recently fallen) snow for the } \\
\text { previous day in the model for converting snow depth in SWE } \\
\text { to actual snow depth, inches }\end{array}$ \\
\hline$I$ & $\begin{array}{l}\text { Daily net infiltration depth passed to the bottom of the soil } \\
\text { layer as a result of soil layer water balance, length, (e.g., } \\
\text { inches) }\end{array}$ \\
\hline$I F$ & Daily soil interflow depth, length (e.g., inches) \\
\hline$K$ & $\begin{array}{l}\text { Factor used in the Thornthwaite PET method to adjust for } \\
\text { the average number of daylight hours in the month }\end{array}$ \\
\hline$K_{d}$ & $\begin{array}{l}\text { Sorption distribution coefficient for partitioning an } \mathrm{MC} \\
\text { between soil particles and water, } \mathrm{L} / \mathrm{kg}\end{array}$ \\
\hline$K_{s}$ & $\begin{array}{l}\text { Saturated hydraulic conductivity for porous media, } \\
\text { length/time }\end{array}$ \\
\hline$k_{s}$ & $\begin{array}{l}\text { First-order decay rate of new snow transforming into base } \\
\text { snow in the model for converting snow depth in SWE to } \\
\text { actual snow depth, per day }\end{array}$ \\
\hline$K_{k}$ & $\begin{array}{l}\text { Measured value of hydraulic conductivity corresponding to } \\
\theta_{k} \text { in the modified van Genuchten soil water retention } \\
\text { function, length/time }\end{array}$ \\
\hline$M A E$ & Mean absolute error statistic \\
\hline mbase & $\begin{array}{l}\text { Base temperature for snowmelt computations during non- } \\
\text { rain periods, an input for the TREECS }{ }^{T M} \text { Snow } 17 \text { model, }{ }^{\circ} \mathrm{C}\end{array}$ \\
\hline
\end{tabular}


mf-max Maximum melt factor during non-rain periods, an input for the TREECS ${ }^{\mathrm{TM}}$ Snow17 model, $\mathrm{mm} /{ }^{\circ} \mathrm{C} / 6$ hours

$m f$-min Minimum melt factor during non-rain periods, an input for the TREECSTM Snow17 model, $\mathrm{mm} /{ }^{\circ} \mathrm{C} / 6$ hours

$\mathrm{NH} \quad$ Average number of daylight hours in a particular month

$n m f$

Maximum negative melt factor, an input for the TREECSTM

Snow17 model, $\mathrm{mm} /{ }^{\circ} \mathrm{C} / 6$ hours

$O_{i} \quad$ Observed snow depth for day $i$, inches

$O_{M} \quad$ Mean of observed data for snow depth, inches

$P \quad$ Daily precipitation depth, length (e.g., inches)

$P i \quad$ Predicted snow depth for day $i$, inches

plwhe Percent liquid water holding capacity, an input for the

TREECS ${ }^{\text {TM }}$ Snow17 model, decimal fraction

pxtemp The temperature that separates rain from snow, an input for the TREECS ${ }^{\mathrm{TM}}$ Snow17 model, ${ }^{\circ} \mathrm{C}$

pxtemp1 The lower temperature used with pxtemp2 and $\mathrm{T}_{\mathrm{a}}$ in interpolation to split precipitation between rain and snow, an input for the TREECSTM Snow17 model, ${ }^{\circ} \mathrm{C}$

pxtemp2 The upper temperature used with pxtemp1 and $\mathrm{T}_{\mathrm{a}}$ in interpolation to split precipitation between rain and snow, an input for the TREECSTM Snow17 model, ${ }^{\circ} \mathrm{C}$

$R \quad$ Daily rainfall depth, length (e.g., inches)

$R^{2} \quad$ Coefficient of determination or the goodness-of-fit of the model compared to the observed data

$R E \quad$ Relative error statistic, percent

$R S \quad$ Daily water loading depth to soil surface, length (e.g., inches)

rvs an integer to indicate which option of three to use for dividing precipitation between rain and snow, an input for the TREECSTM Snow17 model

scf The multiplying factor which adjusts precipitation that is determined to be snow, an input for the TREECS ${ }^{\text {TM }}$ Snow17 model

$Q \quad$ Daily total runoff depth from soil surface, length (e.g., inches)

$Q R \quad$ Daily rainfall runoff depth from soil surface, length (e.g., inches)

QS Daily runoff depth from soil surface due to excess soil water loading $R S$, length (e.g., inches)

$Q_{i f} \quad$ Average annual flow rate for soil interflow, m3/yr

$q \quad$ Daily water percolation depth to vadose zone for fully thawed active soil layer, length (e.g., inches)

$S \quad$ Daily snowfall depth, length (e.g., inches) 
$S F \quad$ Snowfall for the day in the model for converting snow depth in SWE to actual snow depth, SWE inches

$S D \quad$ Daily snow cover depth, length (e.g., inches)

$S M \quad$ Daily snow melt depth, length (e.g., inches)

$S W E_{n e w} \quad$ Depth of new snow as SWE for the present day in the model for converting snow depth in SWE to actual snow depth, inches

$S W E_{n e w o} \quad$ Depth of new snow as SWE for the previous day in the model for converting snow depth in SWE to actual snow depth, inches

TS Temperature at the top of the soil column, soil surface, ${ }^{\circ} \mathrm{C}$

$T_{a}$ Daily average air temperature, ${ }^{\circ} \mathrm{C}$

$T_{B A L} \quad$ Temperature at the bottom of the active soil layer, ${ }^{\circ} \mathrm{C}$

$T_{T A L} \quad$ Temperature at the top of the active soil layer, ${ }^{\circ} \mathrm{C}$

$t$ subscript in surface soil water balance representing time (e.g., today and previous day)

uadj Average wind function during rain-on-snow periods, an input for the TREECS ${ }^{\mathrm{TM}}$ Snow17 model, $\mathrm{mm} / \mathrm{mb} / 6$ hours

WC Soil water storage (i.e., volumetric water content resulting from soil water balance), fraction

$Z_{b} \quad$ Thawed soil layer thickness used in the soil fate model

Zcheck Threshold value for the soil layer thickness used to define fully frozen soil conditions in the soil fate model, $=Z_{\min }+$ $0.001 \mathrm{~m}$

$Z_{\min } \quad$ Minimum value allowed for the soil layer thickness in the soil fate model

$Z_{\max } \quad$ Maximum value allowed for the soil layer thickness in the soil fate model

$\alpha \quad$ Parameter in the soil water retention function for Hydrus-1D

$n \quad$ Parameter in the soil water retention function for Hydrus-1D

$n \quad$ Number of days in a TREECS ${ }^{\mathrm{TM}}$ Snow17 simulation

$\rho_{n} \quad$ Density of new recently accumulated snow, $\mathrm{g} / \mathrm{cm}^{3}$

$\rho_{o} \quad$ Asymptotic, average, base density of old snow in the snow pack for the model that converts snow depth in SWE to actual snow depth

$\theta_{a} \quad$ Parameter in the modified van Genuchten soil water retention function for Hydrus-1D, fraction

$\theta_{k} \quad$ Soil water content corresponding to $\mathrm{K}_{\mathrm{k}}$ in the modified van Genuchten water retention function for Hydrus-1D, fraction

$\theta_{m} \quad$ Parameter in the modified van Genuchten soil water retention function for Hydrus-1D, fraction 
$\theta_{r} \quad$ Soil residual water content, fraction

$\theta_{s} \quad$ Soil saturated water content, fraction

$\theta_{F C} \quad$ Soil water content at field capacity, fraction

$\Theta \quad$ Unfrozen water content of the soil for the GIPL soil thermal model, fraction 


\section{Introduction}

\subsection{Background}

The military footprint of the United States (U.S.) in the Arctic/sub-Arctic region falls within the state of Alaska, where the U.S. Army manages approximately $10 \%$ of all active Army training lands worldwide, which cover nearly 2,500 square miles in total land area. Additionally, the state of Alaska is home to 338 Formerly Used Defense Sites (FUDS), which are the responsibility of the U.S. Army Corps of Engineers (USACE) for executing site environmental restoration.

Primary recalcitrant contaminants of concern at active training ranges and at legacy FUDS include energetics, high explosives (HE), and heavy metals. Under the Defense Environmental Restoration Program (DERP), the Army has the unique responsibility of ensuring environmental stewardship, which includes managing risks associated with the fate and transport of military relevant compounds that have been, or will be, released into the environment. Currently, there are limited management tools for assessing contaminant fate and transport and identifying associated risks in Arctic/sub-Arctic environments.

The Arctic is warming faster than any other region on Earth, resulting in changing seasonality and precipitation patterns that, in turn, are leading to alterations in above ground vegetation, permafrost stability, and summer sea ice extent. Such ecosystem changes can affect the transport, and eventual fate, of persistent military relevant contaminants through unique Arctic/sub-Arctic terrestrial environments. As a result, management of military contaminants in a changing Arctic represents a unique and potentially significant liability to the Army and the Department of Defense (DoD).

Mathematical models offer the most reliable and cost effective method of predicting the fate/transport $(\mathrm{F} / \mathrm{T})$ and risks of contaminants in the environment, particularly in remote areas with limited data (e.g., the Arctic). However, research, development, implementation, and testing of $\mathrm{F} / \mathrm{T}$ processes for Arctic/sub-Arctic conditions is required for mathematical models to attain the accuracy needed for predictions to assess environmental management alternatives. 
Fortunately, there exists a wealth of previous capability for modeling the fate of contaminants in the environment, particularly for military installations and past and active training/firing ranges. Much of this capability resides within the Training Range Environmental Evaluation and Characterization System (TREECS ${ }^{\mathrm{TM}}$ ), https://treecs.el.erdc.dren.mil/. TREECS ${ }^{\mathrm{TM}}$ was developed for the Army to predict the fate of and risk from munitions constituents (MC), such as high explosives (HE) and metals, as well as other contaminants, within and transported from firing/training ranges, or other potential contaminant sources to surface water and groundwater. TREECS ${ }^{\mathrm{TM}}$ uses site characteristics and chemical-specific properties as part of the inputs. TREECS ${ }^{\mathrm{TM}}$ has been peer reviewed (Dortch et al. 2013) and validated/demonstrated (Dortch 2012; Dortch et al. 2017a), and user guidance for its use is available (Dortch et al. 2017b). Thus, TREECS ${ }^{\mathrm{TM}}$ is the most logical modeling system to adopt for housing predictive tools extended to Arctic regions.

TREECS $^{\mathrm{TM}}$ can handle a wide variety of site conditions. However, the previous version had limitations for application to Arctic conditions. As a result, the work reported herein was necessary to overcome these limitations. This work was performed as the first subtask of Task 5 (referred to as Integrated Processes for Informed Risk Management) of the overall project, "Biogeochemical Processes affecting Military Materials in Arctic/Sub-Arctic Terrestrial Environments."

\subsection{Objectives}

The overall objective of this work (subtask 5.1 of Task 5) is to further develop and modify TREECS ${ }^{\mathrm{TM}}$ to more properly simulate the F/T of contaminants for Arctic/sub-Arctic conditions, where the upper soil horizon experiences seasonal freeze and thaw, and various amounts of permafrost may exist below the freeze/thaw layer. The goal is to minimize the modeling complexity while capturing the key feature to enable reasonable $\mathrm{F} / \mathrm{T}$ predictions in the Arctic.

Secondary objectives include testing the revised modeling system for Arctic/sub-Arctic conditions and documenting the revisions and test results. This technical report (TR) serves as that documentation. For the remainder of this TR, all references to the Arctic feature of TREECS ${ }^{\mathrm{TM}}$ refers to a broader area to include sub-Arctic (or near Arctic) as well. 


\subsection{Approach}

TREECS $^{\mathrm{TM}}$ has been developed for modeling the fate of MCs and other contaminants within multiple media (soil, vadose zone, groundwater, and surface water including benthic sediments). Mathematical models within TREECSTM are of limited form, including a zero dimensional, fully mixed surface soil model; a one-dimensional (1D) vadose zone model; an aquifer model with $1 \mathrm{D}$ longitudinal advection and three-dimensional (3D) dispersion; and a 1D longitudinal surface water model for streams. Models of limited form provide rapid implementation and execution with reduced data requirements, while providing reasonable accuracy and valuable insights.

Arctic conditions include an active surface soil layer that seasonally freezes and thaws from the ground surface to about one to two meters below ground (see Figure 1). A layer of permafrost may exist below the active layer. Permafrost can extend hundreds of meters below the ground surface and can be continuous, discontinuous, or sporadic. These physical heterogeneities caused by ice result in a complex system for modeling. Climate warming further complicates the system. Warming can lower the elevation of the bottom of the active layer (i.e., the top of the permafrost layer), causing a warmer shift in the permafrost thermal gradient, thus, raising the elevation of the bottom of the permafrost layer (or permafrost base). Continuous permafrost causes surface infiltrating water to move horizontally as soil interflow towards seepage points in streams, rather than flowing vertically into the underlying aquifer. Discontinuous permafrost can result in both soil interflow, and percolation to aquifer, introducing further complexity.

Climate warming affects below ground thermal regimes. The below ground thermal dynamics have a profound impact on water movement. Water movement affects contaminant $\mathrm{F} / \mathrm{T}$. As an example, receding permafrost tends to shift the path of infiltrating water from interflow seepage into surface water to percolation to groundwater. A rather complete and comprehensive suite of models should include the following modeling components to address Arctic features:

- ground-surface hydrology associated with snowfall, snow accumulation, and snowmelt

- soil thermal regime taking into account snow pack and freeze-thaw dynamics 
- surface soil hydrology including rainfall and snow melt runoff, soil erosion, water infiltration, soil water storage for variably-saturated conditions, evapotranspiration (ET), percolation to deeper vadose and groundwater, and soil interflow with seepage to surface water

- F/T in surface soil associated with surface soil hydrology

- surface water systems (i.e., streams and lakes), including water flow, suspended and benthic sediments, hydrology, and F/T; and

- deeper vadose and aquifer for water flow and F/T.

There are various models that could be used to satisfy the above list of needs, but the difficulty lies in trying to minimize model complexity while retaining the key features to provide meaningful $\mathrm{F} / \mathrm{T}$ predictions. The approach here was to retain and use as much of the existing TREECS ${ }^{\mathrm{TM}}$ framework and associated models as possible, while implementing changes and adding new components needed for the Arctic. The following chapters discuss the details of these additions and changes. 
Figure 1. Schematic of soil profile with permafrost (from

https://www.erdc.usace.army.mil/CRREL/Permafrost-Tunnel-Research-Facility/General-Facts/).

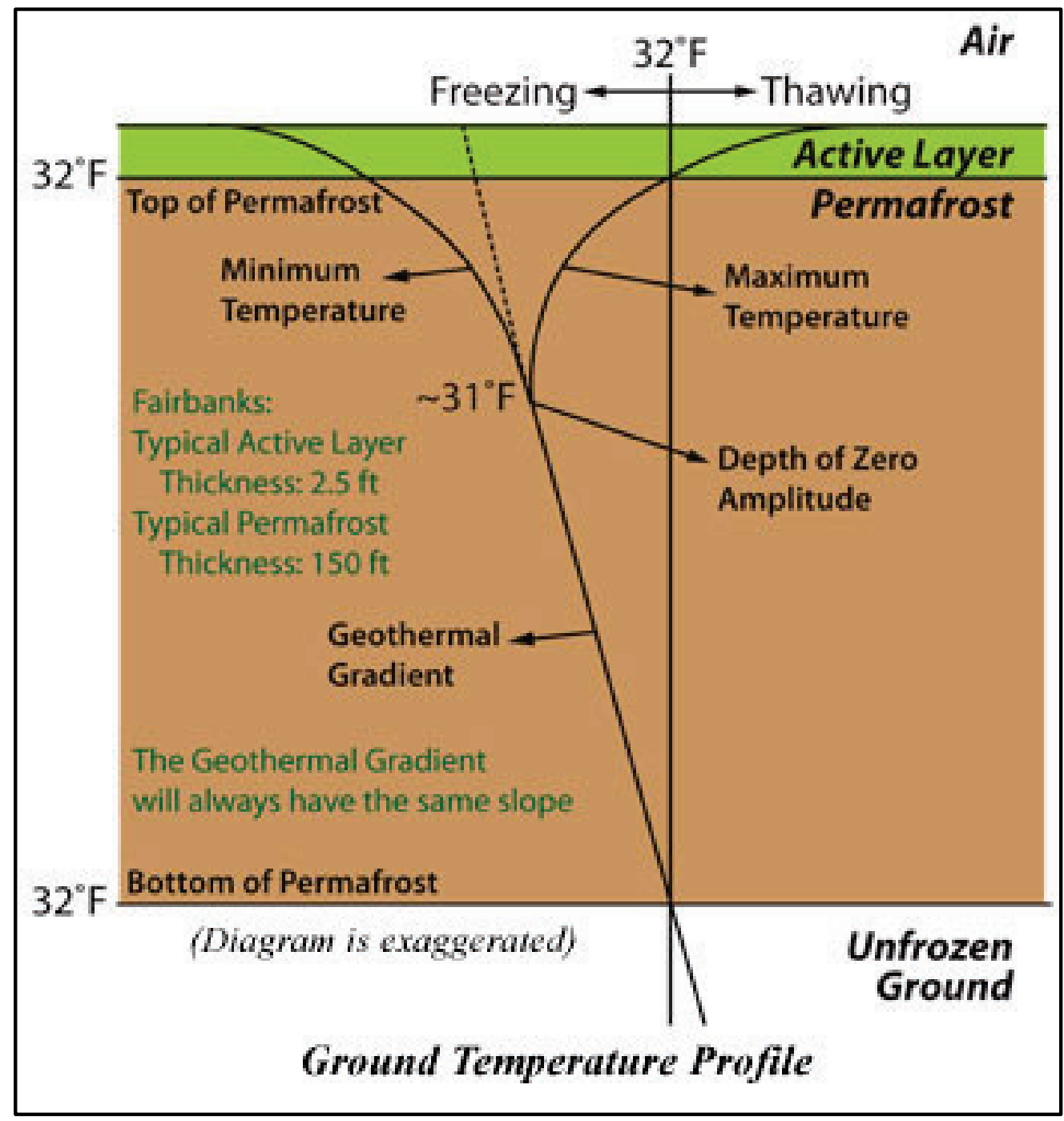




\section{Overall Plan}

The overall plan evolved primarily around seeking the best approach for addressing the needs for modeling surface soil, including water movement and contaminant $\mathrm{F} / \mathrm{T}$ as affected by freeze/thaw and permafrost conditions. Secondary considerations involved proper handling of groundwater F/T through the deeper vadose zone to aquifer, and soil interflow that eventually makes its way to surface water. Considerations for these modeling components are discussed below.

\subsection{Surface soil water movement and contaminant F/T with freeze/thaw}

\subsubsection{Model reviews}

Much consideration was given to using models that solve both the soil thermal characteristics (including freeze/thaw conditions) and the soil water movement for unsaturated and saturated conditions as affected by freeze/thaw. Rühaak et al. (2015) evaluated four models that solve coupled water flow and heat transport equations in porous media. This comparison was part of a larger effort within the Interfrost freeze/thaw benchmark consortium (https://wiki.lsce.ipsl.fr/interfrost/) where 13 models of this class were being evaluated. The models evaluated by Rühaak et al. (2015) included Cast3M, SMOKER, SUTRA-ICE, and FEFLOW. All four codes were found to exhibit similar behavior and computational requirements for three separate benchmark test cases.

The SUTRA code (Voss and Provost 2002) is a two- and three-dimensional (2D and $3 \mathrm{D}$, respectfully) numerical, finite element code for saturated/unsaturated, variable-density, groundwater flow with solute or energy transport. The model was developed by the U.S. Geological Survey (USGS) and is freely available from https://water.usgs.gov/nrp/gwsoftware/sutra/sutra.html (presently version 2.2). SUTRA was modified to handle freeze/thaw phase transformation for fully saturated conditions, resulting in the version referred to as SUTRA-ICE (McKenzie et al. 2007), which was one of the models evaluated by Rühaak et al. (2015) as noted above. Internet searches revealed that there is a version (SUTRA 3.0) of SUTRA-ICE that possibly handles unsaturated/saturated flow. 
Since the SUTRA models are publicly available, the SUTRA-ICE code was given serious consideration for providing the modeling capability needed for surface soil, vadose, and aquifer flow and constituent $\mathrm{F} / \mathrm{T}$ for freeze/thaw conditions of the Arctic. However, SUTRA-ICE did not include solute (i.e., contaminant constituents) F/T. Discussions were held with the USGS regarding merging the capabilities of SUTRA and SUTRAICE, such that the merger would include constituent F/T. However, the time and funding available for the current project precluded this consideration. Additionally, a model such as this is far more complex than the models in TREECS ${ }^{\mathrm{TM}}$, requiring much higher computational intensity with long execution times and expert personnel to perform such applications.

Other model codes offered promise for modeling water migration and thermal characteristics in porous media undergoing freeze/thaw, such as the application demonstrated by Frampton et al. (2011) using the MarsFlo code (Painter 2011). This model application showed the warming effects on permafrost talik drainage. MarsFlo was originally developed for Martian hydrology, and the code solves non-isothermal, three-phase water migration and heat transport in partially saturated and partially frozen porous media using the finite-volume method with fully implicit time stepping. The model is very comprehensive in terms of water movement and heat transport, but it does not include constituent $\mathrm{F} / \mathrm{T}$. Thus, no further consideration was given to this model.

The Hydrus-1D code is freely available to the public from https://www.pcprogress.com/en/Defaultaspx?h1d-downloads, and it has been used as part of TREECS $^{\text {TM }}$ 1. Hydrus-1D is a 1D finite element model for simulating the movement of water, heat, and multiple solutes in variably saturated porous media. The model is quite comprehensive, accurate, and has been extensively used around the world. The model has been modified to include freeze/thaw conditions as described by Hansson et al. (2004), and has been successfully applied (Watanabe et al. 2007) for such conditions. The freeze/thaw version of Hydrus-1D can be downloaded from https://www.pc-progress.com/en/Default.aspx?h1d-lib-freezing, but the site has the following warning.

\footnotetext{
1 B. E. Johnson, 2016. Research Civil Engineer, Environmental Laboratory, U.S. Army Engineer Research and Development Center, personal communication.
} 
"The freezing/thawing module was developed for the manuscript Hansson et al. (2004). However, this module is not a regular module of the standard HYDRUS-1D software package, since it is significantly less stable than regular HYDRUS codes. However, since we were often asked by the HYDRUS users to share this module with them, we have decided to do so, even though we realize that they may encounter numerical problems, especially if they attempt to run more complicated simulations than we did for the manuscript and examples posted below. Please note that this code works only for unsaturated soils and will likely become unstable when the soil becomes saturated. Also be aware that the model is much less stable than regular HYDRUS and usually stops working once the full saturation is reached. It should work reasonably well for unsaturated conditions and several other colleagues have been using it for such conditions."

Based on the above warning and other considerations mentioned above regarding model complexity and ease-of-use normally associated with TREECS $^{\mathrm{TM}}$, the decision was made not to consider the use of this model for this project.

\subsubsection{Hydrus-1D tests}

Testing with the Hydrus-1D model (without freeze/thaw) was performed to obtain a better understanding of water movement and soil water content in surface soil experiencing seasonal hydrologic changes that mimic freeze/thaw. The model was set up for water flow and standard solute transport in a vertical soil column with a single material type. The depth of the soil column was set to $2.0 \mathrm{~m}$ (represented by 101 computational nodes) ( $2 \mathrm{~cm}$ thick layers). A $2 \mathrm{~m}$ soil column was selected to represent the approximate thickness of the active layer in Arctic regions with permafrost.

The model was run for 10,000 days using a set of boundary conditions at the soil surface covering 1,000 days that was repeated ten times. The surface boundary conditions set consisted of 12 values of water flux into the soil that cycled approximately every six months (actually every 167 days) to either zero, or $0.00055 \mathrm{~m} /$ day. Thus, there were six, six-monthlong periods over 1,000 days of either constant zero flux or constant flux of $0.00055 \mathrm{~m} /$ day. This boundary flux was equivalent to an annual water loading flux of $0.1 \mathrm{~m} / \mathrm{yr}$ (3.9 in./yr) into the soil column. The six-month 
cycles of constant water flux and zero water flux loading was intended to mimic seasonal cycles of water flow and no flow that occur for thawed and frozen soil. There was no evapotranspiration or runoff in these tests.

The bottom boundary condition of the soil column was set to free drainage, and the initial condition consisted of uniform soil water content of o.2. The modified van Genuchten soil water retention option was selected for a single porosity, hydraulic model without hysteresis. Water flow parameters for sand and clay were tested as two separate test cases, where sand and clay provide the extremes in the spectrum of soil texture. The model default values for water flow parameters of sand and clay were used and are shown in Table 1. The solute was treated as conservative (without decay) with a soil sorption partitioning distribution coefficient $\left(K_{d}\right)$ of $0.1 \mathrm{~L} / \mathrm{kg}$. The solute entered at the soil surface with a boundary flux concentration of $1.0 \mathrm{~g} / \mathrm{m}^{3}$. A zero concentration gradient condition was applied for the lower boundary, and the initial concentration was set to zero in the soil column.

Table 1. Water flow parameters used in Hydrus-1D tests.

\begin{tabular}{|l|c|c|}
\hline \multicolumn{1}{|c|}{ Parameter } & Value for sand & Value for clay \\
\hline Residual soil water content, $\theta_{r}$ & 0.045 & 0.068 \\
\hline Saturated soil water content, $\theta_{s}$ & 0.43 & 0.38 \\
\hline Parameter $\alpha$ in the soil water retention function, $\mathrm{m}^{-1}$ & 14.5 & 0.8 \\
\hline Parameter $n$ in the soil water retention function & 2.68 & 1.09 \\
\hline Saturated hydraulic conductivity, $K_{s}$, m/day & 7.128 & 0.048 \\
\hline Tortuosity parameter in the conductivity function & 0.5 & 0.5 \\
\hline $\begin{array}{l}\text { Parameter } \theta_{a} \text { in the soil water retention function when } \\
\text { using modified van Genuchten }\end{array}$ & 0.045 & 0.068 \\
\hline $\begin{array}{l}\text { Parameter } \theta_{m} \text { in the soil water retention function when } \\
\text { using modified van Genuchten method }\end{array}$ & 0.43 & 0.048 \\
\hline $\begin{array}{l}\text { Measured value of the hydraulic conductivity, } K_{k}, \\
\text { corresponding to } \theta_{k} \text { when } \text { using the modified van } \\
\text { Genuchten method, } m / \text { day }\end{array}$ & 7.128 & 0.43 \\
\hline $\begin{array}{l}\text { Soil water content, } \theta_{k} \text {, corresponding to } K_{k} \text { when } \text { using } \\
\text { the modified van Genuchten method }\end{array}$ & & 0.38 \\
\hline
\end{tabular}

The model results for the above test case with sand revealed that the soil water content over the $2 \mathrm{~m}$ column was uniform at 0.082 during the flow season and nearly uniform, varying from 0.054 at the surface to 0.069 at the bottom, during the non-flow season. Bottom water flux reached cyclic 
(i.e., seasonally varying) steady-state almost immediately. The bottom solute concentration reached a constant value equal to the influx concentration after about 2,000 days. Water fluxes within the soil column were uniform. Solute concentration was also uniform in the soil column after reaching the constant bottom flux concentration. All time-varying results exhibited cyclic steady-state results each year following the initial spin-up to reach cyclic steady-state.

The model results for the above test case with clay revealed similar behavior to those with sand with the exception that the soil column remained more saturated, and it took longer for the solute to penetrate through to the bottom of the column. The results with clay revealed that the soil water content over the $2 \mathrm{~m}$ column was uniform at 0.372 during the flow season and nearly uniform, varying from 0.353 at the surface to 0.361 at the bottom, during the non-flow season, where both results are near saturation. Bottom water flux reached cyclic steady-state rapidly within a year or less. The bottom solute concentration reached a constant value equal to the influx concentration after about 5,000 days. Water fluxes within the soil column were uniform. Solute concentration was also uniform in the soil column after reaching the constant bottom flux concentration. All time-varying results exhibited cyclic steady-state results each year following the initial spin-up to reach cyclic steady-state.

These tests were repeated with the same inputs except for the bottom boundary condition for flow where a constant water content of 0.2 was applied. This condition was tested to mimic the effect of water piling up at the permafrost interface. The results were similar to those with free drainage.

\subsubsection{Conclusions}

Based upon the results of the above Hydrus-1D tests, it was concluded that it is reasonable to represent the $2 \mathrm{~m}$ surface soil layer, or active layer, as a single homogeneous layer for flow and transport subjected to seasonal conditions with water loading (with flow), and no water loading (no flow), similar to freeze/thaw situations. This conclusion justified adapting and using the existing TREECS ${ }^{\mathrm{TM}}$ modeling components for surface soil hydrology and surface soil constituent $\mathrm{F} / \mathrm{T}$, both of which are based on single layer modeling concepts. 
Since the TREECS ${ }^{\mathrm{TM}}$ components do not model soil thermal characteristics, it was necessary to provide such information via another separate model. The TREECS ${ }^{\mathrm{TM}}$ surface soil hydrology model does include rudimentary calculations for snow accumulation and melt that are acceptable for temperate climates, but may not be suitable for Arctic climates. Thus, it was necessary to consider a separate model for snow accumulation and melt information. The details for these two new modeling components are discussed in Chapters 3 and 4. Modifications required of the TREECS ${ }^{\mathrm{TM}}$ surface soil hydrology model and soil fate and transport model are provided in Chapters 5 and 7, respectively.

\subsection{Groundwater flow and transport}

Water and constituent mass can leave the surface soil either vertically or horizontally, resulting in groundwater flow and transport and soil interflow with transport, respectively. The method for determining the contributions to groundwater and interflow are described in section 7.2. Groundwater flow and transport includes two components, vadose zone, and aquifer. The vadose zone consists of the water-unsaturated soil column extending from the bottom of the surface soil layer to the top of the water-saturated aquifer. The aquifer extends from the bottom of the vadose zone to the bottom of the aquifer, or bedrock, which is a thickness specified by the user.

Two existing TREECS ${ }^{\mathrm{TM}}$ modeling components are used for the vadose zone and aquifer, which originated from the Multimedia Environmental Pollutant Assessment System (MEPAS) (Buck et al. 1995) for time-varying contaminant fate/transport in the vadose zone and aquifer. The MEPAS version 5.0 groundwater models (Whelan and Castleton 2006) are used within TREECS ${ }^{\mathrm{TM}}$ to compute constituent mass fluxes through the vadose zone and aquifer and resulting aquifer concentrations. The MEPAS vadose zone model is a homogeneous layer model with a semi-analyticalnumerical solution of the $1 \mathrm{D}$, reactive, dissolved constituent transport equation in the vertical direction. The MEPAS aquifer model solves the reactive, dissolved constituent transport equation with $3 \mathrm{D}$ dispersion and 1D longitudinal advection along the primary Darcy flow axis. The aquifer model also uses a semi-analytical-numerical solution procedure. The scientific documentation of the MEPAS groundwater models for vadose and aquifer is provided by Whelan et al. (1996), thus, further details of these models are not presented herein. 
The MEPAS groundwater models are used for Arctic conditions without any modifications to the model codes and without any restrictions imposed on their application. However, due to special circumstances, such as the presence of permafrost and organic peat layers in the vadose zone, there is a need to consider how the models are applied. As explained in Section 7.2, the post-processor of the soil fate model distributes the water and mass fluxes through the surface soil layer to soil interflow and groundwater (vadose zone) based on the surface area extent of permafrost, which is assumed to be impermeable. The water flux to groundwater is the groundwater recharge rate. With the water and mass flux distribution specified via the soil fate model post-processor, there is no need to further adjust vadose zone soil properties due to the presence of ice since the constituent mass is assumed to flow through frost-free soil. Thus, the vadose zone model inputs for soil properties, such as porosity and saturated hydraulic conductivity, can be set to those typically associated with the site soil without special considerations for ice.

There is often an organic peat layer at the top of the mineral vadose zone of Arctic soils. Processes affecting F/T, including pore-water velocity, sorption partitioning, and degradation, can be quite different in these highly organic layers, thus, requiring special settings for inputs associated with constituent $\mathrm{F} / \mathrm{T}$ processes. Multiple instances of the vadose zone model can be applied to represent different vadose layers with different properties, where the water and mass flux out of the bottom of one vadose model flows into the top of the next. For study sites that have a peat layer, it may be advisable to represent the vadose zone with two instances of the vadose zone model, one for the upper peat layer, and one for the lower mineral layer, which extends from the bottom of the peat layer to the aquifer. The layer thickness of the peat layer, which is on the order of a few meters, would usually be much smaller than that of the mineral layer if the depth to aquifer is very great.

\subsection{Soil interflow and transport}

In previous versions of TREECS ${ }^{\mathrm{TM}}$, soil interflow water and mass fluxes were passed unaltered (i.e., without attenuation due to transport time and adsorption and without degradation) to surface water. In reality, the transport of dissolved constituents in soil interflow from the area of interest (AOI) source zone to the receiving surface water can take a long time, possibly decades, depending on the distance between source and receiving water and soil and constituent characteristics, such as sorption 
partitioning. Thus, it is a poor assumption that there is no constituent attenuation and degradation in soil interflow. Since the presence of permafrost accentuates the role of soil interflow with seepage drainage to surface water, it was even more important to address this modeling limitation.

Keeping to the approach of using existing TREECS ${ }^{\mathrm{TM}}$ components to the extent possible to reduce the time and cost to complete this project, the decision was made to use the MEPAS aquifer model to represent constituent $\mathrm{F} / \mathrm{T}$ in soil interflow. This model provides two basic types of output, aquifer constituent concentrations at user-specified locations (e.g., wells) and constituent mass fluxes (mass/time) and water flux (volume/time) at groundwater discharge locations (e.g., where the aquifer crosses a stream). The flux output type is used to provide water and mass fluxes into surface water due to soil interflow.

The attributes of the MEPAS aquifer model, such as 3D dispersion with $1 \mathrm{D}$ longitudinal advection with sorption partitioning and degradation, render the model as a quite satisfactory approach for representing soil interflow. Soil interflow is typically bounded by the soil surface and a relatively impermeable bottom boundary, such as clay lenses, bedrock, or ice for the Arctic. Thus, the interflow layer has a characteristic thickness. Aquifer thickness is a model input that can be used for the interflow thickness. Interflow can spread laterally, vertically, and longitudinally via dispersion. Dispersion in $3 \mathrm{D}$ is included in the aquifer model with dispersivity values required as input for each dimension (longitudinal, vertical, and lateral).

There should be background flow velocity in soil interflow due to regionally infiltrating water that is diverted to soil interflow. The aquifer model requires the input of Darcy flow velocity (length/time) for background flow, which can serve as the background interflow velocity. An approximate background interflow velocity can be estimated by multiplying the surface soil average annual (AA) net infiltration rate (length/time) that is diverted to soil interflow by the AOI surface area, producing the AA soil interflow flow rate, $Q_{i f}$. Herein, an average annual quantity can be interpreted as the average over all years of the annual mean quantities. The interflow background velocity is then determined by dividing $Q_{i f}$ by the AOI interflow cross-sectional area. This cross-sectional area is the soil interflow thickness times the width of the AOI site perpendicular to the flow path from the AOI to the receiving surface water 
(Figure 2). The AOI shown in Figure 2 is represented as a rectangle, but in reality, the AOI can be a polygon or an irregular shape. Thus, determination of the AOI interflow width can require user discretion.

Other inputs of the MEPAS aquifer model for flux output include the following: media characteristics (total porosity, effective porosity, and dry bulk density), flux location, dispersivity values, and constituent properties ( $K_{d}$, water solubility, and half-life in groundwater). The media characteristics can be estimated from soil texture as normally done. The flux location is the longitudinal distance from the AOI to the surface water where soil interflow is expected to seep or exit. The three dispersivity values can be estimated via the aquifer model's user interface (UI). The constituent properties are estimated and input by the user as normally done.

Given the above overview of MEPAS aquifer model input requirements, there are no obstacles for using that model to represent $\mathrm{F} / \mathrm{T}$ for soil interflow traveling from the AOI to the receiving surface water. The TREECS $^{\mathrm{TM}}$ protocol for applications involving this approach are presented in Chapter 8.

Figure 2. Schematic of soil interflow.

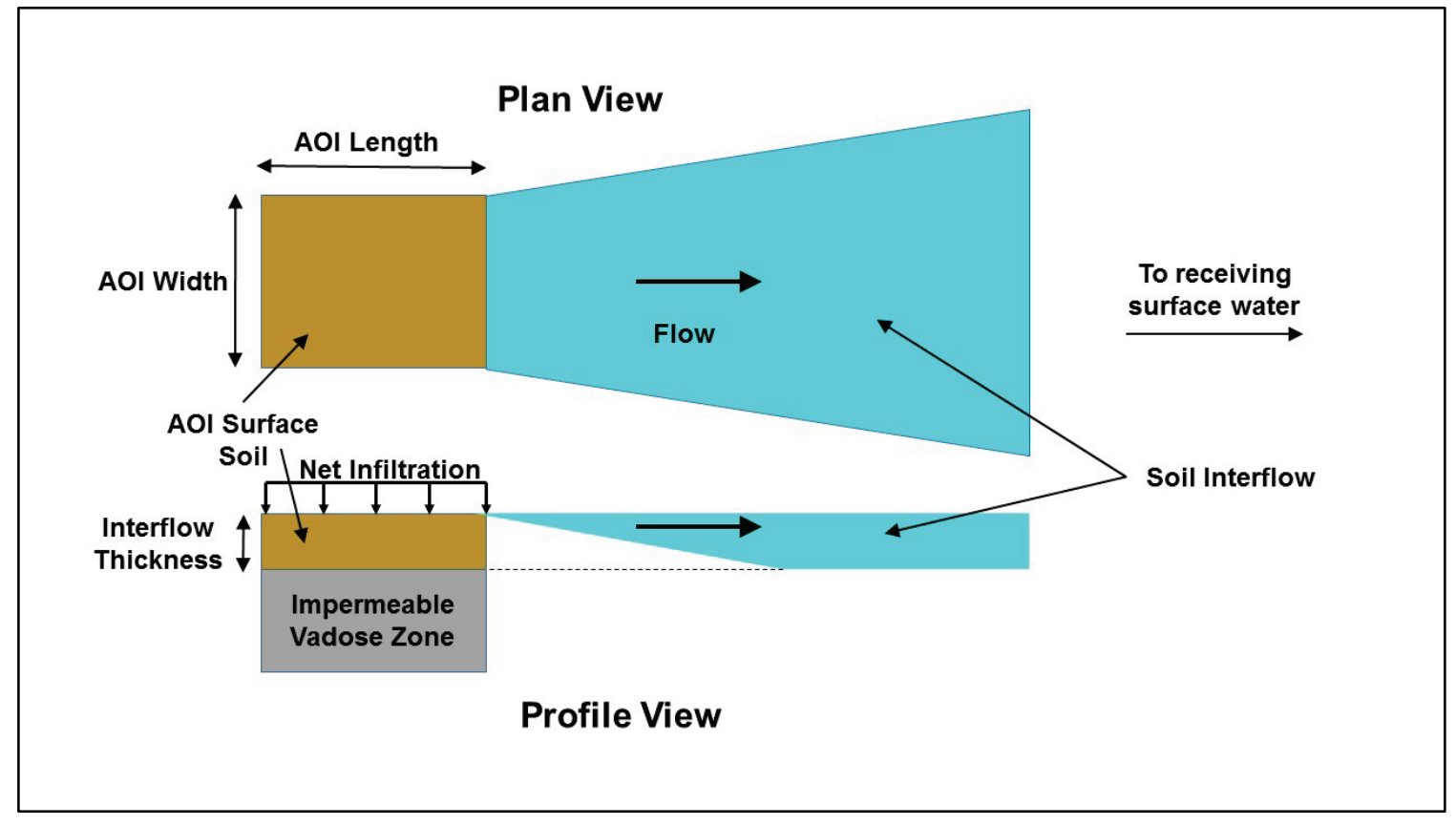




\section{Snowfall, Accumulation, and Melt}

\subsection{Background}

Ground-surface hydrology in the Arctic is heavily influenced by prolonged periods of snow cover followed by snow melt. TREECS ${ }^{\mathrm{TM}}$ includes a ground-surface and surface soil hydrology model that is applied within the Hydrology tab of the Hydro-Geo-Characteristics Toolkit (HGCT). This hydrology model includes snowfall, accumulation, and melt as described by Johnson and Dortch (2014). However, the melt factors in that model are constant rather than varying seasonally. Testing of the hydrology model using meteorological data and observed snow cover data from the Fairbanks International Airport for 2010-2016, showed that computed snow cover depths were less than observed due to possibly poor representation of the snow melt. The observed snow cover depths were converted to snow water equivalent (SWE) depths for comparison with the model, since the model computes snow depth as SWE. A constant snow density of $0.15 \mathrm{~g} / \mathrm{mL}$ was used to convert the measured snow depths to SWE by multiplying snow depth by the density. The density of new snow is approximately $0.15 \mathrm{~g} / \mathrm{mL}$ when the air temperature is zero degrees $\mathrm{C}$ (Anderson 2006). Although snow density varies with air temperature, age of the snow cover, and other seasonably-varying factors, this simple conversion was considered sufficient for evaluating the adequacy of the TREECS $^{\text {TM }}$ hydrology model's snow routine.

Although the computed snowfall agreed with that observed (seven-year average of 3.32 inches of water), the average SWE for the seven-year simulation was under-predicted by 16.7 percent, where the computed and observed averages were 0.78 and 0.94 inches of water, respectively. Maximum computed and observed SWE for the seven years were 4.17 and 4.5 inches, respectively. Although the very simple snow accumulation and melt routine in the TREECS ${ }^{\mathrm{TM}}$ HGCT Hydrology model provides reasonably good results for Fairbanks, and is certainly adequate for nonArctic applications, the routine was judged as marginally adequate for predicting snow cover and melt under Arctic conditions; thus, another model was needed for computing these variables. 


\subsection{Description of Snow17}

A review of existing models for snowfall, accumulation, and melt indicated that the model Snow17 was another viable candidate. Snow17 had been used for many years by the National Weather Service (NWS) of the National Oceanographic and Atmospheric Administration (NOAA), and the source code for a version was available from the NWS. Snow17 has a relatively long history within the NWS with algorithms dating back to the 1970's (Anderson 1973, 1976). Anderson (2006) provides a more recent description of Snow17. The version of the model obtained from the NWS was written in the Python language by Joe Hamman in 2013, was based on the Anderson (2006) report, and a previous MATLAB code by Mark Raleigh.

The Python version by Hamman is only applicable to a point location (i.e., an area with uniform conditions rather than spatially-varying conditions) and requires equal time steps for input of precipitation and air temperature data. Additionally, the Python version is a more simplified version compared with the formulations presented by Anderson (2006). For example, this version does not contain the formulations for transmission of water through the snow cover that can cause time lag and amplitude dampening of snow pack water outflow compared with excess surface melt. This version also did not contain any conversion of snow cover as SWE to snow depth, whereas Anderson (2006) presents a fairly detailed method for computing snow density and depth based on varying conditions. Neither Anderson (2006), nor the Python version, include any accounting of water loss from snow sublimation, which assumes that sublimation is a minor loss mechanism of snow compared with melt for Arctic conditions. In spite of the above limitation, the Python version of Snow17 was considered adequate for intended uses in this project, which is to provide snow cover as required for modeling the soil thermal regime.

Snow17 treats the snow pack as a homogeneous, uniform, single layer and accounts for both solid (i.e., ice) and liquid forms of water within the snow pack. Excess liquid water becomes outflow (i.e., runoff) and takes into account melt, rain-on-snow, snow liquid water storage capacity, and the snow heat deficit. Other primary processes included in this version of Snow17 include:

- division of precipitation between rain and snow 
- snow melt factor that depends on time of the year, latitude, maximum and minimum melt factor inputs, and a seasonal adjustment factor specific to the Arctic

- change of snow pack heat deficit due to snowfall and snow pack temperature gradient

- melt that includes melt during periods of no rain (non-rain melt) and melt during rainfall (rain-on-snow melt)

- accounting of the overall ripeness of the snow cover by keeping track of the heat deficit and the liquid water storage, and

- accounting of liquid and solid water depths, heat deficit, and excess liquid water (outflow) based on ripeness.

During this project, the Python version was converted and compiled in Fortran using Microsoft Visual Studio 2010 with Intel Visual Fortran Composer XE 2013 SP1. Testing and debugging of the Fortran code revealed several errors that were in the original Python formulations, all of which were corrected. The corrected Fortran version is referred to herein as TREECS ${ }^{\text {TM }}$ Snow17.

TREECS $^{\mathrm{TM}}$ Snow17 requires observed daily mean air temperature and observed daily precipitation, as well as various model parameters and site conditions as input. The model performs daily updates of the process equations. The time step in the model is actually set to 24 hours since the process equations are based on hourly time units. The primary state variables solved daily in the model are accumulated liquid equivalent of ice in snow cover, accumulated liquid water in snow cover, and excess liquid water in the snow cover. The units of these variables are in millimeters of water for each day. The primary output consists of daily snow cover and snow cover outflow (referred to as melt in the output file) in SWE. The sum of the accumulated depth of ice and water in the snow cover for each day becomes the daily SWE for output. The daily excess liquid water in the ice cover is the daily outflow (i.e., melt) for output. The ice cover outflow includes any rain-on-snow, but rainfall when there is no snow cover is not included. The daily depth units are converted from millimeters to inches for the output file (SnowCoverMeltDepth.txt).

Water loss by sublimation and water transmission through the snow pack were not added to TREECS ${ }^{\mathrm{TM}}$ Snow17. However, conversion of snow cover as SWE to actual snow depth was added for output since the model for the soil thermal regime requires this information. The method implemented 
for converting snow depth in SWE to actual snow depth is discussed in the next section.

\subsection{Conversion of snow cover from SWE to actual depth}

In general, SWE must be divided by the snow density $\left(\mathrm{g} / \mathrm{cm}^{3}\right)$ to obtain the snow depth. Anderson (2006) discusses methods for calculating snow density, but these methods are fairly involved and require seven parameters. Therefore, a much simpler empirical approach was adopted as explained below.

The density of newly and recently fallen snow is much lower than aged snow in the snow pack. Additionally, the colder the air temperature, the lower is the density of falling snow. Older snow within the snow pack experiences metamorphism and compaction that increases snow density with time. The approach used here is to track new (recently fallen) and old snow depths in the model. Old snow is referred to as base snow herein. New snow and base snow have different densities. The density of falling snow $\left(\rho_{n}\right)$ depends on daily mean air temperature as stated in Equation 3-1 (Anderson 2006).

$$
\rho_{n}=0.05+0.1\left(1.5^{T_{a}}\right)
$$

Where, $T_{a}$ is the mean daily air temperature in ${ }^{\circ} \mathrm{C}$. Equation $3^{-1}$ gives values for $\rho_{n}$ of 0.05 and $0.15 \mathrm{~g} / \mathrm{cm}^{3}$ for $T_{a}$ of -15.0 and $0.0^{\circ} \mathrm{C}$, respectively, as stated by Anderson (2006) for the snow densities at those temperatures. The density of new snow is not allowed to be less than 0.05 $\mathrm{g} / \mathrm{cm}^{3}$ or greater than $0.20 \mathrm{~g} / \mathrm{cm}^{3}$ in the model. The density of base snow is assumed to approach a constant value that is climate class dependent based on the work of Sturm et al. (2010).

The depth of new (falling and recently fallen) snow for the present day $\left(H_{n e w)}\right.$ is determined from Equation 3-2.

$$
H_{\text {new }}=H_{\text {new } 0}+\frac{S F}{\rho_{n}}-k_{s} H_{\text {new } 0}
$$

Where, $H_{\text {newo }}$ is the depth of new snow from the previous day, $S F$ is the snowfall for the day (SWE), and $k_{s}$ is the first-order decay rate of new snow 
transforming into base snow. The SWE must be updated using Equation 33 .

$$
S W E_{\text {new }}=S W E_{\text {new } 0}+S F-k_{s} S W E_{\text {new } 0}
$$

Where, $S W E_{\text {new }}$ is the new snow as SWE for the present day, and $S W E_{n e w o}$ is the new snow as SWE for the day before. The depth of base snow for the present day $\left(H_{b a s e}\right)$ is determined from Equation 3-4.

$$
H_{\text {base }}=H_{\text {base } 0}+k_{s} \frac{S W E_{\text {new } 0}}{\rho_{0}}
$$

Where, $H_{b a s e o}$ is the base snow depth for the day before, and $\rho_{o}$ is the asymptotic, average base snow density as time progresses since the last snowfall. The total snow depth is the sum $H_{\text {base }}$ and $H_{\text {new }}$. Testing of the above snow depth conversion method showed that the method worked reasonably well (as discussed in section 3.5).

\subsection{Implementation of Snow17}

TREECS $^{\text {TM }}$ Snow17 is available within TREECS ${ }^{\mathrm{TM}}$ Tools as a stand-alone pre-processor application. All TREECS ${ }^{\mathrm{TM}}$ Snow17 simulations should start on January 1 . There are three input files consisting of daily precipitation, daily air temperatures, and model parameters. The precipitation and air temperature files can have any names the user chooses, but the model parameter file must be named snow17_inputs.txt, and this file contains the names of the precipitation and air temperature input files. The same precipitation and air temperature files are also used by the HGCT Arctic hydrology model. Examples of the precipitation, air temperature, and parameter input files for TREECS ${ }^{\mathrm{TM}}$ Snow17 for an application for Fairbanks, AK, are shown in Figures 3-5, respectively. It is noted that the year, month, and day are included for each record of precipitation and air temperatures. The precipitation data are provided in units of inches per hour for the entire day; thus, the model multiplies these values by 609.6 (i.e., 24 hours/day x $25.4 \mathrm{~mm} /$ inch) to obtain the daily precipitation in millimeters. The daily mean and maximum air temperatures are included. The maximum air temperature is not required for Snow17, rather it is used by the HGCT hydrology model. 
The first four lines of the model parameters file are used to identify the following: that it is a Snow17 simulation, the title and/or location for the simulation, and the names of the precipitation and air temperature input files. Latitude and elevation are pertinent to the site location for the simulation. The other parameters shown in Figure 5 are described in Table 2.

Figure 3. Example of precipitation input file used by TREECSTM Snow17.

\begin{tabular}{|c|c|c|c|}
\hline $\begin{array}{l}\text { Fairbank } \\
\text { Station }\end{array}$ & $\begin{array}{l}\text { AK Int } \\
\text { CND: USW }\end{array}$ & $\begin{array}{l}\text { irpo } \\
2641\end{array}$ & cipitati \\
\hline year & month & day & $\mathrm{in} / \mathrm{hr}$ \\
\hline 2010 & 1 & 1 & 0.000000 \\
\hline 2010 & 1 & 2 & 0.000000 \\
\hline 2010 & 1 & 3 & 0.000000 \\
\hline 2010 & 1 & 4 & 0.000000 \\
\hline 2010 & 1 & 5 & 0.000000 \\
\hline 2010 & 1 & 6 & 0.000000 \\
\hline 2010 & 1 & 7 & 0.000000 \\
\hline 2010 & 1 & 8 & 0.000000 \\
\hline 2010 & 1 & 9 & 0.000000 \\
\hline 2010 & 1 & 10 & 0.000000 \\
\hline 2010 & 1 & 11 & 0.000000 \\
\hline 2010 & 1 & 12 & 0.000000 \\
\hline 2010 & 1 & 13 & 0.000000 \\
\hline 2010 & 1 & 14 & 0.000000 \\
\hline 2010 & 1 & 15 & 0.000000 \\
\hline 2010 & 1 & 16 & 0.000000 \\
\hline 2010 & 1 & 17 & 0.000000 \\
\hline 2010 & 1 & 18 & 0.000000 \\
\hline 2010 & 1 & 19 & 0.000000 \\
\hline 2010 & 1 & 20 & 0.000000 \\
\hline 2010 & 1 & 21 & 0.000492 \\
\hline
\end{tabular}

Figure 4. Example of air temperature input file used by TREECS ${ }^{\mathrm{TM}}$ Snow17.

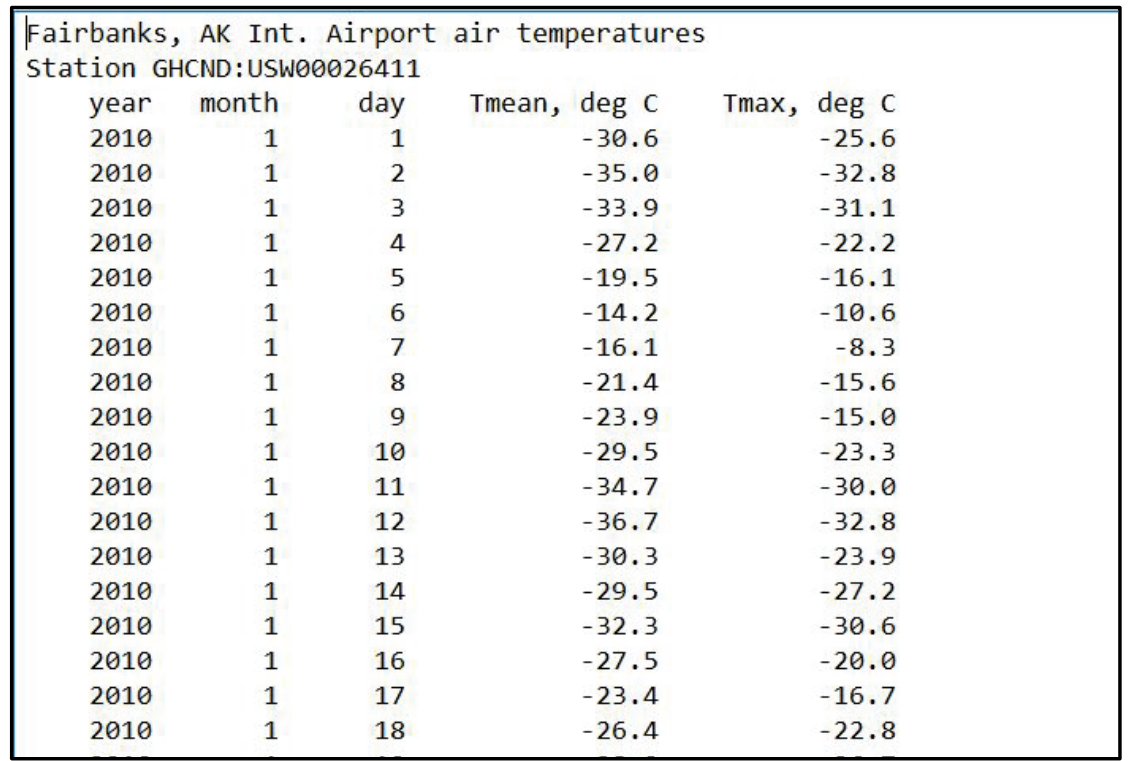


Figure 5. TREECSTM Snow17 model parameters input file, snow17_inputs . txt.

\begin{tabular}{|ll|}
\hline Snow17 simulation \\
Test case for & Fairbanks Int A/P AK \\
PrecipIn, & FairbanksPrecip.txt \\
TempsIn, & FairbanksTemps.txt \\
Latitude, & 64.0 \\
Elevation (m), & 136. \\
TIPM, & 0.1 \\
uadj, & 0.05 \\
scf, & 1.0 \\
plwhc, & 0.04 \\
mbase (C), & 0.0 \\
rvs, & 1 \\
pxtemp (C), & 1.0 \\
pxtemp1 (C), & 0.0 \\
pxtemp2 (C), & 1.0 \\
nmf, & 0.15 \\
mf-max, & 0.8 \\
mf-min, & 0.1 \\
Hini (in.), & 10.0 \\
den_0 (g/cc), & 0.20 \\
decay (1/day), & 0.07 \\
& \\
\hline
\end{tabular}

Table 2. Description of TREECSTM Snow17 model parameter inputs.

\begin{tabular}{|l|c|}
\hline \multicolumn{1}{|c|}{ Parameter } & $\begin{array}{c}\text { Recommended } \\
\text { default value }\end{array}$ \\
\hline $\begin{array}{l}\text { TIPM - Antecedent temperature index (ATI) parameter } \\
\text { (range is 0.01 to 1.0). Controls how much weight is put } \\
\text { on temperatures from previous time intervals when } \\
\text { computing ATI. The smaller the value of TIPM, the more } \\
\text { previous time intervals are weighted. }\end{array}$ & 0.1 \\
\hline $\begin{array}{l}\text { uadj - The average wind function during rain-on-snow } \\
\text { periods (mm/mb/6 hr). Only a major parameter when } \\
\text { there are fairly frequent rain-on-snow events with } \\
\text { relatively warm temperatures. }\end{array}$ & 0.04 \\
\hline $\begin{array}{l}\text { scf - The multiplying factor which adjusts precipitation } \\
\text { that is determined to be in the form of snow. Accounts } \\
\text { for gage catch deficiencies, but also implicitly includes } \\
\text { the net effect of vapor transfer (sublimation and } \\
\text { condensation, including from intercepted and blowing } \\
\text { snow) and transfers across areal divides. }\end{array}$ & \\
\hline $\begin{array}{l}\text { plwhc - Percent liquid water holding capacity (decimal } \\
\text { fraction). Indicates the maximum amount of liquid water }\end{array}$ & 0.04 \\
\hline
\end{tabular}




\begin{tabular}{|c|c|}
\hline Parameter & $\begin{array}{l}\text { Recommended } \\
\text { default value }\end{array}$ \\
\hline $\begin{array}{l}\text { as a fraction of the ice portion of the snow that can be } \\
\text { held against gravity drainage (maximum allowed value is } \\
0.4 \text { ). The expected range of plwhc is } 0.02-0.3 \text {. }\end{array}$ & \\
\hline $\begin{array}{l}\text { mbase - Base temperature }\left({ }^{\circ} \mathrm{C}\right) \text { for snowmelt } \\
\text { computations during non-rain periods. }\end{array}$ & 0.0 \\
\hline $\begin{array}{l}\text { rvs - An integer to indicate which option of three to use } \\
\text { for dividing precipitation between rain and snow. } \\
\text { rvs = 0: if } T_{a} \leq \text { pxtemp, all precipitation is snow, } \\
\text { otherwise it is rain } \\
\text { rvs = 1: if } T_{a} \leq \text { pxtemp1, all precipitation is snow; if } T_{a} \geq \\
\text { pxtemp2, all precipitation is rain; otherwise, } \\
\text { interpolation between pxtemp1 and pxtemp2 is used to } \\
\text { split precipitation between snow and rain. } \\
\text { rvs = 2: all precipitation is assumed to be snow } \\
\text { (normally should not be used). }\end{array}$ & 1 \\
\hline $\begin{array}{l}\text { pxtemp - The temperature }\left({ }^{\circ} \mathrm{C}\right) \text { that separates rain from } \\
\text { snow }\left({ }^{\circ} \mathrm{C}\right) \text {. If the air temperature is less than or equal to } \\
\text { pxtemp, the precipitation is assumed to be in the form of } \\
\text { snow. }\end{array}$ & 0.0 \\
\hline $\begin{array}{l}\text { pxtemp1 - The lower temperature }(\circ \mathrm{C}) \text { used with } \\
\text { pxtemp2 and } \mathrm{T}_{\mathrm{a}} \text { in interpolation to split precipitation } \\
\text { between rain and snow. }\end{array}$ & 0.0 \\
\hline $\begin{array}{l}\text { pxtemp2 - The upper temperature }\left({ }^{\circ} \mathrm{C}\right) \text { used with } \\
\text { pxtemp1 and } T_{a} \text { in interpolation to split precipitation } \\
\text { between rain and snow. }\end{array}$ & 1.0 \\
\hline $\begin{array}{l}\mathrm{nmf}-\text { Maximum negative melt factor }\left(\mathrm{mm} /{ }^{\circ} \mathrm{C} / 6 \mathrm{hr}\right) . \text { The } \\
\text { negative melt factor has the same seasonal variation as } \\
\text { the non-rain melt factor, thus the maximum value is } \\
\text { assumed to occur on June } 21 \mathrm{st} \text {. }\end{array}$ & 0.15 \\
\hline $\begin{array}{l}\text { mf-max - Maximum melt factor during non-rain periods, } \\
\text { assumed to occur on June } 21 \mathrm{st}\left(\mathrm{mm} /{ }^{\circ} \mathrm{C} / 6 \mathrm{hr}\right) \text {. }\end{array}$ & $\begin{array}{c}\text { within } \\
\text { approximate } \\
\text { range } 0.5 \text { to } 2.2\end{array}$ \\
\hline $\begin{array}{l}\text { mf-min - Minimum melt factor during non-rain periods - } \\
\text { assumed to occur on December } 21 \mathrm{st}\left(\mathrm{mm} /{ }^{\circ} \mathrm{C} / 6 \mathrm{hr}\right) \text {. }\end{array}$ & $\begin{array}{l}\text { within } \\
\text { approximate } \\
\text { range } 0.05 \text { to } \\
0.9\end{array}$ \\
\hline $\begin{array}{l}\text { Hini - Initial actual snow depth (inches) on January } 1 \text {, } \\
\text { the beginning of the simulation. }\end{array}$ & Site specific \\
\hline den_0 - asymptotic average base snow density $\left(\mathrm{g} / \mathrm{cm}^{3}\right)$ & Site specific \\
\hline $\begin{array}{l}\text { decay - First-order decay rate (per day) of new snow } \\
\text { transforming into base snow. }\end{array}$ & Site specific \\
\hline
\end{tabular}


Appropriate values for the parameters in Table 2 are discussed further in the next section. A new tool was implemented within TREECS ${ }^{\text {TM }}$ Tools, which is on the main menu bar, entitled Arctic Preprocessors. When Arctic Preprocessors is clicked, a user interface (UI) is launched that allows the user to open an existing or new case. For a new case, the user must enter the names of their project directory and project case. The UI also includes a button entitled Launch Excel Workbook, which launches a copy of the Excel workbook TREECSArcticProc.xlsm. This workbook is a pre- and post-processor that includes instructions and sheets for setting up parameters and generating input files, executing, and examining output for the TREECS ${ }^{\text {TM }}$ Snow17 model. The workbook also generates the output file SnowCoverMeltDepth. txt, which is required for other models. This workbook also serves as the pre- and post-processor for the soil thermal model discussed in the next chapter.

Two output files are generated by the TREECS ${ }^{\mathrm{TM}}$ Snow17 model, snow17_outputs.txt and SnowCoverMeltDepth.txt. The first file is for diagnostic purposes and consists of daily output (SWE, inches) of snowfall, rainfall, rain-on-snow, snow cover, and snow melt (i.e., excess liquid water in snow cover that results in outflow). An example of the first file is shown in Figure 6. The second file is used by the TREECS ${ }^{\mathrm{TM}}$ Arctic hydrology model and the soil thermal model (i.e., the Geophysical Institute Permafrost Laboratory (GIPL) model which is discussed in the next chapter). The second file consists of daily output of SWE, snow melt, and snow depth. An example of the second file is shown in Figure 7. All units are in inches. 
Figure 6. Example of TREECS ${ }^{\mathrm{TM}}$ Snow17 output file, snow17_outputs . txt.

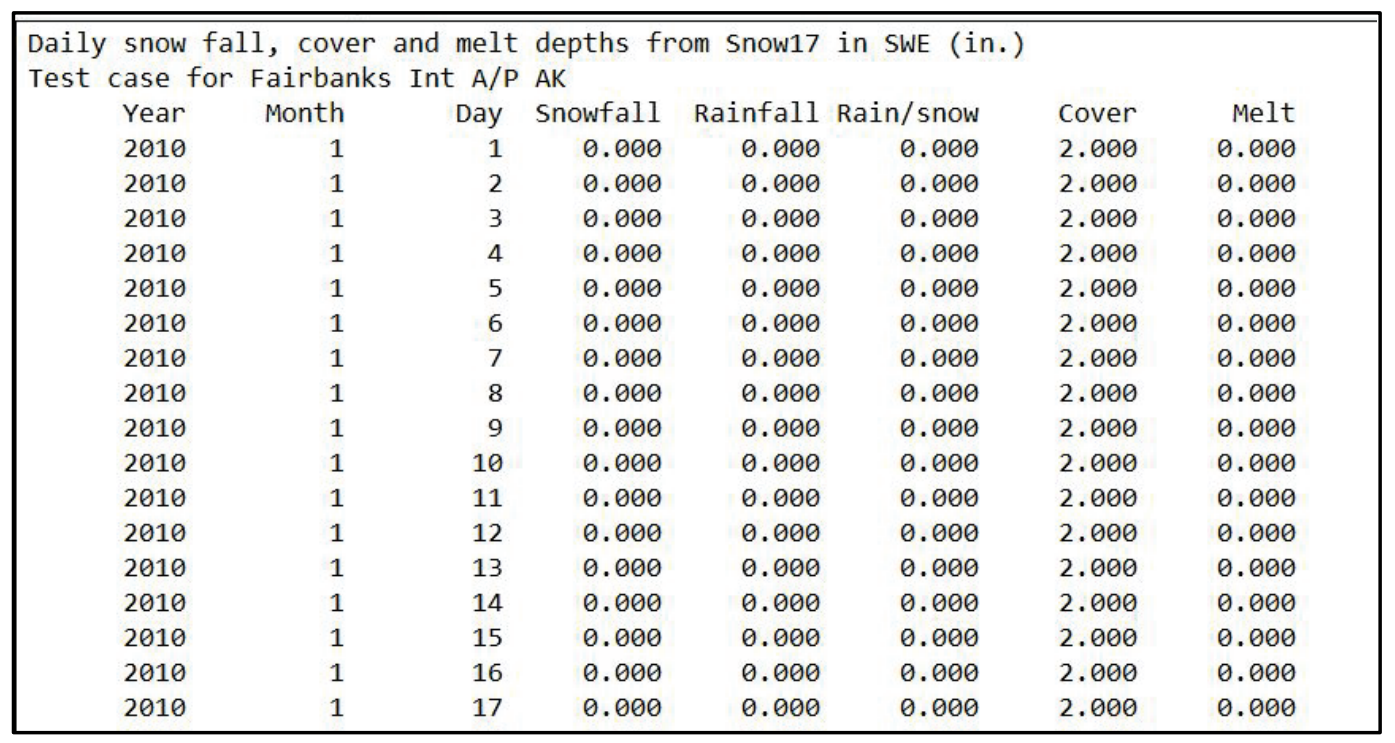

Figure 7. Example of TREECSTM Snow17 output file, SnowCoverMeltDepth . txt.

\begin{tabular}{|c|c|c|c|c|c|}
\hline \multicolumn{6}{|c|}{$\begin{array}{l}\text { Daily snow fall, cover and melt depths from Snow17 in SWE (in.) } \\
\text { Test case for Fairbanks Int A/P AK }\end{array}$} \\
\hline Year & Month & Day & H-SWE & Melt & H-Snow \\
\hline 2010 & 1 & 1 & 2.000 & 0.000 & 10.000 \\
\hline 2010 & 1 & 2 & 2.000 & 0.000 & 10.000 \\
\hline 2010 & 1 & 3 & 2.000 & 0.000 & 10.000 \\
\hline 2010 & 1 & 4 & 2.000 & 0.000 & 10.000 \\
\hline 2010 & 1 & 5 & 2.000 & 0.000 & 10.000 \\
\hline 2010 & 1 & 6 & 2.000 & 0.000 & 10.000 \\
\hline 2010 & 1 & 7 & 2.000 & 0.000 & 10.000 \\
\hline 2010 & 1 & 8 & 2.000 & 0.000 & 10.000 \\
\hline 2010 & 1 & 9 & 2.000 & 0.000 & 10.000 \\
\hline 2010 & 1 & 10 & 2.000 & 0.000 & 10.000 \\
\hline 2010 & 1 & 11 & 2.000 & 0.000 & 10.000 \\
\hline 2010 & 1 & 12 & 2.000 & 0.000 & 10.000 \\
\hline 2010 & 1 & 13 & 2.000 & 0.000 & 10.000 \\
\hline 2010 & 1 & 14 & 2.000 & 0.000 & 10.000 \\
\hline 2010 & 1 & 15 & 2.000 & 0.000 & 10.000 \\
\hline 2010 & 1 & 16 & 2.000 & 0.000 & 10.000 \\
\hline 2010 & 1 & 17 & 2.000 & 0.000 & 10.000 \\
\hline 2010 & 1 & 18 & 2.000 & 0.000 & 10.000 \\
\hline 2010 & 1 & 19 & 2.000 & 0.000 & 10.000 \\
\hline 2010 & 1 & 20 & 2.000 & 0.000 & 10.000 \\
\hline 2010 & 1 & 21 & 2.012 & 0.000 & 10.236 \\
\hline 2010 & 1 & 22 & 2.031 & 0.000 & 10.617 \\
\hline 2010 & 1 & 23 & 2.031 & 0.000 & 10.585 \\
\hline
\end{tabular}




\subsection{TREECS ${ }^{\mathrm{TM}}$ Snow17 testing}

Three types of tests were performed on TREECS ${ }^{\mathrm{TM}}$ Snow17: water budget verification, sensitivity of input parameters, and validation of snow cover. Each type of test is explained in the next three sections.

\subsubsection{Water budget verification}

Meteorological data from Fairbanks International Airport, AK (Station GHCND:USWoo026411) was downloaded on the World Wide Web from the National Oceanic and Atmospheric Administration's National Centers for Environmental Information (NCEI) web site, formerly the National Climatic Data Center (NCDC). The observations included daily recordings of total precipitation, snow depth, average, maximum, and minimum air temperatures, and average wind speed. These data were processed into the daily precipitation and air temperature input files discussed in the previous section. Seven years of data from 1 January 2010 to 31 December 2016, were downloaded and used for conducting the TREECS ${ }^{\mathrm{TM}}$ Snow17 simulations.

Water budget verification included a precipitation balance that consisted of summing the model daily output for all of the precipitation types, including snowfall, rainfall (no snow) and rain-on-snow, and comparing to the sum of the total precipitation that was input. The seven-year averages of these sums are reported rather than the raw sums (for the seven years). The seven-year average total precipitation of the input was 12.716 inches, whereas the seven year average of the total precipitation of the output was 12.718 inches. The total precipitation of the output was obtained by summing the seven-year averages of snowfall, rainfall with no snow, and rain-on-snow. Thus, the model maintains a nearly perfect balance for precipitation.

The water budget verification also included a snow water balance involving comparison of snow entering versus snow exiting the site for the seven years. Snow entering includes the initial snow cover (SWE) at the start of the simulation, the sum of the snowfall, and sum of the rain-onsnow for the seven years. The snow exiting the site included the sum of the melt over the seven years, plus the snow cover (SWE) at the end of the simulation. The snow melt is actually the excess water in the snow pack that is outflow from the snow pack. The total snow water entering the site over the seven years was 27.65 SWE inches, and the snow water exiting 
was 27.65 SWE inches. Thus, perfect agreement was obtained for the snow water balance. At this point, it was concluded that the model was maintaining accurate water balances.

\subsubsection{Sensitivity testing}

Observed daily snow depths for 2010-2016 at the Fairbanks International Airport were converted to daily SWE by multiplying by a constant snow density of $0.15 \mathrm{~g} / \mathrm{cm}^{3}$. Computed and observed daily snow depths as SWE were used to compute the relative error, $R E$ (\%), as provided by Equation 3-5.

$$
R E=\frac{\sum_{i=1}^{n}\left|P_{i}-O_{i}\right|}{\sum_{i=1}^{n} O_{i}}
$$

Where, $P_{i}$ and $O_{i}$ are the predicted and observed values of the $i^{\text {th }}$ day, respectively, and $n$ is the total number of days in the seven-year simulation. A different input parameter was varied for each model run, and the $R E$ was computed and recorded. The variation in $R E$ among runs was used to assess model sensitivity and model accuracy relative to changes in the input parameter.

The input parameters (Table 2) that were considered the most important, and that were varied during the sensitivity analysis included TIPM, plwhc, $n m f, m f-\max$, and $m f-\min$. The initial round of sensitivity runs revealed that the most sensitive of these parameters were $n m f, m f$-max, and $m f$ min. A TIPM of 1.0 yielded $R E$ of $15.77 \%$ compared with $R E$ of $15.23 \%$ for the base run TIPM value of 0.1. The upper and lower bounds of the expected range of plwhc were tested, yielding $R E$ of $15.19 \%$ for plwhc of 0.02 and $R E$ of $16.81 \%$ for plwhc of 0.3 compared to $R E$ of $15.23 \%$ for the base case plwhc value of 0.04. It was concluded from these results that input values for TIPM and plwhe did not merit extra attention for model applications, and the default values should be sufficient as inputs. The expected range of $n m f$ is $0.05-0.3$ with the recommended default value of 0.15 (Anderson 2002); however, an upper limit of 0.5 is suggested by Franz et al. (2008). Testing of the limits for $n m f$ of 0.05 and 0.5 yielded respective $R E$ values of 15.24 and $17.24 \%$ compared to the base $R E$ of $15.23 \%$ using the default value for $n m f$ of 0.15 . Although model results are 
more sensitive to inputs for $n m f$ than those for TIPM and plwhc, there appears to be some consistency for using a value for $n m f$ of 0.15 (Franz et al. 2008; Shamir and Georgakakos, 2007). Following these results, the decision was made to focus on the two parameters, $m f$-max and $m f$-min, as model inputs that would require the most attention during model calibration applications.

The maximum expected range of input values for $m f$-max and $m f$-min are 0.5-2.2, respectively (Anderson 2002), and 0.05-0.9, respectively (Franz et al. 2008). There are no recommended default values for either of these two parameters, and initial sensitivity testing revealed that model results are moderately sensitive to both parameters. Furthermore, the values of the two parameters should be decided conjunctively. Thus, systematic testing was conducted with these two parameters where $m f$-min was varied between 0.1 and 0.6 , and $m f$-max was varied between 0.8 and 2.2 in an attempt to find the combination of the two inputs that produced the lowest value of $R E$. The input values for $m f$-min and $m f$-max of 0.3 and 1.5, respectively, produced the $R E$ value of $13.92 \%$, which was the lowest $R E$ for all the combinations tested. This $R E$ value should be compared with the base case $R E$ of $15.23 \%$ to assess the relative sensitivity of model results to these two inputs.

From the sensitivity testing, it was concluded that the recommended default values shown in Figure 5 can usually be used for all parameters with the exception $m f$-min and $m f$-max. Additionally, the input values for Hini, den_o $\left(\rho_{o}\right)$, and decay $\left(k_{s}\right)$ are site or snow-cover-class-specific and should be varied for different application locations. Of course, the inputs for latitude and elevation are also site-specific.

\subsubsection{Validation of snow cover}

These tests were performed with the Fairbanks International Airport data for 2010-2016 to evaluate how well the model could reproduce actual snow cover using the method described in Section 3.3. Multiple model runs were performed using the inputs shown in Figure 5, with the exception that values of 0.3 and 1.5 were used, respectively, for $m f$-min and $m f$-max, since these values provided the best results as discussed in the previous section. Also, inputs for den_o $\left(\rho_{o}\right)$ and decay $\left(k_{s}\right)$ were varied among the runs in an attempt to find the most suitable values for $\rho_{o}$ and $k_{s}$ for the Fairbanks, AK, snow cover. 
Fairbanks snow cover can be classified as Taiga (Sturm et al. 1995). Sturm et al. 2010 present an empirical model for converting actual snow cover depth to SWE for various snow cover classes. This model depends on the initial and maximum bulk density of the snow cover, and these two densities depend on snow class as shown in Table 3. The base snow pack density $\left(\rho_{o}\right)$ to use in the model is expected to be between the values shown in Table 3 for a particular snow class. For Taiga, both the maximum and initial snow densities are $0.217 \mathrm{~g} / \mathrm{cm}^{3}$. A review of snow depth and SWE data presented by Plumb and Lilly (1996) revealed that snow pack density was 0.22 and $0.24 \mathrm{~g} / \mathrm{cm}^{3}$ for the respective maximum and minimum snow depths measured on 1 April 1995, when melt had started and snow density was increasing. These observed values help confirm a base snow pack density of $0.217 \mathrm{~g} / \mathrm{cm}^{3}$ for this area.

Table 3. Initial and maximum snow cover density by snow class from Sturm et al. (2010).

\begin{tabular}{|l|c|c|}
\hline \multicolumn{1}{|c|}{ Snow cover class } & $\begin{array}{c}\text { Initial snow cover density, } \\
\mathbf{g} / \mathrm{cm}^{3}\end{array}$ & $\begin{array}{c}\text { Maximum snow cover density, } \\
\mathbf{g} / \mathrm{cm}^{3}\end{array}$ \\
\hline Alpine & 0.2237 & 0.5975 \\
\hline Maritime & 0.2578 & 0.5979 \\
\hline Prairie & 0.2332 & 0.5940 \\
\hline Tundra & 0.2425 & 0.3630 \\
\hline Taiga & 0.2170 & 0.2170 \\
\hline
\end{tabular}

The result of each model run was evaluated by comparing error statistics of predicted and observed snow depths, where the statistics used were $R E$, mean absolute error (MAE), and the coefficient of determination $\left(R^{2}\right)$, or the goodness-of-fit, of the model compared to the observed data. The MAE is shown in Equation 3-6

$$
M A E=\frac{\sum_{i=1}^{n}\left|P_{i}-O_{i}\right|}{n}
$$

Where all variables have been previously defined. The $R^{2}$ is defined by Equation 3-7. 


$$
R^{2}=1-\frac{\sum_{i=1}^{n}\left(P_{i}-O_{i}\right)^{2}}{\sum_{i=1}^{n}\left(O_{i}-O_{M}\right)^{2}}
$$

Where, $O_{M}$ is the mean of the observed data.

Using a value of $\rho_{o}=0.217$, the best model results for snow depth were obtained using $k_{s}=0.06$, for which $M A E=1.12, R E=17.87$, and $R^{2}=0.92$. However, the best model results for snow depth were obtained using a slightly lower value of $\rho_{o}=0.2 \mathrm{~g} / \mathrm{cm}^{3}$ and $k_{s}=0.07$ per day, where $M A E=$ 1.04, $R E=16.49$, and $R^{2}=0.93$. The average predicted and observed snow depths for the seven years were 6.44 and 6.29 inches, respectively, resulting in an over-prediction error of only $2 \%$ compared with an underprediction error of $16.7 \%$ for the very simple snow model in the TREECS $^{\text {TM }}$ HGCT Hydrology model.

The predicted (model) and observed snow depths vs. days of the simulation are plotted in Figure 8. The predicted snow depths compare well with observed depths, even reproducing the sharply rising and falling periods of depth and many of the peaks occurring during heavier snowfall.

Figure 8. Predicted and observed snow depths vs. days of simulation with $\rho_{o}=0.2$ and $k_{s}=0.07,2010-2016$, Fairbanks International Airport, AK.

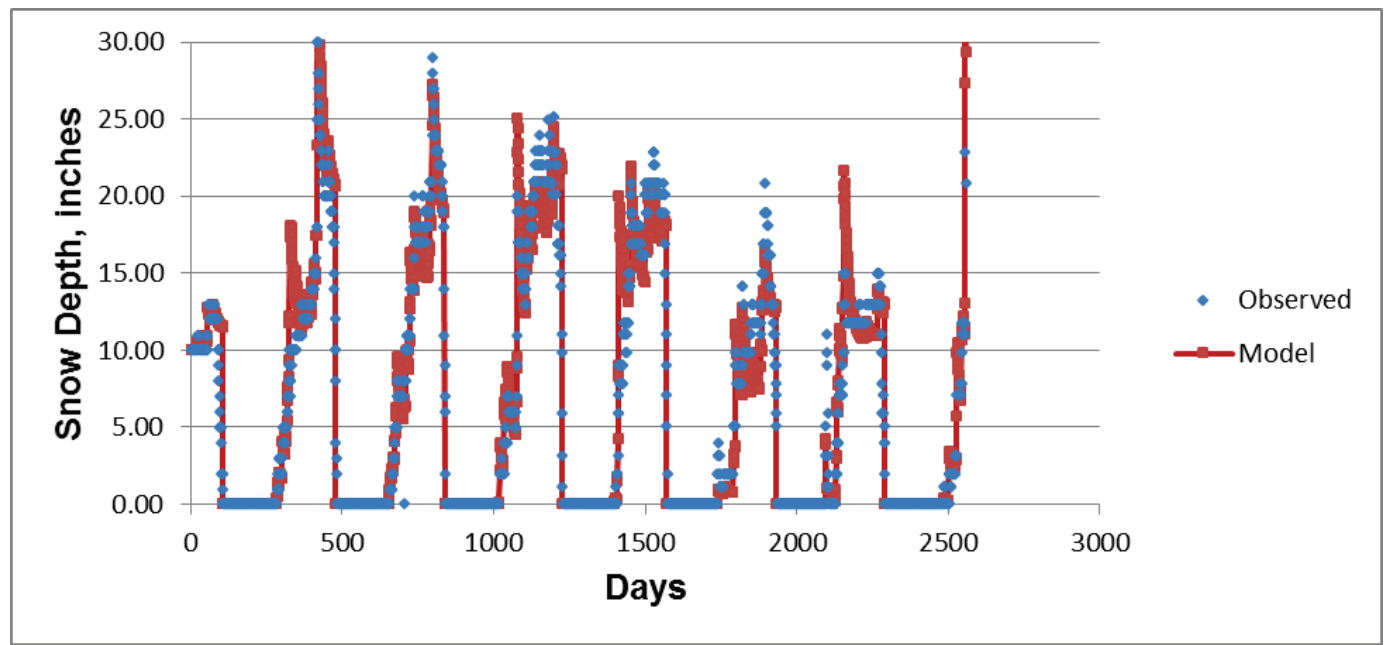

A plot of predicted vs. observed snow depths is presented in Figure 9 to show the trend for how the model-computed values compare with observed values. The black line in Figure 9 is the perfect fit (i.e., $P=O$ ). This plot shows that the model tends to over-predict snow depth, probably due to the 
relatively low and constant value of base density $\left(\rho_{o}\right)$. The base density should probably increase during the spring when melting begins. However, the model performs fairly well overall considering the simplicity of it.

Figure 9. Predicted vs. observed snow depths with $\rho_{o}=0.2$ and $k_{s}=0.07$ compared with a perfect fit (black line), 2010-2016, Fairbanks International Airport, AK.

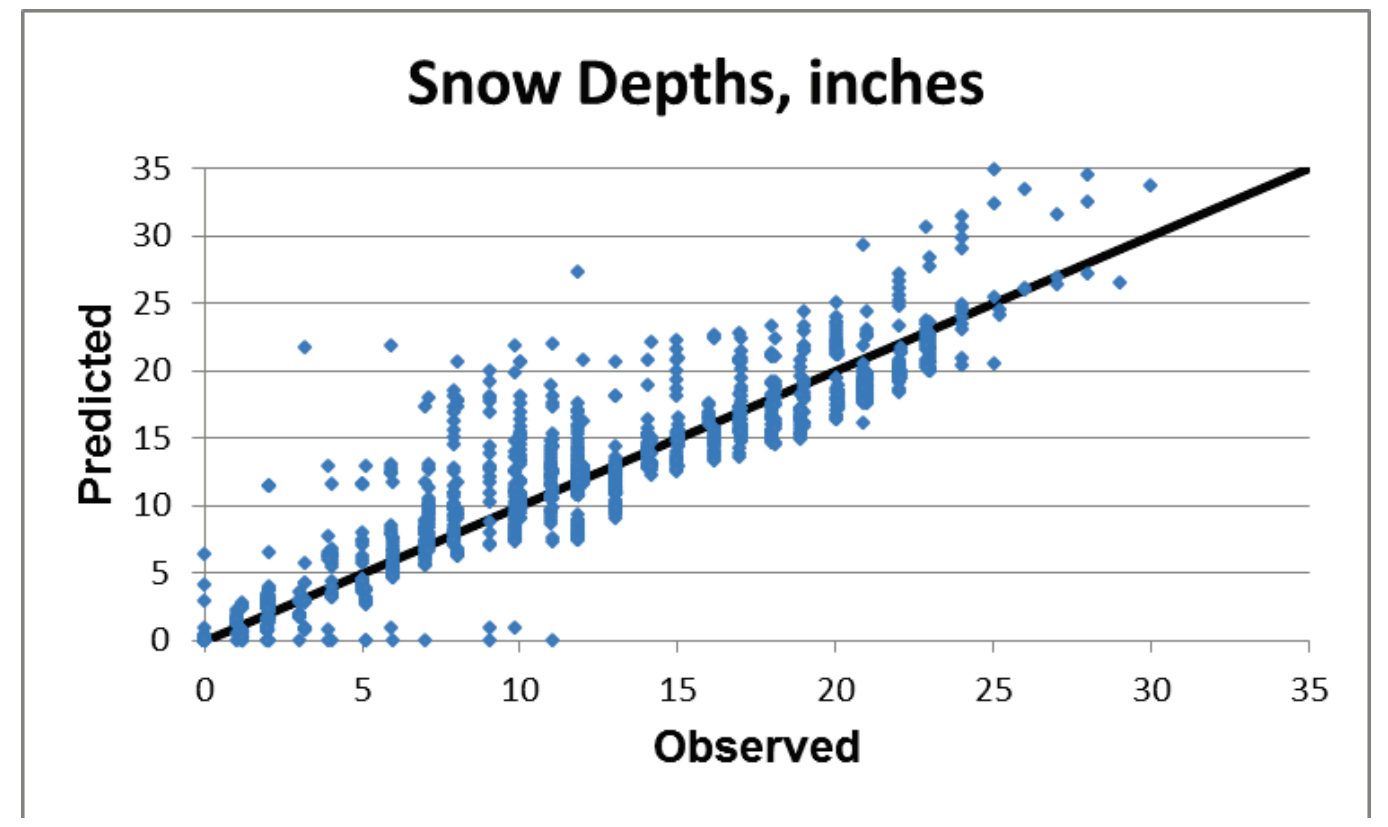

The cumulative probably distributions for model-computed and observed snow depths is shown in Figure 10. Figure 10 shows how well the two distributions compare. It was concluded that the simple model for computing snow depth from SWE described in Section 3.3 is sufficiently accurate for the need, which is to provide daily snow cover for the GIPL model. 
Figure 10. Cumulative probably distribution for model-computed and observed snow depths with $\rho_{0}=0.2$ and $k_{s}=0.07,2010-2016$, Fairbanks International Airport, AK.

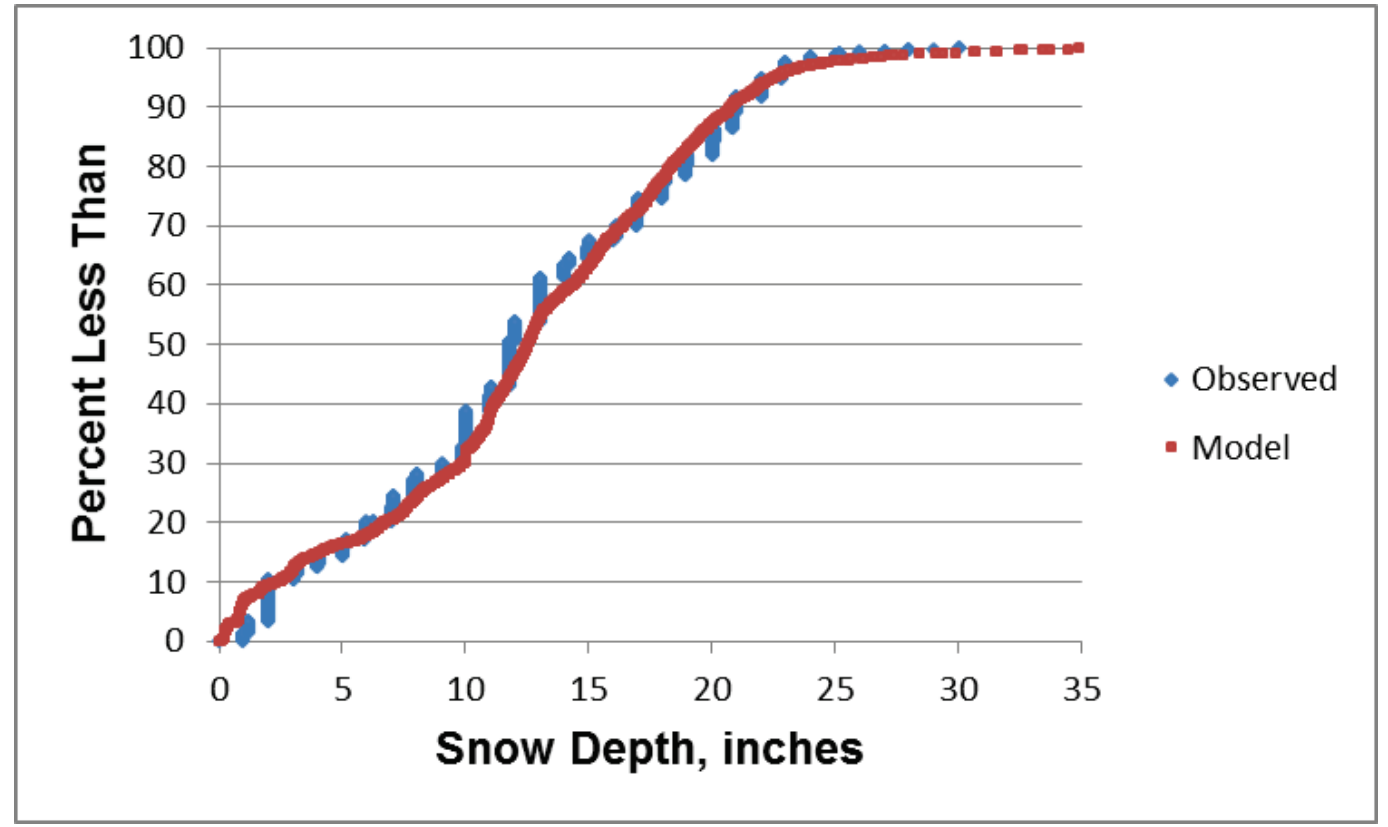

The above comparisons of predicted and observed snow depths also served as validation of the TREECS ${ }^{\mathrm{TM}}$ Snow17 model since model snow depth is computed from predicted SWE. It would have been preferable to also have observed snow cover as SWE and snow pack outflow for model comparison, but these data were not collected. Given the relatively good results presented in this section and the water budget verification of section 3.5.1, the TREECS ${ }^{\mathrm{TM}}$ Snow17 model was deemed validated. 


\section{Soil Thermal Regime}

Modeling the soil thermal regime is necessary, since it affects freeze-thaw dynamics, which affect water movement and contaminant F/T.

Additionally, the thermal regime affects the depths to the top and bottom of the permafrost as shown in Figure 1. Following a review of soil thermal models for Arctic conditions, the Geophysical Institute Permafrost Laboratory (GIPL) model (Jafarov et al. 2012) was selected for use.

The GIPL model consists of an implicit finite difference solution to a 1D heat transfer function with phase change applied to a vertical column of air, snow, and soil. An unlimited number of layers can be utilized in the model domain which may be designated as air, snow, or soil (containing air, water, ice, and organic or mineral solids) layers. The snow depth is variable in time. Soil saturation and material properties are variable by layer. Users must input thermal conductivities for snow, as well as the soil and organic matter, in the frozen and thawed state. The upper boundary condition is air temperature. The lower boundary can be either a fixed temperature or a fixed flux (i.e., gradient) condition. The initial condition is a vertical temperature profile through the domain.

\subsection{Implementation of the GIPL model and input}

The GIPL model code is written in Fortran and was retrieved from the Community Surface Dynamics Modeling System website on 19 July 2016 (Model:GIPL 2016). The code was compiled with Intel ${ }^{\circledR}$ Fortran Compiler for applications running on Intel ${ }^{\circledR}$ 64, version 10.0.025. Minor formatting changes were needed and several compiler warnings remained, but the code was run and compared against the solution provided in the download package to verify functionality. The fixed lower boundary temperature option was selected before compiling. A fixed gradient boundary condition version of the application is available on request.

The model was added to the Tools menu screen of TREECS ${ }^{\mathrm{TM}}$ as part of a stand-alone Excel ${ }^{\odot}$ workbook application to pre- and post- process the inputs and outputs for Snow17 and GIPL. Users make entries into the processor spreadsheet tabs, and it in turn produces the input files needed by the GIPL model, runs the model, and displays the results. This chapter details the input requirements within the processor as a guide to users implementing GIPL from within TREECS ${ }^{\mathrm{TM}}$. Appendix A incudes 
examples of the nine text input files (gipl_config. cfg,

in/sites.txt, in/grid.txt, in/mineral.txt,

in/organic.txt, in/bound.txt, in/snow.txt,

in/rsnow.txt, and in/initial.txt) and three output

files (dump/result.txt, dump/mean.txt, and

dump/start.txt) created by the processor after running the GIPL model.

The GIPL model should be applied to the same time period as TREECS ${ }^{\text {TM }}$ Snow17 and begin on January $1^{\text {st. }}$ TREECS ${ }^{\text {TM }}$ Snow17 output, in the form of daily average snow depth measured in meters, may be transferred from the Snow17 section of the processor to the boundary conditions tab of the GIPL section. The same temperature data should be used a boundary condition for TREECS ${ }^{\text {TM }}$ Snow17 and the GIPL model.

The general process of running the GIPL model is as follows. The user begins on the GIPL tab (Figure 11). This tab contains the information needed to write the GIPL model configuration file, gipl_config.cfg, and size the number of inputs needed for the other GIPL input files. Users should refer to Table 4 for descriptions of the parameters and typical value ranges.

Figure 11. Example of GIPL processor input tab used to create the control file for TREECSTM GIPL, gipl_config.cfg.

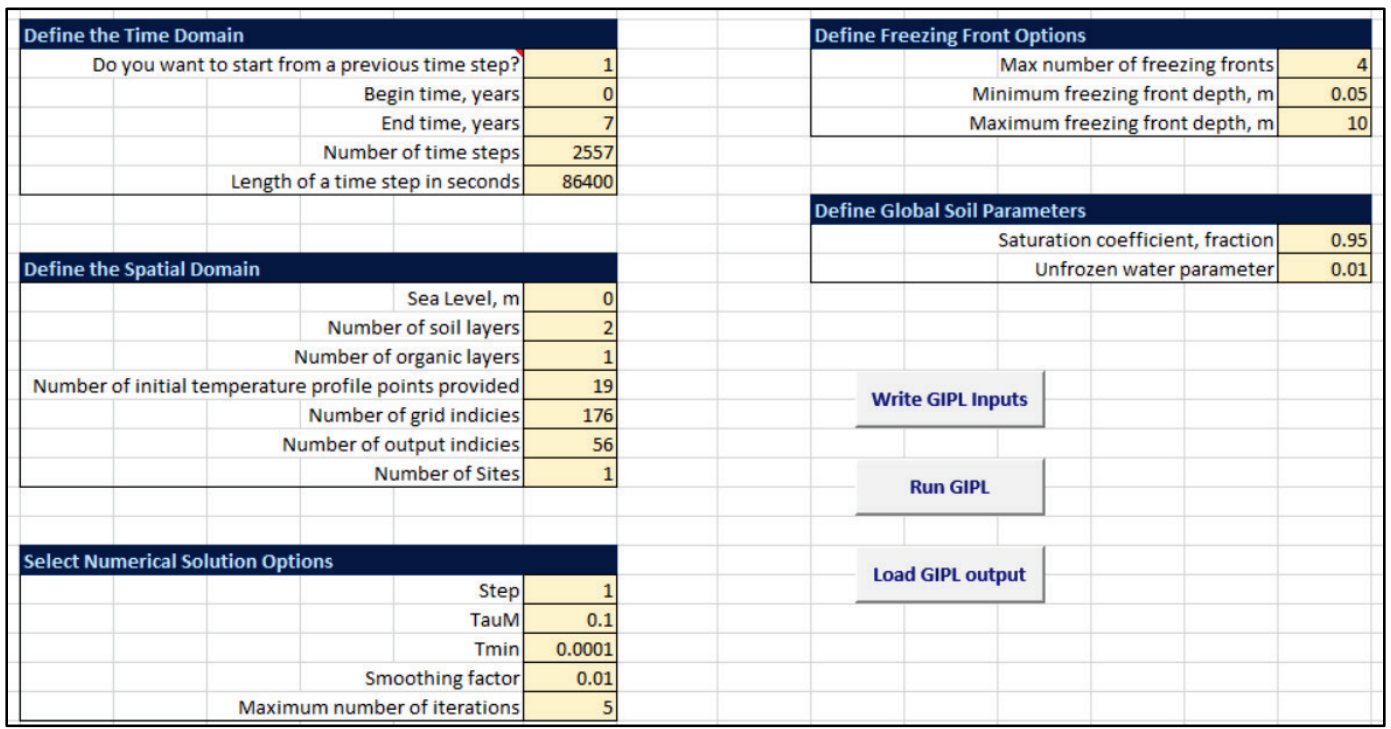


Table 4. Description of TREECSTM GIPL input parameters for the gipl_config.cfg, in/sites.txt, and in/grid. txt files.

\begin{tabular}{|c|c|}
\hline Parameter & $\begin{array}{l}\text { Recommended } \\
\text { default value }\end{array}$ \\
\hline $\begin{array}{l}\text { Begin time - The year represented by the first time data } \\
\text { point. It will usually be time }=0 \text { (years). }\end{array}$ & 0 \\
\hline End time - The length of the model run (years). & 1 \\
\hline Number of time steps - The length of a model run (days). & $\begin{array}{l}\text { Multiples of } \\
\quad 365\end{array}$ \\
\hline $\begin{array}{l}\text { Length of a time step in seconds - The duration of a time } \\
\text { step (seconds). Daily time steps are required to coordinate } \\
\text { the data input needs of the Snow } 17 \text { and GIPL models. }\end{array}$ & 86400 \\
\hline Sea level - Reference elevation of sea level (m). & 0 \\
\hline $\begin{array}{l}\text { Number of soil layers - The number of soil layers described } \\
\text { in the mineral.txt file. Layers are defined on the basis of } \\
\text { thermal properties. Mineral layers begin at the land surface } \\
\text { datum and extend vertically downward. }\end{array}$ & 2 or more \\
\hline $\begin{array}{l}\text { Number of organic layers - The number of organic soil layers } \\
\text { described in the organic.txt file. Layers are defined on the } \\
\text { basis of thermal properties. Organic layers extend vertically } \\
\text { upward from the ground surface datum. }\end{array}$ & 1 or more \\
\hline $\begin{array}{l}\text { Number of initial temperature profile points provided - The } \\
\text { number of temperature points listed in the initial.txt file. The } \\
\text { initial temperature profile extends vertically downward from } \\
\text { the land surface. }\end{array}$ & 10 or more \\
\hline $\begin{array}{l}\text { Number of grid indices - Number of vertical discretization } \\
\text { points. The vertical grid should extend from above the } \\
\text { expected snowpack depth to below the permafrost layer. }\end{array}$ & $10-300$ \\
\hline $\begin{array}{l}\text { Number of output indices - number of vertical grid locations } \\
\text { included in modeled temperature output. The actual nodes } \\
\text { selected are indicated in the grids.txt file. }\end{array}$ & $10-50$ \\
\hline Number of sites - Number of locations modeled at a time. & 1 \\
\hline Step - The first time step. & 1 \\
\hline $\begin{array}{l}\text { TauM - A convergence parameter used in the Stefan } \\
\text { subroutine. }\end{array}$ & 0.1 \\
\hline $\begin{array}{l}\text { Tmin - The minimum time step used in the heat transfer } \\
\text { subroutine. }\end{array}$ & 0.0001 \\
\hline $\begin{array}{l}\text { Smoothing factor - Used in the solution of the heat transfer } \\
\text { subroutine. }\end{array}$ & 0.01 \\
\hline $\begin{array}{l}\text { Maximum number of iterations - The maximum number of } \\
\text { attempts at convergence in the heat transfer subroutine. }\end{array}$ & 5 \\
\hline $\begin{array}{l}\text { Max number of freezing fronts - The maximum number of } \\
\text { freezing fronts allowed in the vertical column at any time. }\end{array}$ & 4 \\
\hline
\end{tabular}




\begin{tabular}{|l|c|}
\hline \multicolumn{1}{|c|}{ Parameter } & $\begin{array}{c}\text { Recommended } \\
\text { default value }\end{array}$ \\
\hline $\begin{array}{l}\text { Minimum freezing front depth - The soil is considered frozen } \\
\text { when the freezing front reaches this depth }(\mathrm{m}) .\end{array}$ & 0.05 \\
\hline $\begin{array}{l}\text { Maximum freezing front depth - The deepest penetration of } \\
\text { a freezing front }(\mathrm{m}) .\end{array}$ & 10 \\
\hline $\begin{array}{l}\text { Saturation coefficient - The saturation level of the soil in its } \\
\text { fully thawed state (fraction of 1). Most arctic soils are nearly } \\
\text { saturated. }\end{array}$ & 0.95 \\
\hline $\begin{array}{l}\text { Unfrozen Water Parameter - A parameter describing the } \\
\text { shape of the unfrozen water curve (fraction of } 1) .\end{array}$ & 0.01 \\
\hline
\end{tabular}

The sites tab (Figure 12) produces the in/sites . txt file. This file describes the number of locations the GIPL model will be applied to and the lower boundary condition selection. In TREECSTM the same conditions are applied to the entire domain so it is recommended that the user not change the first five parameters on this tab. If there is knowledge about the temperature at the bottom of the soil domain, the user may wish to change the value in the temp_bdr box. A description of the sites parameters is included in Table 5 .

Figure 12. Example of sites input tab used by the TREECSTM GIPL pre-processor to create the in/sites. txt file.

Site snow code veg code geo code gt_zone_code temp_bdr

\begin{tabular}{|l|l|l|l|l|l|}
1 & 246 & 1 & 1 & 1 & -0.2021 \\
\hline
\end{tabular}

Table 5. Description of TREECS ${ }^{\mathrm{TM}}$ GIPL input parameters.

\begin{tabular}{|c|c|c|}
\hline Input File & Parameter & $\begin{array}{l}\text { Recommended } \\
\text { default value }\end{array}$ \\
\hline in/sites.txt & Site - The number of the site being identified. & 1 \\
\hline in/sites.txt & Snow code - ID code for snow. & 246 \\
\hline in/sites.txt & Veg code - Id code for site vegetation. & 1 \\
\hline in/sites.txt & Geo code - Id code for the site geography. & 1 \\
\hline in/sites.txt & Gt_zone_code - Geothermal gradient zone code. & 1 \\
\hline in/sites.txt & $\begin{array}{l}\text { Temp_bdr - temperature at the bottom boundary of the } \\
\text { domain }\left({ }^{\circ} \mathrm{C}\right) .\end{array}$ & $-13-0$ \\
\hline in/grid.txt & $\begin{array}{l}\text { Input grid indices - Number the grid nodes from } 1 \text { at the } \\
\text { highest point (integer). }\end{array}$ & $1-200$ \\
\hline in/grid.txt & $\begin{array}{l}\text { Depth of grid indices - Indicate the depth of each grid } \\
\text { node }(m) \text {. The vertical profile should start above the }\end{array}$ & $-2-200$ \\
\hline
\end{tabular}




\begin{tabular}{|c|c|c|}
\hline Input File & Parameter & $\begin{array}{l}\text { Recommended } \\
\text { default value }\end{array}$ \\
\hline & $\begin{array}{l}\text { depth of the deepest expected snowpack with negative } \\
\text { elevation. The land surface is the zero datum and depth } \\
\text { increases positively with depth. Grid nodes should be } \\
\text { very closely spaced }(0.001 \mathrm{~m}) \text { just below the ground } \\
\text { surface to capture the propagation of freezing fronts } \\
\text { downward through the profile but may be } 10 \text { or more } \\
\text { meters apart at depth without affecting the result. An } \\
\text { example is supplied in Appendix A. }\end{array}$ & \\
\hline In/grid.txt & $\begin{array}{l}\text { Flag for output - Indicate if a grid node is selected for } \\
\text { output by placing a mark (number or letter) in this } \\
\text { column. The number of grid nodes selected must match } \\
\text { the number of output indices indicated on the GIPL tab. }\end{array}$ & Any character \\
\hline $\begin{array}{l}\text { in/mineral.txt } \\
\text { and } \\
\text { in/organic.txt }\end{array}$ & $\begin{array}{l}\text { Layers - ID for each layer beginning with } 1 \text { and } \\
\text { increasing vertically downward in the profile. }\end{array}$ & integers \\
\hline $\begin{array}{l}\text { in/mineral.txt } \\
\text { and } \\
\text { in/organic.txt }\end{array}$ & $\begin{array}{l}\text { Thickness of layer - The thickness of each layer }(\mathrm{m}) \text {. The } \\
\text { characteristics of the deepest indicated layer are applied } \\
\text { from the layer to the bottom of the domain regardless of } \\
\text { the thickness listed. }\end{array}$ & $\begin{array}{l}\text { Should sum to } \\
\text { the total } \\
\text { thickness of the } \\
\text { domain }\end{array}$ \\
\hline $\begin{array}{l}\text { in/mineral.txt } \\
\text { and } \\
\text { in/organic.txt }\end{array}$ & $\begin{array}{l}\text { Cumulative depth - The depth to the bottom of each } \\
\text { layer }(m) \text {. }\end{array}$ & $\begin{array}{l}\text { Should match } \\
\text { total depth of } \\
\text { domain }\end{array}$ \\
\hline $\begin{array}{l}\text { in/mineral.txt } \\
\text { and } \\
\text { in/organic.txt }\end{array}$ & $\begin{array}{l}\text { Volumetric water content - The volumetric water content } \\
\text { of each layer (percent). }\end{array}$ & 0 - porosity \\
\hline $\begin{array}{l}\text { in/mineral.txt } \\
\text { and } \\
\text { in/organic.txt }\end{array}$ & $\begin{array}{l}\text { a coefficient - A coefficient of the unfrozen water curve } \\
\text { which has the form of } \Theta=a T^{b} \text { where } \Theta \text { is the unfrozen } \\
\text { water content and T is temperature }\left({ }^{\circ} \mathrm{C}\right) \text {. Refer to Lovell } \\
\text { (1957) and Tice et al. (1989). }\end{array}$ & $\begin{array}{l}\text { Clay } 32.10 \\
\text { Silty Clay } 13.14 \\
\text { Clayey Silt } 5.10\end{array}$ \\
\hline $\begin{array}{l}\text { in/mineral.txt } \\
\text { and } \\
\text { in/organic.txt }\end{array}$ & $\begin{array}{l}b \text { coefficient - B coefficient of the unfrozen water curve } \\
\text { which has the form of } \Theta=a T^{b} \text { where } \Theta \text { is the unfrozen } \\
\text { water content and } T \text { is temperature }\left({ }^{\circ} \mathrm{C}\right) \text {. Refer to Lovell } \\
\text { (1957) and Tice et al. (1989). }\end{array}$ & $\begin{array}{l}\text { Clay }=0.271 \\
\text { Silty Clay }= \\
0.197 \\
\text { Clayey Silt }= \\
0.393\end{array}$ \\
\hline $\begin{array}{l}\text { in/mineral.txt } \\
\text { and } \\
\text { in/organic.txt }\end{array}$ & $\begin{array}{l}\text { Frozen volumetric heat capacity - The amount of heat } \\
\text { (joules) needed to raise one cubic meter of frozen soil by } \\
\text { one degree Kelvin }\left(\mathrm{J} / \mathrm{m}^{\wedge} 3 \mathrm{~K}\right) \text {. Refer to Farouki (1981), } \\
\text { Konovalov and Roman (1973), and Nicolsky et al. } \\
\text { (2007). }\end{array}$ & $\begin{array}{l}2,400,000- \\
2,000,000\end{array}$ \\
\hline $\begin{array}{l}\text { in/mineral.txt } \\
\text { and } \\
\text { in/organic.txt }\end{array}$ & $\begin{array}{l}\text { Thawed volumetric heat capacity - The amount of heat } \\
\text { (joules) needed to raise one cubic meter of thawed soil } \\
\text { by one degree Kelvin }\left(\mathrm{J} / \mathrm{m}^{\wedge} 3 \mathrm{~K}\right) \text {. Refer to Farouki (1981), } \\
\text { Konovalov and Roman (1973), and Nicolsky et al. } \\
(2007) \text {. }\end{array}$ & $\begin{array}{l}1,600,000- \\
2,300,000\end{array}$ \\
\hline $\begin{array}{l}\text { in/mineral.txt } \\
\text { and } \\
\text { in/organic.txt }\end{array}$ & $\begin{array}{l}\text { Frozen heat conductivity - The ability of frozen soil to } \\
\text { transmit heat (W/mK). Refer to Farouki (1981), }\end{array}$ & $1.9-3.08$ \\
\hline
\end{tabular}




\begin{tabular}{|c|c|c|}
\hline Input File & Parameter & $\begin{array}{l}\text { Recommended } \\
\text { default value }\end{array}$ \\
\hline & $\begin{array}{l}\text { Konovalov and Roman (1973), and Nicolsky et al. } \\
\text { (2007). }\end{array}$ & \\
\hline $\begin{array}{l}\text { in/mineral.txt } \\
\text { and } \\
\text { in/organic.txt }\end{array}$ & $\begin{array}{l}\text { Thawed heat conductivity - The ability of thawed soil to } \\
\text { transmit heat (W/mK). Refer to Farouki (1981), } \\
\text { Konovalov and Roman (1973), and Nicolsky et al. } \\
\text { (2007). }\end{array}$ & $3.11-3.29$ \\
\hline in/bound.txt & $\begin{array}{l}\text { Daily averaged surface temperature - Daily air } \\
\text { temperature in the location of interest }\left({ }^{\circ} \mathrm{C}\right) \text {. This } \\
\text { temperature is be applied to the top node in the domain. }\end{array}$ & $-60-120$ \\
\hline In/snow.txt & $\begin{array}{l}\text { Daily average snow depth - The snow depth }(\mathrm{m}) \text {. Snow } \\
\text { depth should not exceed the elevation of the top node in } \\
\text { the grid. }\end{array}$ & $0-2$ \\
\hline In/rsnow.txt & $\begin{array}{l}\text { Daily average snow conductivity - The average thermal } \\
\text { conductivity of the snowpack (W/mK). Snow conductivity } \\
\text { increases as snow compacts (Sturm et al. 1995). }\end{array}$ & $0.08-0.75$ \\
\hline in/initial.txt & $\begin{array}{l}\text { Depth - The depth of each initial temperature value }(\mathrm{m}) \text {. } \\
\text { Initial temperatures should include the highest node and } \\
\text { deepest node of the vertical grid. }\end{array}$ & $-2-200$ \\
\hline in/initial.txt & $\begin{array}{l}\text { Temperature - The temperature of each node specified } \\
\left({ }^{\circ} \mathrm{C}\right) \text {. The highest node should match the initial air } \\
\text { temperature given in the in/bound.txt file and the } \\
\text { deepest node should be below zero. }\end{array}$ & $-60-120$ \\
\hline
\end{tabular}

The grid tab (Figure 13) is used to create the in/grid.txt file. This file describes the division of the column into computational nodes and designates which nodes will be included in the final output. The nodes should be numbered from 1 and increasing downward in column B. The domain should extend above the deepest expected snow. The datum is the land surface and elevations that are above negative. The boundary air temperature condition is applied to the highest node. The lowest node should be significantly deeper than the bottom of the active layer, because a fixed temperature boundary condition will be applied. Experimentation with the GIPL code revealed that $90-200 \mathrm{~m}$ is a good placement of the lower boundary. A fine node spacing just below the datum is appropriate to track the rapid changes in freeze depth at this location. Select nodes for output by placing a mark in column D. All nodes are used for computation but the temperature is only output at the selected nodes. 
Figure 13. Example of grid input tab used by the TREECSTM GIPL preprocessor to create the in/grid. txt file.

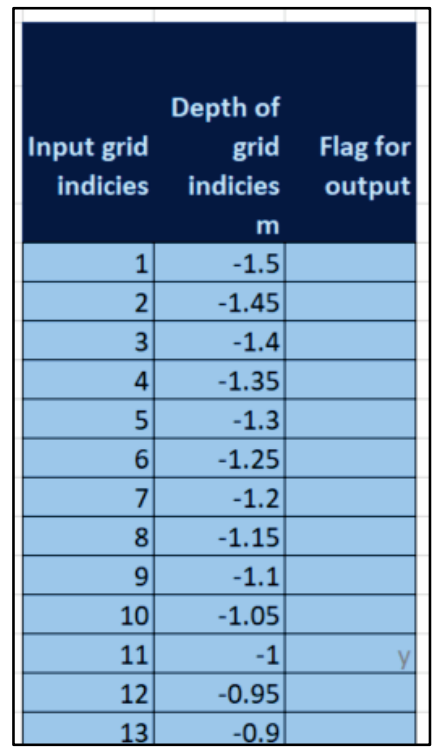

The mineral (Figure 14) and organic (Figure 15) tabs create the in/mineral.txt and in/organic.txt files. These files describe the solid materials beneath the snow. The depth and thickness of each layer is used to assign properties to grid nodes. The properties are held constant from the top of each layer until a new set of properties is designated beneath it. The organic layers are placed above the soil layers, therefore, any number of organic and soil layers may be used. Both frozen and thawed heat capacity and heat conductivities are required due to the fact that the model accounts for phase changes of the water within the soil or organic matter pores. Table 5 describes the required parameters.

Figure 14. Example of mineral input tab used by TREECSTM GIPL preprocessor to create the in/mineral . txt file.

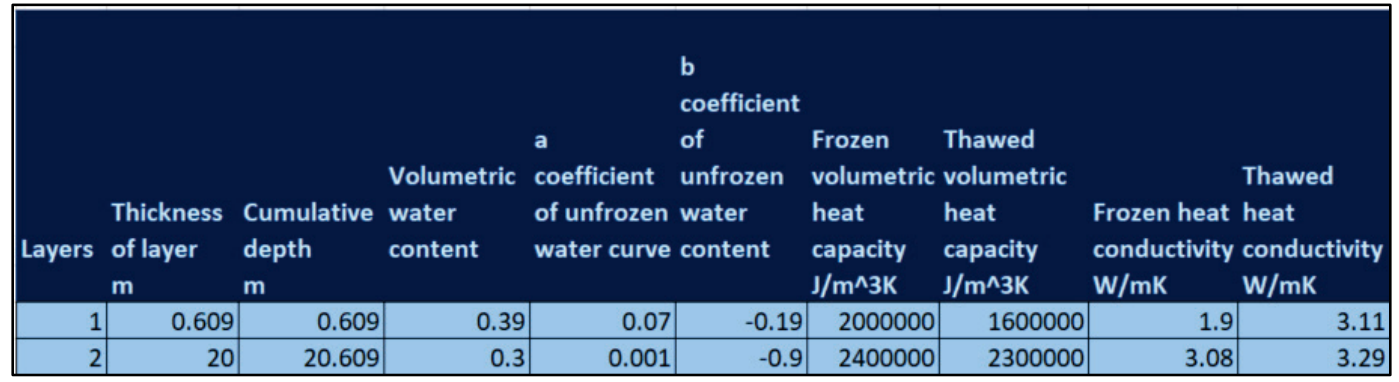


Figure 15. Example of organic input file used by the TREECSTM GIPL preprocessor to create the in/organic. txt file.

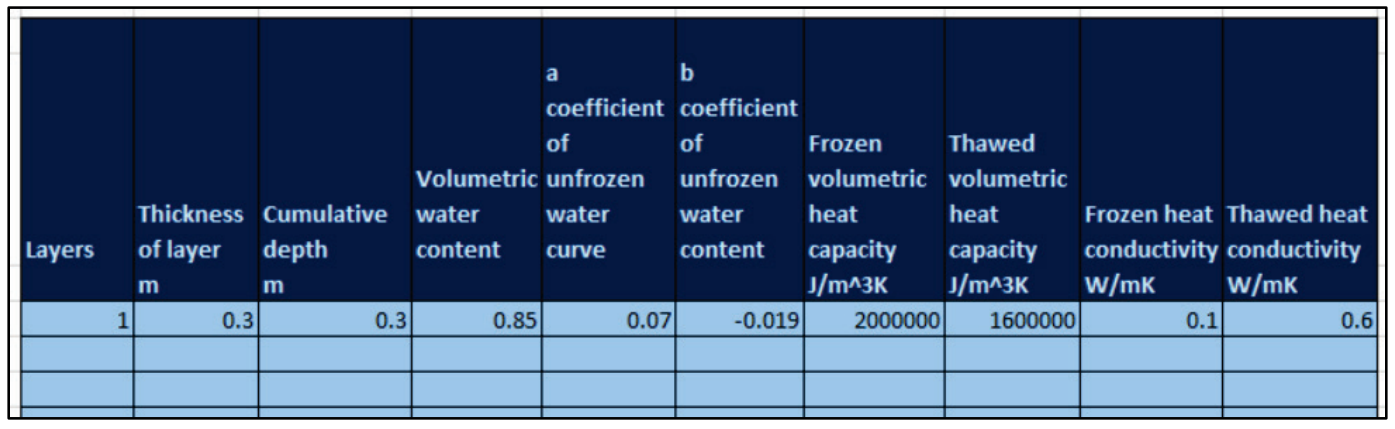

The BOUNDARY_CONDITIONS tab (Figure 16) combines three time series into one input table. The first column counts the time in days for the entire model domain. There must be at least one value for each day through the number of days indicated by the number of time-steps on the GIPL tab. The second column lists the daily average surface temperature used in the in/bound. txt file. If the SNOW17 checkbox on the Menu tab is selected, then pressing the Import Snow17 button on the Snow17 tab will transfer the temperature and snow depth information from TREECS ${ }^{\mathrm{TM}}$ Snow17 to the second and third columns in the correct units for the in/bound. txt and in/snow . txt files. The daily average snow conductivity must be entered by the user. The snow conductivity on days with no snow should be a value of zero. Snow conductivity will be translated to the in/rsnow. txt file.

Figure 16. Example of bound input tab used by the TREECSTM GIPL preprocessor to create the in/bound. txt, in/snow. txt, and in/rsnow. txt files.

\begin{tabular}{|c|c|c|c|}
\hline $\begin{array}{l}\text { Time } \\
\text { Days }\end{array}$ & $\begin{array}{l}\text { Daily } \\
\text { averaged } \\
\text { surface } \\
\text { temperat } \\
\text { ure } \\
\text { deg-C }\end{array}$ & $\begin{array}{l}\text { Daily } \\
\text { average } \\
\text { snow } \\
\text { depth } \\
\text { m }\end{array}$ & $\begin{array}{l}\text { Daily } \\
\text { average } \\
\text { snow } \\
\text { conductiv } \\
\text { ity } \\
\mathrm{W} / \mathrm{mK}\end{array}$ \\
\hline 1 & -30.6 & $\quad 0.25$ & 0.1 \\
\hline 2 & -35 & 0.25 & 0.1 \\
\hline 3 & -33.9 & 0.25 & 0.1 \\
\hline 4 & -27.2 & 0.25 & 0.1 \\
\hline 5 & -19.5 & 0.25 & 0.1 \\
\hline 6 & -14.2 & 0.25 & 0.1 \\
\hline 7 & -16.1 & 0.25 & 0.1 \\
\hline 8 & -21.4 & 0.25 & 0.1 \\
\hline 9 & -23.9 & 0.25 & 0.1 \\
\hline 10 & -29.5 & 0.25 & 0.1 \\
\hline 11 & -34.7 & 0.25 & 0.1 \\
\hline 12 & -36.7 & 0.25 & 0.1 \\
\hline 13 & -30.3 & 0.25 & 0.1 \\
\hline 14 & -29.5 & 0.25 & 0.1 \\
\hline
\end{tabular}


The INITIAL_CONDITIONS tab (Figure 17) provides an initial temperature profile as a starting point for the numerical solution. The user should provide the depth and temperature of several points. GIPL will interpolate between points and extend the lowest assigned value vertically to the lowest node. Thus, it is recommended that a lower boundary temperature be provided. The output file dump/start. txt can be used to continue a second run with the conditions at the end of a first. The example initial profile is typical for January in central Alaska. This example was created to represent an expected profile for the time of year and a Goldstream Histols example. The temperature profile of the GIPL example problem provided with the code was adjusted to the temperature range expected for the test location outside Fairbanks.

\section{Figure 17. Example of initial input file used by the TREECS ${ }^{T M}$ GIPL preprocessor to create the in/initial. txt file.}

\begin{tabular}{|r|r|r|}
\hline \multirow{2}{*}{$\begin{array}{r}\text { Node } \\
\text { Depth } \\
\text { m }\end{array}$} & \multicolumn{2}{c|}{$\begin{array}{l}\text { Temperature } \\
\text { deg-C }\end{array}$} \\
\hline & -1.5 & -12.6 \\
\hline & 0.01 & -4.612 \\
\hline & 0.02 & -4.6081 \\
\hline & 0.1 & -3.9004 \\
\hline & 0.16 & -3.4188 \\
\hline & 0.24 & -3.0496 \\
\hline & 0.32 & -2.6052 \\
\hline & 0.4 & -2.286 \\
\hline & 0.48 & -1.9465 \\
\hline & 0.56 & -1.5635 \\
\hline & 0.7 & -0.7951 \\
\hline & 0.86 & -0.2021 \\
\hline & 1.05 & -0.2021 \\
\hline & 1.5 & -0.2021 \\
\hline & 2 & -0.2021 \\
\hline & 2.5 & -0.2021 \\
\hline & 3 & -0.2021 \\
\hline & 10 & -0.2021 \\
\hline & 90 & -0.2021 \\
\hline & & \\
\hline
\end{tabular}

\subsection{GIPL model output}

Once the blue tabs have been completed, the user should press the Write GIPL Inputs button on the GIPL tab (Figure 11) to convert the inputs from the processor tabs to text files, then click the Run GIPL button. Excel may flash or appear to be busy for a few seconds to minutes, depending on computer processing speed. After running GIPL, the user can click the Load GIPL output button to bring the output into the GIPL_output tab. This will overwrite any previously loaded output. To save a previous model 
run, copy the GIPL_output tab and give it a new name before clicking Load GIPL output.

GIPL produces three output files, dump/result.txt, dump/mean.txt, and dump/start . txt. The dump/result . txt file (Figure 18) is explained as follows, whereas, the other two files are described in Appendix A. The GIPL_output tab is organized as a matrix with time running vertically in the second column. The boundary condition time series applied to run the model is reported under the blue headers in the third and fourth columns. The output nodes are listed in the green headers of the $7^{\text {th }}$ row. The values down each column under the green headers are the subsurface temperatures calculated for each time step at the node listed in the green header bar.

Figure 18. Example of the GIPL_output tab produced by TREECSTM GIPL running in the preprocessor. This tab presents the data in the dump/result. txt file.

\begin{tabular}{|c|c|c|c|c|c|c|c|c|c|c|c|c|c|c|c|c|}
\hline \multirow[b]{2}{*}{1.000} & \multirow[b]{2}{*}{2557.000} & \multirow[b]{2}{*}{-0.300} & \multirow[b]{2}{*}{0.745} & \multirow{2}{*}{\multicolumn{2}{|c|}{$\begin{array}{cc}-2.133 & -2.131 \\
\text { Node depths, } m \rightarrow \rightarrow\end{array}$}} & \multirow[b]{2}{*}{0.652} & \multirow[b]{2}{*}{0.014} & \multirow[b]{2}{*}{-0.057} & \multicolumn{4}{|c|}{$\begin{array}{l}\text { Average active laver thickness, } m \\
\text { Average active later temp, deg-C }\end{array}$} & 2.325 & \multirow{2}{*}{\multicolumn{2}{|c|}{ O Fully Froze }} & \multirow[b]{2}{*}{1} \\
\hline & & & & & & & & & -0.157 & -0.184 & -0.202 & -0.202 & 0.000 & & & \\
\hline sito & ta & $\begin{array}{r}\text { Upper } \\
\text { boundary }\end{array}$ & Snow & 0 & a not & & 0 & 10 & 16 & 30 & 0 & 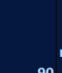 & $\begin{array}{r}\text { Shallowest } \\
\text { unfrozen } \\
\text { node depth, }\end{array}$ & $\begin{array}{r}\text { Next } \\
\text { shallowest } \\
\text { node depth }\end{array}$ & $\begin{array}{r}\text { ALT } \\
\text { Temp, }\end{array}$ & Cron \\
\hline $\begin{array}{r}\text { Site } \\
1.000\end{array}$ & $\begin{array}{l}\text { Jday } \\
1.000\end{array}$ & $\begin{array}{l}\text { temperature, } \mathbf{C} \\
-30.600\end{array}$ & $\begin{aligned} \text { depth, } m & =254 \\
0.254 & \end{aligned}$ & -4.665 & -4.660 & -0.202 & $\begin{array}{r}-0.202 \\
-1\end{array}$ & -0.202 & -0.2021 & -0.2021 & -0.2021 & $\begin{array}{r}-0.2021 \\
-\end{array}$ & $\begin{array}{r}\mathrm{m} \\
0.000\end{array}$ & & $\begin{array}{l}\text { deg C } \\
\text { Fully Froze }\end{array}$ & 1 \\
\hline 1.000 & 2.000 & -35.000 & 0.254 & -3.151 & -3.149 & -0.202 & -0.202 & -0.202 & -0.2021 & -0.2021 & -0.2021 & -0.2021 & 0.000 & & Fully Froze & 1 \\
\hline 1.000 & 3.000 & -33.900 & 0.254 & -3.184 & -3.181 & -0.202 & -0.202 & -0.202 & -0.2021 & -0.2021 & -0.2021 & -0.2021 & 0.000 & & Fully Froze & 1 \\
\hline 1.000 & 4.000 & -27.200 & 0.254 & -3.339 & -3.336 & -0.202 & -0.202 & -0.202 & -0.2021 & -0.2021 & -0.2021 & -0.2021 & 0.000 & & Fully Froze & 1 \\
\hline 1.000 & 5.000 & -19.500 & 0.254 & -3.391 & -3.388 & -0.202 & -0.202 & -0.202 & -0.2021 & -0.2021 & -0.2021 & -0.2021 & 0.000 & & Fully Froze & 1 \\
\hline 1.000 & 6.000 & -14.200 & 0.254 & -3.311 & -3.309 & -0.202 & -0.202 & -0.202 & -0.2021 & -0.2021 & -0.2021 & -0.2021 & 0.000 & & Fully Froze & 1 \\
\hline 1.000 & 7.000 & -16.100 & 0.254 & -3.170 & -3.168 & -0.202 & -0.202 & -0.202 & -0.2021 & -0.2021 & -0.2021 & -0.2021 & 0.000 & & Fully Froze & 1 \\
\hline 1.000 & 8.000 & -21.400 & 0.254 & -3.090 & -3.089 & -0.202 & -0.202 & -0.202 & -0.2021 & -0.2021 & -0.2021 & -0.2021 & 0.000 & & Fully Froze & 1 \\
\hline 1.000 & 9.000 & -23.900 & 0.254 & -3.128 & -3.126 & -0.202 & -0.202 & -0.202 & -0.2021 & -0.2021 & -0.2021 & -0.2021 & 0.000 & & Fully Froze & 1 \\
\hline
\end{tabular}

To the right of the output, there are four columns automatically calculated based on the GIPL model output with summary calculations above. The first column to the right of the output is the shallowest unfrozen node depth (m). This is the calculated active layer thickness as all the nodes above it are unfrozen at that time step. If the surface is frozen, the value is zero. The next column is the next shallowest node depth (m). This node is the depth of the highest frozen node in the profile. The third column to the right of the GIPL output is the daily thawed active layer temperature (ALT) $\left({ }^{\circ} \mathrm{C}\right)$ of the soil, which is computed from the depth-weighted average of the temperature computed by the GIPL model for all the nodes above and including the shallowest unfrozen node. The temperature of each node from the shallowest unfrozen node depth and shallower is multiplied by the depth of its node. The products are summed and divided by the shallowest unfrozen node depth to determine the ALT for each time step (row). If the surface node is frozen (depth of o $\mathrm{m}$ ) then it is indicated with a "Fully Frozen" label in the ALT Temp column. This does not mean that 
every node in the profile is frozen, but rather that there is no thawed region that water can access from the surface. The final column to the right is the thaw flag used by the soil fate model (chapter 7).

Two summary values, the average annual active layer thickness (AAALT) $(\mathrm{m})$ and average annual active layer temperature $\left({ }^{\circ} \mathrm{C}\right)$, are also reported at the upper right corner above the output matrix. The average annual active layer thickness is the average of the annual active layer thickness (AALT) (m) for all the years of a given model simulation. This value is used in the soil fate model (Chapter 7). The average active layer temperature is simply an average of the ALT over the model run.

The AALT is the maximum vertically mixed, thawed soil layer thickness for each year. The thawed thickness is defined as the depth below ground surface where the temperature changes from above zero to below zero ${ }^{\circ} \mathrm{C}$, and is equivalent to the shallowest unfrozen node depth. The thawed thickness generally increases through the late spring and summer to reach a maximum at the AALT, and then rapidly decreases to zero when the surface begins freezing in the fall. The AALT is determined by comparing the depth of each daily shallowest unfrozen node depth to the day before. If it is deeper, the AALT is updated to the deeper value. When the calculation loop reaches the next January $1^{\text {st }}$, the current (maximum) value of the AALT is recorded under the green bar above and to the right of the GIPL output data columns as the annual active layer thickness.

The minimum annual active layer thickness (AALTmin) is the shallowest AALT over the model simulation duration. AALTmin is used to determine the thaw flag in the final column. For example, in part a, Figure 19, AALTmin is $0.42 \mathrm{~m}$. For each day in the simulation, the thaw flag is 1 if the shallowest frozen node depth is less than the minimum annual active layer thickness, and $o$ if it is at least as deep as AALTmin. This flag indicates to the Soil Fate Model when the active layer has reached the minimum depth to be considered fully thawed for the year.

Table 6 summarizes each column. The GIPL post-processor automatically calculates the active layer depths, temperatures, and the summary values when the GIPL model output is loaded into the GIPL-output sheet. The SoillayerThickness. txt file, needed by the Soil Fate model, is also created automatically. 
Figure 19. Example plots from the GIPL_output tab in the TREECSTM GIPL preprocessor: Part a) shallowest unfrozen node depth time series, Part b) output time series, Part c) input vs. output, and Part d) depth profiles.

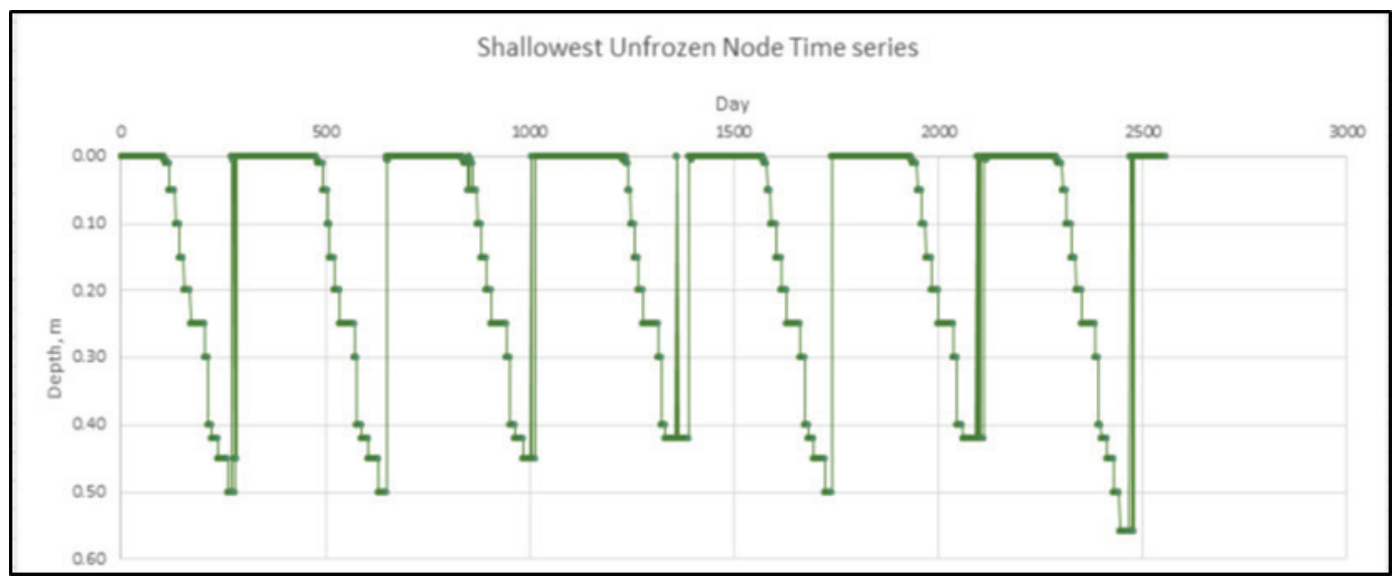

Part a

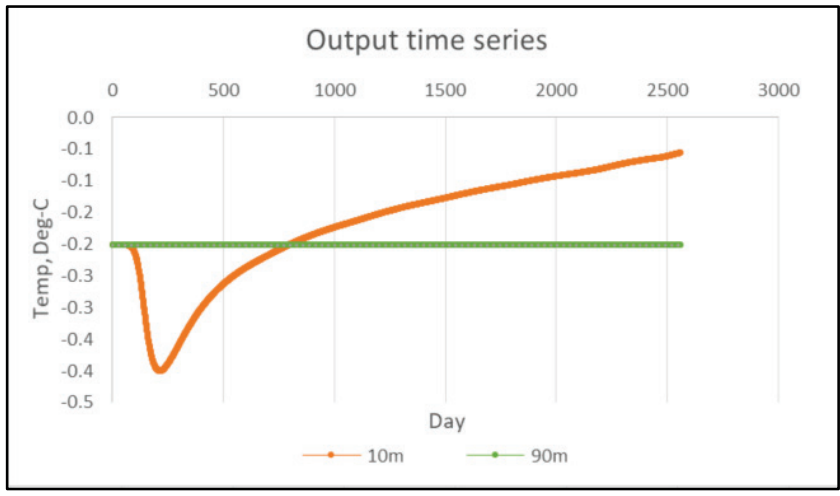

Part b

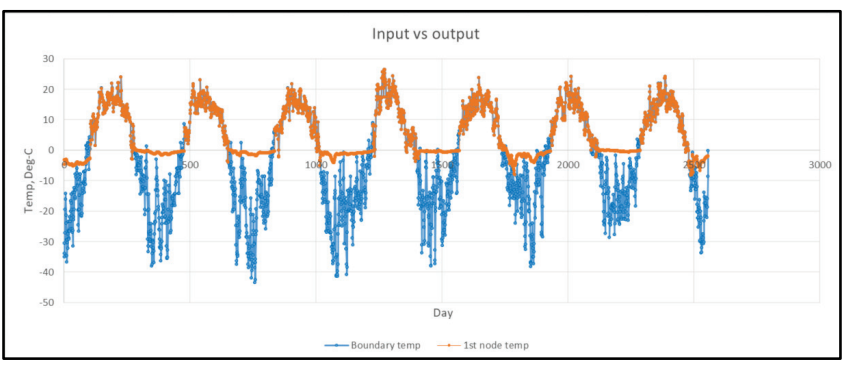

Part c 


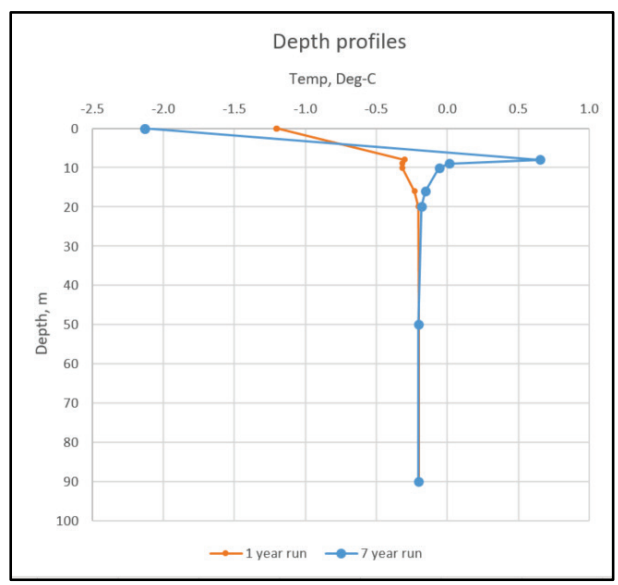

Part d

Table 6. Description of TREECS ${ }^{\mathrm{TM}}$ GIPL output parameters.

\begin{tabular}{|c|c|c|}
\hline Output File & Parameter & Expected range \\
\hline dump/result.txt & Site - The number of the site being identified. & 1 \\
\hline dump/result.txt & Jday - the day of model output. & - \\
\hline dump/result.txt & $\begin{array}{l}\text { Upper boundary temperature - The boundary } \\
\text { condition imposed at the upper boundary from the } \\
\text { in/bound.txt file }\left({ }^{\circ} \mathrm{C}\right) \text {. This is useful for identifying } \\
\text { seasonal patterns. }\end{array}$ & $-40-120$ \\
\hline dump/result.txt & $\begin{array}{l}\text { Snow depth - The snow depth from the in/snow.txt } \\
\text { file }(m) \text {. }\end{array}$ & $0-2$ \\
\hline \multirow[t]{5}{*}{ dump/result.txt } & $\begin{array}{l}\text { Output - Column E will begin the output of the } \\
\text { modeled temperatures }\left({ }^{\circ} \mathrm{C}\right) \text { for each node specified } \\
\text { in the in/grids.txt file. }\end{array}$ & $-40-65$ \\
\hline & $\begin{array}{l}\text { Shallowest unfrozen node depth - The active layer } \\
\text { thickness }(\mathrm{m}) \text {. When the output is loaded the post- } \\
\text { processor automatically scans each set of daily } \\
\text { output temperatures and determines which node is } \\
\text { the shallowest node that has not frozen on that day. } \\
\text { The next node beneath this one will be the } \\
\text { shallowest frozen node. }\end{array}$ & $0-16$ \\
\hline & $\begin{array}{l}\text { Next shallowest node depth (frozen) - The depth of } \\
\text { the node closest to the surface that is frozen }(\mathrm{m}) \text {. } \\
\text { Nodes beneath this node may be frozen or thawed. }\end{array}$ & $0-16$ \\
\hline & $\begin{array}{l}\text { ALT Temp - Active Layer Thickness Temperature } \\
\left({ }^{\circ} \mathrm{C}\right) \text {. On any given day (row) if the surface node is } \\
\text { frozen this cell will read "Fully Frozen". Otherwise } \\
\text { the depth weighted average temperature for the } \\
\text { portion of the subsurface from the shallowest } \\
\text { unfrozen node to the surface is reported. }\end{array}$ & $\begin{array}{l}\text { Fully Frozen- } \\
16\end{array}$ \\
\hline & 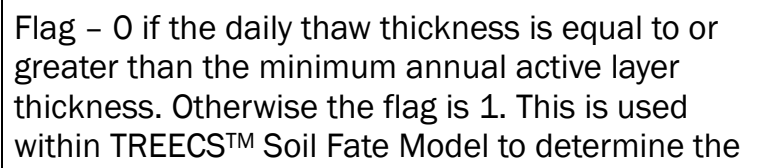 & 0 or 1 \\
\hline
\end{tabular}




\begin{tabular}{|l|l|c|}
\hline Output File & \multicolumn{1}{|c|}{ Parameter } & Expected range \\
\hline & $\begin{array}{l}\text { routing of water between groundwater and interflow } \\
\text { versus runoff. }\end{array}$ & $0-16$ \\
\hline & $\begin{array}{l}\text { Average active layer thickness - (AAALT) The } \\
\text { average of the annual active layer thicknesses for } \\
\text { each year of the model duration }(\mathrm{m}) .\end{array}$ & $0-5$ \\
\hline & $\begin{array}{l}\text { Average active layer temperature-The average } \\
\text { temperature of the thawed active layer over the } \\
\text { model duration }\left({ }^{\circ} \mathrm{C}\right) .\end{array}$ \\
\hline
\end{tabular}

Since the processor is an Excel workbook, the user can add plots or additional calculations outside of the columns used by the processor. The active layer depth time series from the shallowest unfrozen node column is plotted to the right of the output matrix (part a, Figure 19). Output time series for particular depths are plotted to the far right (part b, Figure 19). Each line on this plot represents a column from the output matrix. The input boundary temperature time series is also plotted for comparison with the surface node and a deeper node (part c, Figure 19). And finally, the temperature vs. depth is plotted as a time series on the lower right (part d, Figure 19). Each line on this plot is a row representing the model output at a particular time step. If fewer than 56 output nodes are selected (the default example), the user may need to adapt the graphs to display them properly. Click on the graphed data to highlight the selected data and then drag the selection box to a new column or row to observe how the soil temperature changes in space and time.

\subsection{TREECS ${ }^{\mathrm{TM}}$ GIPL verification and validation}

The GIPL model, as implemented in the TREECSTM, processor was verified by running with a default set of inputs provided with the model download from CSDMS (Model: GIPL, 2016), and comparing the output to an output case also provided with the model download. The model was provided as uncompiled source code, therefore, this verification ensured that the stylistic changes made to compile with Intel ${ }^{\circledR}$ Fortran Compiler for applications version 10.0.025 did not affect the output. There was perfect agreement with the supplied default case output. The preprocessor was also used to construct input files to verify the correctness of the pre-processor.

The implementation of the GIPL model within the TREECS ${ }^{\mathrm{TM}}$ pre and postprocessor was validated by comparison to observed site conditions in the Fairbanks area. The examples in section 4.1 are from the validation case. 
The parameters shown in Figure 11 through Figure 17 were utilized to describe typical conditions for areas adjacent to the Fairbanks International Airport. Figure 11 shows the GIPL runtime selections made for the validation test. The model was run for seven years (2557 daily time steps). One organic layer and two mineral layers were input based on the description of the Goldstream Histels complex, o to 3 percent slopes. The soil profile (Figure 20) is described as 0-9 inches of dark brown mucky peat, high permeability; 12-20 inches of very dark grayish brown mucky silt loam, moderately high permeability, and 20-72 inches of dark brown permanently frozen material, impermeable (Mulligan, 2004). The expected average annual active layer thickness, based on the depth to permafrost described by the soil survey, was 0.26-0.61 meters (14-24 inches).

Figure 20. Goldstream Histels complex used in validation of TREECSTM GIPL implementation.

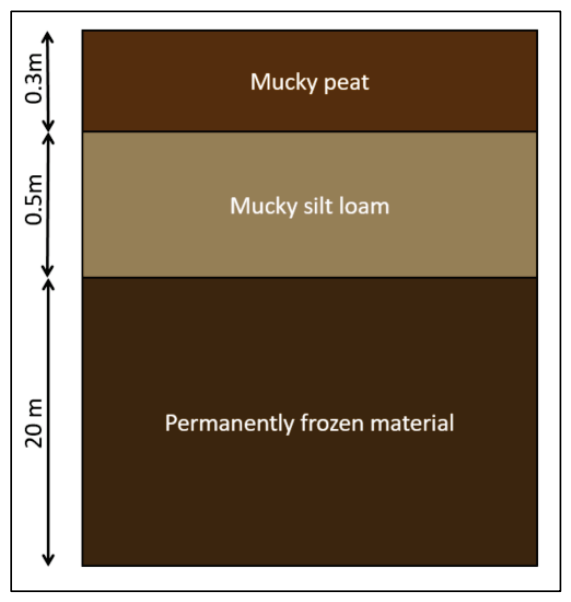

Figure 12 describes the inputs to the SITES tab used in the validation case. The lower temperature boundary was set to $-0.2021{ }^{\circ} \mathrm{C}$ based on the expectation that the lower boundary temperature should be below freezing (Ping 1987). Figure 13 shows the GRIDS tab detailing the physical domain of the validation case. The validation case utilized 176 nodes which extended from 1.5 meters above ground to 90 meters below ground (not shown). The deep lower boundary for the domain reduces the sensitivity of the solution to the lower boundary temperature selected on the SITES tab.

The model was calibrated by adjusting the unfrozen water curve coefficients, heat capacity, and heat conductivity values within reasonable ranges for the layer materials until the AAALT was in the expected range. During calibration it was noted that the temperature profile is more 
sensitive to these parameters than the AAALT. TREECSTM does not use the soil temperatures produced by the GIPL model, only the AAALT, so no attempt was made to fit measured borehole temperatures. The AAALT is very sensitive to the choice of layers and boundary conditions. It is highly recommended that an organic layer be employed to capture the unique thermal properties of this layer. In the validation case, the organic layer (Figure 15) was set to 0.3 meters thickness and a volumetric water content of 0.85 to reflect the high porosity and saturation of peat mucks. The coefficients of the unfrozen water curve ( 0.07 for $a$, and -0.019 for $b$ ) are within the ranges suggested by Nicolsky et al. (2007) and Tice et al. (1989). The volumetric heat capacity and heat conductivity values selected for frozen and thawed peat were based on Farouki (1981) as well as Technical Manual TM 5-852-1/AFR 88-19 (Joint Departments of the Army and Air Force 1987). Two mineral layers were selected, $0.5 \mathrm{~m}$ thick and 20 $\mathrm{m}$ thick (Figure 14). The volumetric water contents were selected to increase with depth to the saturation level of 0.485 based on silt (Clapp and Hornberger 1978). The remaining parameters were based on silty loam or silty clay materials from the same references as the organic layers.

Boundary condition inputs for the first few time steps are shown in Figure 16. As described in section 3.5.1, meteorological data for Fairbanks International Airport from 2010-2016 was used as input to TREECSTM SNOW17 and GIPL. This data was entered into the Met inputs tab and also used for the daily averaged surface temperature column on the BOUNDARY_CONDITIONS tab. The daily average snow depth was calculated from SNOW17 using the parameters described in section 3.5.3. The daily average snow conductivity was set to $0.1 \mathrm{~W} / \mathrm{mK}$ when snow was present, and o when it was not. This may overestimate snow conductivity early in the cold season and underestimate it as snow melts (Sturm et al. 1995), but when an organic layer is employed, the model is relatively insensitive to this parameter and a seasonal average is sufficient.

The INITIAL_CONDITION profile (Figure 17) was selected to model a wintertime condition near Fairbanks with a permafrost temperature approximately equal to the lower boundary condition temperature of $0.2021^{\circ} \mathrm{C}$, and an upper boundary temperature near the average January surface temperature (Ping 1987).

Using the inputs described above, the model produces an average AAALT of 0.42 meters. In addition, the AALTmin over the seven-year period of the 
model is 0.3 meters, and the soil profile is thawed to this depth for an average of 67 days each year. The deepest active layer thickness occurs in the first and final years and reaches 0.5 meters depth. The model compares favorably with the soil survey description of the Goldstream Histels complex having an active layer thickness of 0.26-0.61 m (Mulligan 2004). 


\section{Surface Soil Hydrology}

The TREECS ${ }^{\mathrm{TM}}$ surface soil hydrology model that resides within Tools/HGCT/Hydrology was deemed to be appropriate for determining surface soil hydrologic variables after revising the model for Arctic conditions. The revised hydrology model for Arctic conditions is described below.

\subsection{Description of Arctic surface soil hydrology model}

The Arctic surface soil hydrology model is based on the previous nonarctic version described by Johnson and Dortch (2014), and as later modified for an improved soil water balance (Dortch 2014). The soil water balance approach was refined yet again during the development of the Arctic version, thus, the refined approach was implemented in both the non-Arctic and Arctic versions and is included in the description below.

The model uses a daily time step with daily time-varying inputs. A schematic of the water pathways at the soil column surface is shown in Figure 21. Precipitation can fall as rain or snowfall based on daily mean air temperature being greater than, or less than, zero degrees Celsius $\left({ }^{\circ} \mathrm{C}\right)$.

Figure 21. Schematic of water pathways at the top of the soil column.

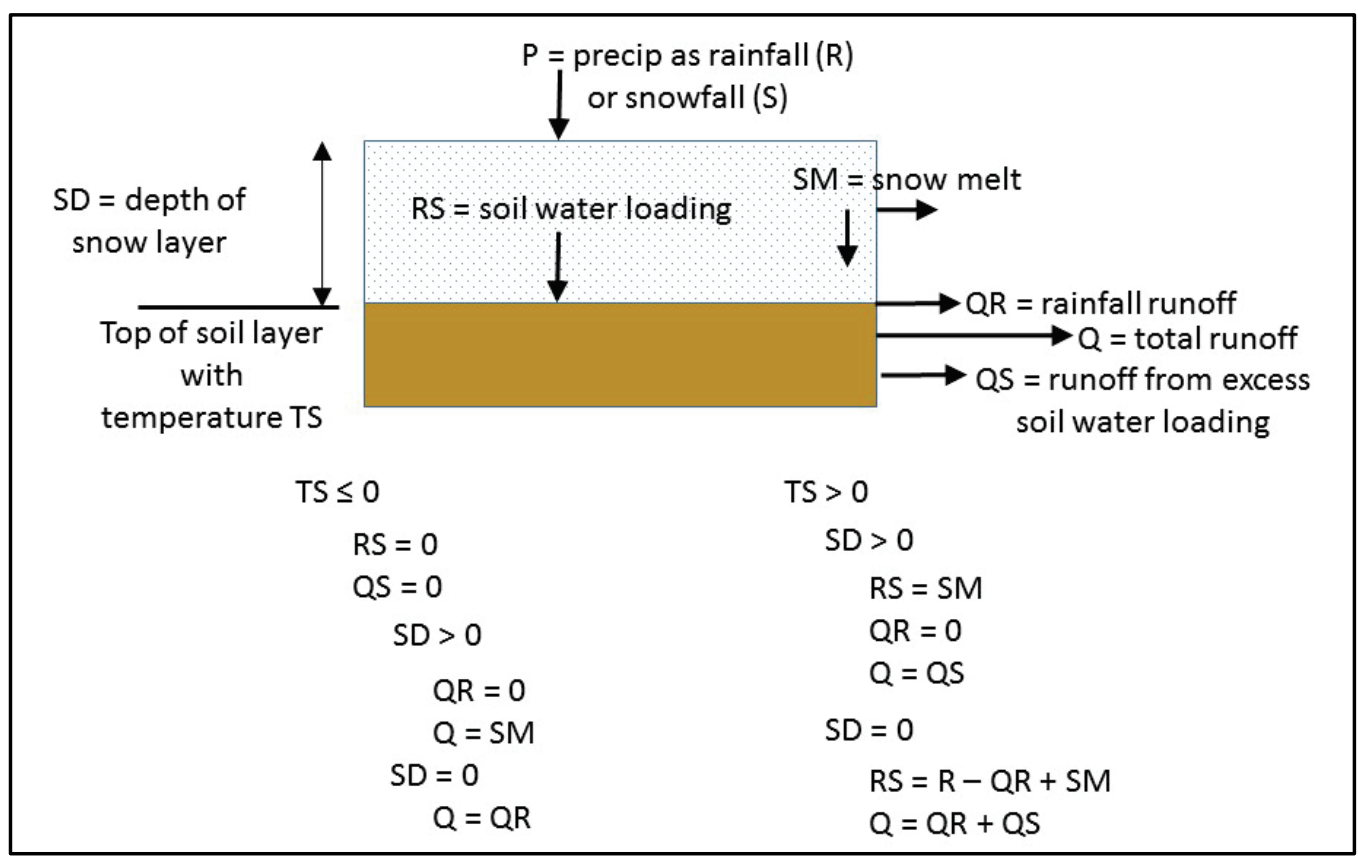


All variables shown in Figure 21 are daily depths in inches in the model. Daily snow melt depth $(S M)$ and snow depth $(S D)$ are provided as input from the TREECS ${ }^{\mathrm{TM}}$ Snow17 model, whereas for the non-Arctic version, $S M$ and $S D$ are computed in the model (Johnson and Dortch 2014).

Similar to the non-Arctic hydrology model, TREECS ${ }^{\mathrm{TM}}$ Snow17 requires daily mean air temperatures and daily precipitation as input. Daily precipitation depth $(P)$ is either rainfall $(R)$ or snowfall $(S)$ in the hydrology model depending if the daily average air temperature is greater than, or less than, zero ${ }^{\circ} \mathrm{C}$. Daily rainfall is used in the model to compute rainfall runoff and water loading into the soil column as explained below. The other variables shown in Figure 21 depend on the temperature of the top of the soil column (TS) and the snow depth. As explained later, the thawed soil layer depth (i.e., thawed soil layer thickness) is actually used in the Arctic version rather than $T S$ for establishing these other variables since $T S<O$ represents frozen soil with zero (or very thin) thawed soil layer depth. However, for now, the value of $T S$ (i.e., being < or $>$ zero) is used for explanation. As explained previously, soil temperatures are computed by the GIPL model, and that information is used by a GIPL model post-processor to determine the thawed soil layer depth.

If the soil is frozen ( $T S \leq O$ ), the water loading depth to soil $R S$ and the runoff from excess soil water loading depth $Q S$ are zero. If $S D>$ o for frozen soil, rainfall runoff $Q R$ is zero, and total runoff $Q=S M$ should air temperature permit snow melt quantities within Snow17. Any rainfall that occurs when $S D>O$ is ignored and not added to the snow pack in the Arctic version since such precipitation is already taken into account by Snow17 in snow depth accumulation. If $S D=0$, and the ground is frozen, any rainfall must runoff, and $Q=Q R+S M$, where $S M$ is expected to be zero (usually for this situation).

If the soil is not frozen ( $T S>O$ ) and $S D>O$, it is assumed for the Arctic version that the snow pack intercepts any rainfall, so there cannot be any rainfall runoff, and all snow melt infiltrates before running off; thus, $Q R=$ $o, R S=S M$, and $Q=Q S$. It is most likely rare that there will be snow accumulation and melt when the soil is not frozen, with the exception of those days when it has been warm, but suddenly turns cold enough to snow and possibly accumulate and then melt. If $T S>O$ and $S D=O$, soil water loading $R S$ can be due to rainfall that did not runoff and snowfall for the day that melts, or $R S=R-Q R+S M$; most likely $S M$ will be zero for this condition. Rainfall runoff depth for the day $(Q R)$ is subtracted from rainfall 
for computing $R S$. Total runoff is $Q=Q R+Q S$. The variable $Q S$ was added to allow runoff for excess water soaking into the ground via $R S$. However, testing has shown that $Q S$ is zero for all conditions tested thus far.

For the non-Arctic version, the ground is assumed to be frozen when $S D>$ $O$, and $R S, Q S$, and $Q R$ are zero, and $Q=S M$. Any rainfall that occurs during snow cover is added to the snow pack. If $S D=O$, the ground is assumed to be thawed, and as with the Arctic version $R S=R-Q R+S M$, and $Q=Q R+Q S$. Thus, any snowfall that occurs when $S D=O$ must melt and is assumed to soak into the soil (i.e., add to $R S$ ) rather than runoff. The variable $Q S$ was also added to the non-arctic version to allow runoff for excess water soaking into the ground via $R S$.

Daily runoff associated with rainfall $(Q R)$ is computed in both versions of the hydrology model using a modified Soil Conservation Service (SCS) curve number method as described by Johnson and Dortch (2014). When $P$ is rainfall and $S D=0, Q R$ is computed; otherwise, $Q R$ is zero. The only variable that has not been resolved in the above water pathways description is $Q S$, which is explained in the soil water balance discussions below.

A schematic is shown in Figure 22 of Arctic soil with the various hydrologic processes included in the Arctic hydrology model's soil water balance for the thawed soil layer. The non-Arctic soil layer processes looks the same as Figure 22, except that there is no annual active layer of soil for freeze/thaw, and the soil layer thickness $H$ is constant.

Soil daily water balance processes for the thawed soil layer of thickness $H$ include the following:

- Daily water loading depth to the soil surface, $R S$

- Evapotranspiration depth, ET, resulting from a water balance and potential evapotranspiration, $P E T$

- Runoff depth due to excess soil water loading, $Q S$

- Total runoff depth, $Q$, which can include rainfall runoff $(Q R)$, snow melt $(S M)$, and $Q S$

- Net infiltration depth passed to the bottom of the soil layer, $I$, resulting from a water balance

- Soil water storage (i.e., soil volumetric water content (fraction)), $W C$, resulting from a water balance

- Soil interflow depth, $I F$ 
- Percolation depth to vadose zone, $q$, for fully thawed active soil layer.

Figure 22. Schematic of Arctic soil hydrologic processes and water balance.

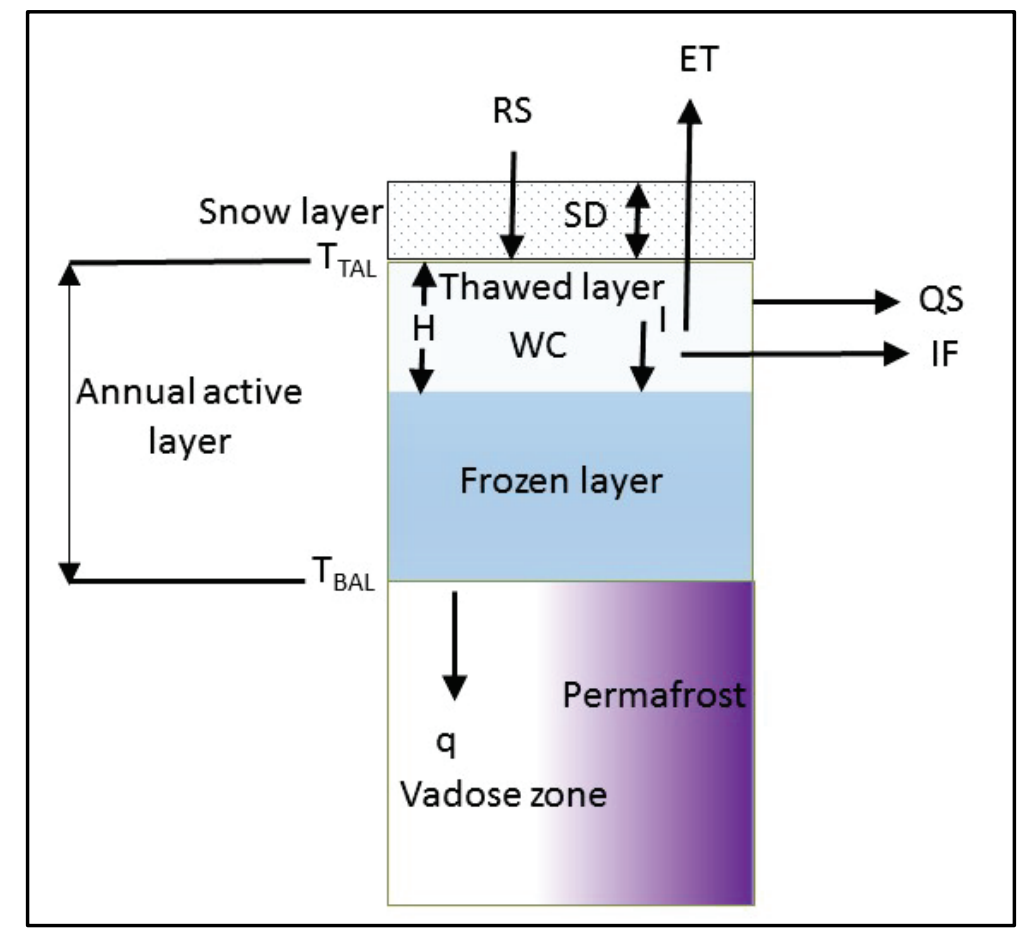

There is seasonal freezing and thawing of the active soil layer, which can be underlain by various amounts of permafrost (e.g., continuous, discontinuous, sporadic, isolated, and absent). The amount of permafrost is specified by the user as a fraction, $f_{P F}$, of the area of interest (AOI) surface area as described in section 7.2. Permafrost is assumed to be impermeable.

The determination of $I F$ and $q$ are not handled in the soil hydrology model, rather they are determined by the soil fate model post-processor with hydrology model output and information submitted via the soil fate model UI as explained in Section 7.2. The net infiltration $I$, which is computed by the soil hydrology model, is used in determining $I F$ and $q$ (i.e., $I=I F+q$ ).

Monthly PET is computed using the Thornthwaite method based on mean monthly air temperature as described by Johnson and Dortch (2014). This PET method was extended in both versions of the hydrology model from 60 degrees north and 50 degrees south latitudes to 80 degrees north and south latitudes to be more inclusive of Arctic-like regions. This extension was performed by computing the $\mathrm{K}$ factors in the method for latitudes that are further north and south. The $\mathrm{K}$ factor is a monthly adjustment for the 
average number of daylight hours in the month computed from $K=d / 30 x$ $N H / 12$, where $d$ is the number of days in the month, and $N H$ is the average number of daylight hours in the month. The number of daylight hours (or day length) was computed using the Brock (1981) model, which uses the day of the year from January 1 to compute the declination of the sun, and the latitude is used with the declination to compute the solar hour angle for sun rise/sunset, which is used to compute NH. Forsythe et al. (1995) compares the accuracy of four models for computing day length. The day of the year on the middle of each month was used to compute the monthly average value of $\mathrm{NH}$ used for computing $K$, which is used for computing monthly PET. Daily values of PET used in the hydrology model are the monthly value divided by the number of days in the month.

During freeze/thaw, a portion of the annual active layer can be thawed, and a portion can be frozen. The thawed portion has a thickness $H$ that varies daily and is provided by the GIPL model post-processor that uses soil temperatures computed by the GIPL model (Chapter 4). The soil water balance is conducted for the thawed layer thickness.

The revised non-Arctic and Arctic versions of the hydrology model use the same methods to solve for the daily water balance with the exception of constant $H$, and assumption of frozen soil when $S D>O$ in the non-Arctic version. Daily values of $I, E T, W C$, and $Q S$ are solved from a water balance of $W C$ for the surface soil layer of thickness $H$, where the source of water is $R S$, which is determined based on the rationale shown in Figure 21 and discussed above, and the sinks are $I, E T$, and $Q S$. When the temperature at the top of active layer ( $\left.T_{T A L}\right)$ is frozen (i.e., $T_{T A L} \leq \mathrm{O}$ ), no water can enter the soil, and $R S=O$ and no water balance is computed. The Arctic hydrology model actually uses the value of $H$ rather than $T_{T A L}$. If $H<H_{\min }$, then the top of the active soil layer is assumed to be frozen $\left(T_{T A L} \leq \mathrm{O}\right)$, where $H_{\min }$ is a minimum thawed layer thickness representing $T_{T A L} \leq \mathrm{O}$ (i.e., frozen surface soil) and is set within the code to $1.0 \mathrm{~cm}$. During thawing, or thawed conditions ( $T_{T A L}>\mathrm{o}$ or $H>H_{\min }$ ), water can enter the soil, and a water balance is computed. The inflowing water depth (i.e., soil loading) for the day $(R S)$ is a result of rainfall that did not run off and/or snow melt, as explained previously. All snow melt is assumed to enter the unfrozen soil layer when $H>H_{\min }$. When the top of the soil layer is frozen (i.e., $H<H_{\min }$ ), all snow melt goes to runoff as shown in Figure 21. 
When the temperature at the bottom of the active layer, $T_{B A L}$, is equal to, or greater than zero, the active layer can be considered fully thawed. The postprocessor program for the GIPL model uses this information for establishing the AALT, the AAALT, and the AALTmin as explained in Chapter 4. The daily thaw depth and the AALTmin are used to develop the thaw flag used by the soil fate model postprocessor as discussed in Section 7.2. The thaw flag is not needed, nor is used by the soil hydrology model, but it is used by the soil fate model postprocessor (as discussed in section 7.2).

An implicit solution procedure is used for the water balance. An implicit solution means that all unknowns and forcing variables are taken at the present time step, and an iterative solution is required to reach a convergence criteria. The daily net infiltration depth for any given day $t$ can be computed from the excess water content above the field capacity as shown in Equation 5-1 (ensuring positive values only).

$$
I_{t}=\operatorname{Max}\left[\left(\frac{W C_{t-1}+W C_{t}}{2}-\theta_{F C}\right) H, 0.0\right]
$$

Where, $W C_{t-1}$ and $W C_{t}$ are the volumetric soil water contents (fraction) for the previous day and the end of the present day, respectively, $\theta_{F C}$ is the soil field capacity (fraction), and $H$ is the thawed soil layer thickness as explained above. The field capacity is a constant input that depends on soil texture. The initial value at time zero for $W C$ is assumed to be equal to the field capacity.

Similarly, the $E T$ for any given day $t$ is computed from a soil water balance that ensures that ET does not exceed PET for the day (Equation 5-2).

$$
E T_{t}=\operatorname{Min}\left[\left(W C_{t-1}-\theta_{r}\right) H+R S_{t}-Q S_{t}-I_{t}, P E T_{t}\right]
$$

All variables in Equation 5-2 have been previously defined with the exception of the soil residual water content (fraction), $\theta_{r}$, which is a constant input that depends on soil texture.

The water content for the day is computed from the soil water balance that ensures that $W C$ for the day is not less than $\theta_{r}$ (Equation 5-3). 


$$
W C_{t}=\operatorname{Max}\left(W C_{t-1}+\frac{R S_{t}-Q S_{t}-E T_{t}-I_{t}}{H}, \theta_{r}\right)
$$

The water runoff depth for the day due to excess soil water content above saturation and that ensures positive values is shown in Equation 5-4.

$$
Q S_{t}=\operatorname{Max}\left[\left(W C_{t}-\theta_{s}\right) H, 0.0\right]
$$

Where, $\theta_{s}$ is the soil water saturation content, or the soil porosity, which is a constant input that depends on soil texture. $Q S_{t}$ is included in the total runoff depth for the day $\left(Q_{t}\right)$.

Equations 5-1-5-4 are four equations with four unknowns that are solved iteratively with convergence criteria. At time zero, the water content is assumed to be at field capacity. An initial value of $I_{t}$ is required for each time-step, and this value is obtained using the previously computed water content, or

$$
I_{t}=\operatorname{Max}\left[\left(W C_{t-1}-\theta_{F C}\right) H, 0.0\right]
$$

Equations 5-2-5-4 are solved using the initial value of $I_{t}$, and then $I_{t}$ is updated with Equation 5-1. This solution cycle (i.e., Equations 5-1-5-4) then continues until convergence criteria for $W C_{t}$ has been reached, which is when the absolute difference in the water content for the present and previous iteration is less than or equal to 0.0001 times the present iteration value.

Testing revealed that for small soil layer thickness, the iterative solution would not converge. Thus, a "sneak-up" routine was added to help with convergence where a ten-step loop is used for each day of the water balance solution. This ten-step loop required imposing a tenth of the daily water, forcing load $R S_{t}$ for each step in the ten-step loop, and iteratively solving for $W C$ and a fraction (i.e., 1/10) of the water flow responses ET, $I$, and $Q S$ for each step in the ten-step loop, and then accumulating the fractional water flow responses over the ten-step loop to produce the daily flow responses. This procedure allowed soil layer thickness as small as one inch.

The above water balance solution procedure was implemented in the revised non-Arctic hydrology model. This procedure is a refinement of the 
procedure described by Dortch (2014). The explicit vs. implicit solution option was removed from the revised non-Arctic version and is not in the Arctic version either; thus, only the implicit solution procedure described above is used now.

If $H>H_{\max }$, where $H_{\max }$ is the maximum layer thickness for soil water balance, $H$ is set equal to $H_{\max }$. The value for $H_{\max }$ is input by the user. An input default value of $40 \mathrm{~cm}$ ( 15.748 inches) is recommended. This thickness is also the default soil layer thickness recommended for the TREECS $^{\mathrm{TM}}$ Tier II soil contaminant fate model (see section 7.1). The value for $H$ affects the soil water balance, particularly $I$ and $E T$. As $H$ decreases, $I$ increases and $E T$ decreases, and the reverse occurs as $H$ increases. Ideally, $H_{\max }$ should be equivalent to a soil layer depth that accounts for PET, which can be affected by the plant rooting depth. Grasses are typically found on firing and training ranges. Most of the root biomass of grasses is less than $50 \mathrm{~cm}$ below ground level (Mueller et al. 2013; Nippert et al. 2012). Thus, $H_{\max }$ of $40 \mathrm{~cm}$ for computing the soil water balance is considered reasonable.

\subsection{Implementation of the Arctic surface soil hydrology model}

A copy of the TREECS ${ }^{\mathrm{TM}}$ HGCT revised hydrology model code (written in C language) was used to create the Arctic hydrology model code as described above. The compiled Arctic hydrology model code is a new and separate program executed within the HGCT whenever the Arctic Option is selected within the HGCT Hydrology screen. The Arctic hydrology model code does not include the user-selected input option for average annual vs. daily hydrology output. Rather, the code is hardwired for daily output, and the option was removed from the input stream as well as from the model UI. Additionally, the solution option (explicit vs. implicit) for the soil water balance was removed from the input stream and the UI (same as for the revised non-Arctic version), and only the implicit solution is allowed and used.

Other coding changes made when developing the Arctic hydrology model include the following:

- extended the PET calculation for Arctic latitudes as described in Section 5.1 (same as for the revised non-Arctic version) 
- changed soil layer thickness for water balance from a fixed constant value to daily varying values that are read from an input file produced by the GIPL model post-processor

- revised the surface soil water pathways and soil water balance as described in Section 5.1

- included checks and conditions on minimum and maximum soil layer thicknesses

- removed snow accumulation, evaporation, and melt routines and related output and replaced with input of daily snow depth and snow melt from a single, new input file produced by the TREECS ${ }^{\mathrm{TM}}$ Snow17 model

- added new inputs and removed old inputs as affected by the revised soil water balance and other changes to support the Arctic hydrology model

- modified output of hourly rainfall for use by the soil fate model such that rainfall used by that model is zero whenever there is snow cover or fully frozen soil

The Arctic hydrology model UI also required modifications. The hydrology model UI resides within the HGCT under the Hydrology tab. The changes necessary for the Arctic hydrology model UI are discussed in Chapter 6.

\subsection{Water balance testing}

Tests were performed to assess the accuracy of the water balance solution for both the non-Arctic and Arctic versions of the hydrology model to ensure that the models were maintaining a reasonably accurate accounting of total water within, entering, and leaving the soil layer. The same meteorological data of 2010-2016 from Fairbanks International Airport used for testing Snow17 was used to test the hydrology models. Both versions of the hydrology model were executed and their outputs were analyzed.

Daily output of precipitation, runoff, $E T$, and infiltration depths were summed over the seven years. The total water in was compared with the total water out. Total water in is the sum of the depths for precipitation over the seven years, initial soil water, and initial SWE. The initial soil water depth is the product of the initial soil water content (WC) and the soil layer thickness $(H)$. Total water out is the sum of the depths for the seven years of runoff $(E T)$, and infiltration, plus final soil water and final SWE. For the non-Arctic version simulation, the depths of total water in 
and out were 93.33 and 92.65 inches, respectively, which is an error of $0.72 \%$. For the Arctic version simulation, the depths of total water in and out were 95.33 and 96.09 inches, respectively, which is an error of $0.80 \%$. This overall water balance error ranging from 0.72 to $0.8 \%$ is considered reasonable given that iterative solutions with a set tolerance are being performed each day.

The simulation for the Arctic version was started with 2.0 inches of snow cover (SWE), whereas, the non-Arctic version simulation was started with zero snow cover. The initial SWE is the reason why the total water in for the two simulations are different by 2 inches. The total water out for the two simulations differ by more than 2 inches (i.e., net 1.44 inches different) due to the differences in the solutions for runoff, $E T$, and infiltration, since final $W C$ and $S D$ were about the same for the non-Arctic and Arctic simulations. The Arctic version simulation was conducted with a constant, unfrozen soil layer thickness of $40 \mathrm{~cm}$ for the entire seven years, whereas the soil layer for the non-Arctic version simulation was frozen whenever there was snow cover predicted. The constant unfrozen layer thickness for the Arctic version simulation is not realistic, rather it was an easy setup while awaiting more realistic layer thicknesses from applying the GIPL model. Thus, due to periods of frozen soil, there was greater runoff, less $R S$ and less $E T$ for the non-Arctic version simulation compared with the Arctic version simulation. Values for $Q S$ were zero throughout the seven years for both simulations. These differences in runoff, $R S$, and $E T$ resulted in over-predicted total water out of 0.76 inches for the Arctic version simulation and under-predicted total water out of 0.68 inches for the non-Arctic version simulation. The sum of these underand over-prediction errors is 1.44 inches, which is the net difference in the two simulations for total water out. Thus, this net difference in total water out for the two simulations is attributed to tolerance error in the iterative solution. Overall, it was concluded that the two versions of the hydrology model are maintaining a reasonably accurate water balance. 


\section{Changes to the HGCT}

Changes were made to the HGCT to support the new Arctic hydrology model and to address other needs to support Arctic conditions. These changes are described below.

The option was implemented in $H G C T$ for the user to select between application for an Arctic region and regular (non-Arctic) region where, for the Arctic option, the Arctic hydrology model UI is used in the HGCT Hydrology screen and the Arctic hydrology model is run.

The following fields were added within the HGCT Hydrology model I/O screen when the Arctic Option is selected by the user in HGCT:

- display of the input file for soil thawed layer thickness named soillayerthickness. txt provided from the GIPL model postprocessor

- display of the input file for snow cover and snow melt named SnowCoverMel tDepth. txt provided by the Snow17 model postprocessor

- maximum allowed soil layer thickness $H_{\max }(\mathrm{cm})$, which accounts for depth of contamination and PET utilization, but should be less than the average annual depth to permafrost (i.e., average annual active layer thickness (AAALT), which is on the order of one to two meters); the default value of $40 \mathrm{~cm}$ is recommended, but the user can change this value.

The following parameters are set within the HGCT Hydrology UI by the software rather than requiring input by the user when the Arctic option is selected in $H G C T$ :

- Analysis Type hydrology option is set to time varying (daily) hydrology, and the input field is grayed out when the Arctic Option is selected in $H G C T$

- the soil porosity value from the Soil Properties screen of $H G C T$ is obtained and shown in the Hydrology I/O screen as Soil Water Saturation Content (fraction), $\theta_{s}$, but is not grayed out so the user can change it if desired. 
The HGCT Hydrology model I/O screen for the non-Arctic option was also modified to allow user-specification of $H$ and auto-fill/specification of soil water saturated content, $\theta_{s}$. For both options (i.e., Arctic and non-Arctic), the hydrology $I / O$ screen also now shows the file name for the new output file for daily excess soil loading $(Q S)$. For the non-Arctic option, the name of the output file for daily snow cover is also shown on the screen.

The Arctic hydrology model inputs within the HGCT Hydrology I/O screen were modified to remove the following parameters when the Arctic Option is selected by the user in HGCT:

- Snow Evaporation

- Lagging Factor

- Melt Factor.

There were other changes required of $H G C T$ for the Arctic. The erosion module for daily hydrology in $H G C T$, which uses the Modified Universal Soil Lose Equation (MUSLE) as described by Dortch (2014), was modified to allow erosion due to rainfall to occur only when there is no snow cover for the Arctic option. There is an HGCT file for daily hydrologic output (DailyOutput.out) that includes daily rainfall needed by MUSLE. There is also a new file produced by the Snow17 model called SnowCoverMel tDepth. txt that contains daily SWE. The HGCT MUSLE routine uses these two files for computing daily erosion rates such that there is no erosion if the snow depth is greater than zero. This same change was also implemented for the non-Arctic option. The only difference is that the snow cover depth file is DailysnowCover.txt, which is generated by the non-Arctic hydrology model.

Under the non-Arctic hydrology option, the HGCT computes, displays, and sends to the soil fate model UI the average annual soil-water matrix temperature, which is used in the soil fate model UI to compute solubility of the HE hexahydro-1,3,5-trinitro-1,3,5-triazine (RDX, Royal Demolition Explosive) and trinitrotoluene (TNT) and the volatilization rate of all organic contaminants. The $H G C T$ adds 1.0 degree $\mathrm{C}$ to the average annual air temperature that is determined by the hydrology model to establish the average annual soil-water matrix temperature. As noted previously, the reference to an average annual quantity should be understood to be a single value that is the average for all years of the annual mean values. For Arctic conditions, the unfrozen soil temperature is more complex. The post- 
processor for the GIPL model output determines the average annual temperature (i.e., the average for all years of the annual mean temperatures) for the vertically mixed, thawed, active soil layer. The postprocessor computation is described in Chapter 4. This average annual soil matrix temperature is written into the GIPL output file soillayerthickness. txt that is used by the Arctic hydrology model and the Arctic soil fate model for input of the daily, thawed, soil layer thickness. This temperature is read by the HGCT from the file soillayerthickness. txt and used by the HGCT to supply to the soil fate model UI. 


\section{Soil Fate Model}

The modeling of the fate of contaminants in surface soil is handled in Tier II of TREECS ${ }^{\mathrm{TM}}$ with two separate models based on the type of hydrologic inputs. For average annual (AA) hydrology, the AA version of the soil fate model is applied. The hydrologic inputs for this version are single, constant, average annual values for rainfall, runoff, ET, net infiltration, etc. As explained previously, an average annual quantity is the average over all years of the annual mean values. For time-varying (TV) daily hydrology, the TV version of the soil fate model is applied, and daily hydrologic inputs for rainfall, runoff, ET, etc., are used as input. The TV version of the TREECS ${ }^{\text {TM }}$ Tier II soil fate model was modified and implemented for Arctic conditions are described below resulting in a new separate model.

\subsection{Description of changes for the Arctic soil fate model}

The processes of the AA and TV versions of the TREECS ${ }^{\mathrm{TM}}$ Tier II soil fate model are described by Dortch et al. (2011, 2012, and 2013). The codes are written in Visual Basic 6. A copy of the TV version code was used to provide the basis for the Arctic soil fate model.

Both the non-Arctic and Arctic versions of the soil fate model were changed to use daily rainfall rather than precipitation (which can include snowfall) to compute daily dissolution flux. This change was made to the $\mathrm{AA}$ and TV versions for non-Arctic conditions and the Arctic version. It is reasonable to assume that precipitation as snowfall contributes little to dissolution since most of the snow melt runs off rather than infiltrating soil when the soil is frozen, and the soil is usually frozen for snow to accumulate. Preliminary analyses of model results compared with outdoor dissolution data support this assumption (Dortch 2018).

Daily rainfall rate is read in from the new file DailyRainfall.out. This file is created by the soil fate model UI pre-processor as described in the next section. The rainfall rates in this new file are zero whenever the ground is frozen or there is snow cover. Both the non-Arctic and Arctic versions of the soil fate model were modified to compute dissolution using rainfall from this new file. 
Rain induced, pore-water extrusion of contaminant, and subsequent runoff, is dependent on rainfall rate. The TV soil fate model uses hourly rainfall for the pore-water extrusion calculations. These rainfall values are accessed from the file hourlyrainfall. out. As explained in the next section, the Arctic and non-Arctic versions of the soil hydrology model check for frozen soil (small layer thickness) and snow cover. If either is true, then hourly rainfall is set to zero in the file hourlyrainfall. out. Thus, no modifications were required in the Arctic (and non-Arctic) soil fate model since hourly rainfall is zero from the Arctic (and non-Arctic) hydrology model when it needs to be zero.

The daily, thawed, soil layer thickness file (named soillayerthickness.txt), which is produced by the GIPL model post-processor, is a new input file read by the Arctic soil fate model. The model was modified to read and use the daily-varying, thawed soil layer thickness in some of its computations rather than a constant soil layer thickness as done in the previous (non-Arctic) versions of the soil fate model. The thawed soil layer thickness used for computations, $Z b$, is forced in the model to be between a minimum value, $Z_{\min }$ (that is set in the code to $0.0508 \mathrm{~m}$, or $2 \mathrm{in}$.), and a maximum value, $Z_{\max }$, that is input by the user. The soil layer thickness used by the non-Arctic soil fate model is still read from the input file (ofile.inp), but this value is now used for $Z_{\max }$ in the Arctic soil fate model.

A threshold thickness $\left(Z_{\text {check}}\right.$ ), which is $Z_{\min }+0.001 \mathrm{~m}$, is used in the model to define fully frozen soil conditions. If $Z_{b}<Z_{c h e c k}$, the soil is assumed to be fully frozen, and all soil fate processes cease. Due to the inputs generated by the Arctic surface soil hydrology model for use by the Arctic soil fate model, only a few modifications were required in the soil fate model to shut off processes during fully frozen soil conditions. These modifications involved organic contaminant degradation and volatilization, which do not depend on soil hydrology. The degradation rate and the volatilization rate are set to zero when $Z_{b}<Z_{c h e c k}$, thus, shutting off these processes.

The other fate processes do not occur when the soil is fully frozen since the soil hydrology driving the process has been altered for the fully frozen conditions. The shut-down of each of these processes is explained as follows along with any modifications that were required. 
As explained in Chapter 6, daily erosion rate $E$ ( $\mathrm{m} /$ day), which is provided in the soil fate model input file ofiledaily. inp, is computed by the $H G C T$ using daily rainfall and snow cover data. If snow cover is present, then the erosion rate is set to zero. It is assumed that there can be erosion for frozen soil if there is no snow cover and there is rainfall for the day. The soil fate model reads in daily $E$ values and uses them to compute erosion mass fluxes for constituents adsorbed to soil and for solid-phase (undissolved) constituents, if that option is selected. No further checks or special conditions are necessary in the Arctic soil fate model for mass flux due to soil erosion. However, the computation of solid-phase mass flux due to erosion had to be modified to use $Z_{\max }$ rather than $Z_{b}$ to provide proper balance of solid-phase mass.

The daily leaching flux is computed using daily net infiltration rate through the soil layer, which is read by the soil fate model from the input file ofiledaily.inp, which is developed from the hydrology model output file dailyinfiltration.txt. If the ground is frozen, the Arctic hydrology model produces zero net infiltration rate. Thus, no modifications were required in the Arctic soil fate model for this process.

The precipitation of overly saturated dissolved contaminant in pore-water to solid-phase mass occurs only when there has been dissolution of solidphase contaminant mass for the day. If the soil is frozen, dissolution will not occur as explained above. Thus, no modifications were required in the Arctic soil fate model for this process.

The computation of dissolution flux depends on total solid-phase contaminant mass. If $Z_{b}<Z_{\max }$, a portion of the solid-phase mass can reside in the frozen part of the layer and is unavailable for dissolution. The computed dissolution flux is multiplied by the fraction of maximum soil layer thickness that is thawed $f_{t}$, where $f_{t}=Z_{b} / Z_{\max }$. As stated previously, the user specifies $Z_{\max }$ in the UI inputs. Similar to the surface soil hydrology model discussion of $H_{\max }$ (see Section 5.1), $Z_{\max }$ should be equal to or greater than the depth of contaminated soil and should capture the extent of soil depth where PET is fully utilized, which generally coincides with the vegetation root depth; but it is expected to be less than the depth to permafrost.

The equations that solve for total solid- and non-solid-phase mass concentrations were modified to use the $Z_{\max }$ rather than $Z_{b}$ so that total 
masses are conserved, and concentrations are not affected by varying thawed layer thickness. Otherwise, erroneous results occur.

\subsection{Implementation of the Arctic soil fate model and related processors}

Preprocessing and execution management coding within the TREECS ${ }^{\mathrm{TM}}$ system prepares the soil fate model input files and launches the appropriate soil fate model executable (among AA, TV, and Arctic versions) using the user-specified inputs entered via the Tier II soil fate model UI. Thus, the primary requirement for implementing the Arctic soil fate model in TREECS ${ }^{\mathrm{TM}}$ involved modifications to the soil fate model UI. These modifications resulted in a revised and separate Tier II soil fate model UI, and the changes are discussed below.

When the Arctic soil fate model is chosen for application within TREECS $^{\mathrm{TM}}$, the Arctic version of the soil fate model UI is also applied, and this UI version is specifically tailored to Arctic related inputs. The Hydrology Option on the Hydrology screen of the Arctic soil fate model $\mathrm{UI}$ is set by the code to Time-varying and that option is grayed out so the user cannot change this option. The label for Active Soil Layer Thickness on the Site Characteristics screen of the soil fate model UI was changed to read Maximum Active Soil Layer Thickness. A Help screen was added explaining the meaning of this variable with guidance for setting the value.

As explained by Dortch et al. (2011), the Tier II soil fate model computes the TV mass leaching flux $F_{l}(\mathrm{~g} / \mathrm{yr})$ which can experience two fates, transfer to surface water via soil interflow and percolation to groundwater (i.e., transfer to vadose zone and eventually aquifer). The soil fate model UI provides estimation and input of the fraction of $F_{l}$ diverted to soil interflow, $f_{i f}$, where the remaining fraction $\left(1-f_{i f}\right)$ is used to determine the flux passed to groundwater. The soil fate model post-processor uses this fraction to compute the TV mass fluxes exported to interflow, $F_{i w}$, and groundwater, $F_{g w}$. These fluxes are written to a linkage file for use by the models that receive these fluxes. For non-arctic conditions, the value of $f_{i f}$ depends on the soil hydraulic conductivity in the vadose zone. Alternatively, the user can simply specify $f_{i f}$ as a percentage. Frozen soil and permafrost also affect soil hydraulic conductivity in Arctic regions. The Arctic soil fate model UI still uses the above basic approach with modifications for the presence of permafrost. Thus, special provisions 
were needed to handle soil interflow and percolation to groundwater for Arctic applications as described below.

The Arctic soil fate model UI includes input of a new parameter on the Hydrology screen, which is the fraction of the AOI surface area that is underlain with permafrost, $f_{P F}$, which is specified by the user according to the permafrost classification for the AOI. A Help screen was added to explain permafrost classifications based on average annual air temperature. This Help screen also provides Table 7 below to assist with the classification. The fraction $f_{P F}$ is used by the Arctic soil fate model postprocessor to compute the daily mass fluxes $F_{i w}$ and $F_{g w}$ as shown in Equations 7-1 and 7-2.

$$
\begin{gathered}
F_{i w}=\max \left(f_{P F}, f_{i f}\right) \bullet F_{l} \quad \text { for thawed } \quad F_{i w}=F_{l} \text { for frozen } \\
F_{g w}=F_{l}-F_{i w}
\end{gathered}
$$

A single value is used for $f_{P F}$, whereas daily values of $f_{i f}$ are written by the soil fate model pre-processor into ofiledaily.inp which is used by the soil fate model post-processor to compute $F_{i w}$ and $F_{g w}$. If the active layer is fully or partially frozen, $F_{i w}=F l$, or all the leaching flux is diverted to interflow as shown by Equation 7-1 (frozen). If the active layer is fully thawed to the depth of permafrost, then the leaching flux is distributed between interflow and percolation according to Equations 7-1 (thawed) and 7-2. For the thawed condition, the maximum of the two fractions is used to determine the interflow flux. It can be inferred from Figure 22 that even if there is a fully thawed active layer, the presence of permafrost below the active layer can force water and mass flux to interflow, which is what Equation 7-1 accomplishes.

Equations similar to Equations 7-1 and 7-2 are used by the Arctic soil fate model post-processor to compute soil interflow and groundwater percolation water fluxes (i.e., flow rates (m3/yr)). Using the methodology described above, the post-processor splits the daily net infiltration depth $I$ (see Figure 22) output by the soil hydrology model into the daily water percolation depth $q$ and daily soil interflow depth $I F$. These daily water depths are averaged over the simulation and multiplied by the AOI surface area to compute the average annual water flow rates for percolation and soil interflow $\left(Q_{i f}\right)$ in units of cubic meters per year. These two flow rates are written into their related sections of the Water Flux File (WFF). The 
WFF is a linkage file that all modules use for transferring water and mass fluxes for consumption by other modules.

In order to apply Equations 7-1 and 7-2, it is necessary to know if the active soil layer is fully thawed or not. A daily thaw flag is written into the daily, thawed soil layer thickness file (soillayerthickness.txt) produced by the GIPL model post-processor. A daily thaw flag value of 1 indicates that the active layer is not fully thawed, whereas a value of o indicates that it is fully thawed. The Arctic soil fate model post-processor reads the thaw flag and uses it to apply the logic above for determining soil interflow and percolation water and mass fluxes, which are written to the linkage file (WFF) for use by other models that receive these fluxes (i.e., interflow and vadose zone models) as discussed later in this report.

The procedure for determining the thaw flag is described as follows. The AALT is the maximum thawed soil layer thickness for the year. The AALT and the minimum AALT for the simulation period (AALT min $_{\text {) }}$ are determined by the GIPL model post-processor as discussed in Chapter 4 . If the thaw thickness for the day is equal to or greater than the AALT min, the active layer is fully thawed, and the flag is o. Otherwise, the flag is 1. The thaw thickness is defined as the depth below ground surface where the temperature changes from above zero to below zero degrees C. Of course, when the soil surface freezes in the fall, the thaw thickness is zero.

Table 7. Permafrost classifications with fraction of surface area coverage (based on various Internet searches).

\begin{tabular}{|l|c|c|}
\hline \multicolumn{1}{|c|}{ Classification } & $f_{\text {PF }}$ & $\begin{array}{c}\text { Approximate mean annual air } \\
\text { temperature, deg C }\end{array}$ \\
\hline Continuous & $>0.9$ & $<-5$ \\
\hline Discontinuous & $0.5-0.9$ & -4 to -2 \\
\hline Sporadic & $0.1-0.5$ & -2 to 0 \\
\hline Isolated & $0-0.1$ & $\approx 0$ \\
\hline
\end{tabular}

An additional modification was needed for both the non-Arctic and Arctic versions of the soil fate model UI pre-processor. The two UI preprocessors use data entered into the soil fate model UI and data available from the surface soil hydrology model output files to construct the soil fate model input files. The non-Arctic and Arctic soil fate model UI preprocessors were modified to create an additional input file, DailyRainfall.out, for use by the non-Arctic and Arctic soil fate 
models. This file contains daily rainfall rates (m/day) developed by summing the hourly rainfall rates in the file hourlyrainfall. out, which is created by the Arctic and non-Arctic soil hydrology models. The two versions of the soil hydrology model set hourly rainfall equal to hourly precipitation when the air temperature is positive and when there is no snow cover and the ground is not frozen (i.e., active soil layer thickness greater than $H_{\min }$ (i.e., $1.0 \mathrm{~cm}$ ). Otherwise, hourly rainfall is zero. The nonArctic soil hydrology model only checks for snow cover since the ground is assumed to be frozen only when there is snow cover, and thawed when there is no snow cover. The non-Arctic and Arctic versions of the soil fate model were modified to use the daily rainfall amounts from the new file DailyRainfall.out for computing solid-phase mass dissolution. With all of these changes, dissolution is now driven by rain rather than precipitation, and there is no rainfall dissolution whenever there is snow cover or the ground is frozen.

The non-Arctic soil fate model post-processor combines surface soil export fluxes (i.e., rainfall runoff and erosion fluxes) and soil interflow fluxes for water and mass and writes these combined fluxes for water and mass into the surface water sections of the WFF. For Arctic conditions, it was necessary to keep these two types of fluxes (surface soil export and soil interflow) separate since the fate of soil interflow fluxes are modeled for Arctic conditions rather than directly transferring them to surface water as done for non-Arctic conditions. Thus, the Arctic soil fate model postprocessor does not combine surface soil export and soil interflow water and mass fluxes, rather the soil interflow fluxes are written to a new subtype section within the WFF so that they can be used as input for the interflow fate modeling (see Section 2.3).

The Arctic soil fate model UI includes a new display field on the Site Characteristics screen that provides the value of the AAALT for thawed surface soil, $\mathrm{m}$. The annual active layer thickness is shown in Figure 22. The AAALT is the annual active layer thickness averaged over of all years of the GIPL model simulation (See Chapter 4). The annual active layer thickness is the maximum thawed soil layer thickness for the year. This averaging is performed by the GIPL model post-processor, and the value is written into the GIPL model output file soillayerthickness. txt that is used by the Arctic surface soil hydrology and Arctic soil fate models. The Arctic soil fate model UI reads the AAALT value and displays it within the UI so the user can easily find it and use it for determining AOI crosssectional flow area and calculating AOI background soil interflow velocity (see Section 2.3). 


\section{TREECS ${ }^{\mathrm{TM}}$ Application Protocol for Arctic}

\subsection{General overview}

The application of TREECS ${ }^{\mathrm{TM}}$ for Arctic conditions requires specific procedures that are not generally required for other regions. The standalone models Snow17 and GIPL must be run as preprocessors to develop Arctic-specific hydrologic inputs. An overview of this process is shown by the schematic in Figure 23. These two models require daily inputs of observed air temperatures and precipitation. They produce outputs within files that are accessed by the TREECS ${ }^{\mathrm{TM}}$ Arctic hydrology model that is applied within the HGCT under TREECS ${ }^{\mathrm{TM}}$ Tools. There is a new application within TREECS ${ }^{\mathrm{TM}}$ Tools named Arctic Preprocessors that is used to launch an Excel workbook for setting up the inputs and running the Snow17 and GIPL models, and for generating their appropriate output files. The details of applying the Snow17 and GIPL models are discussed in Chapters 3 and 4, respectively.

Figure 23. Schematic of Arctic hydrology processing.

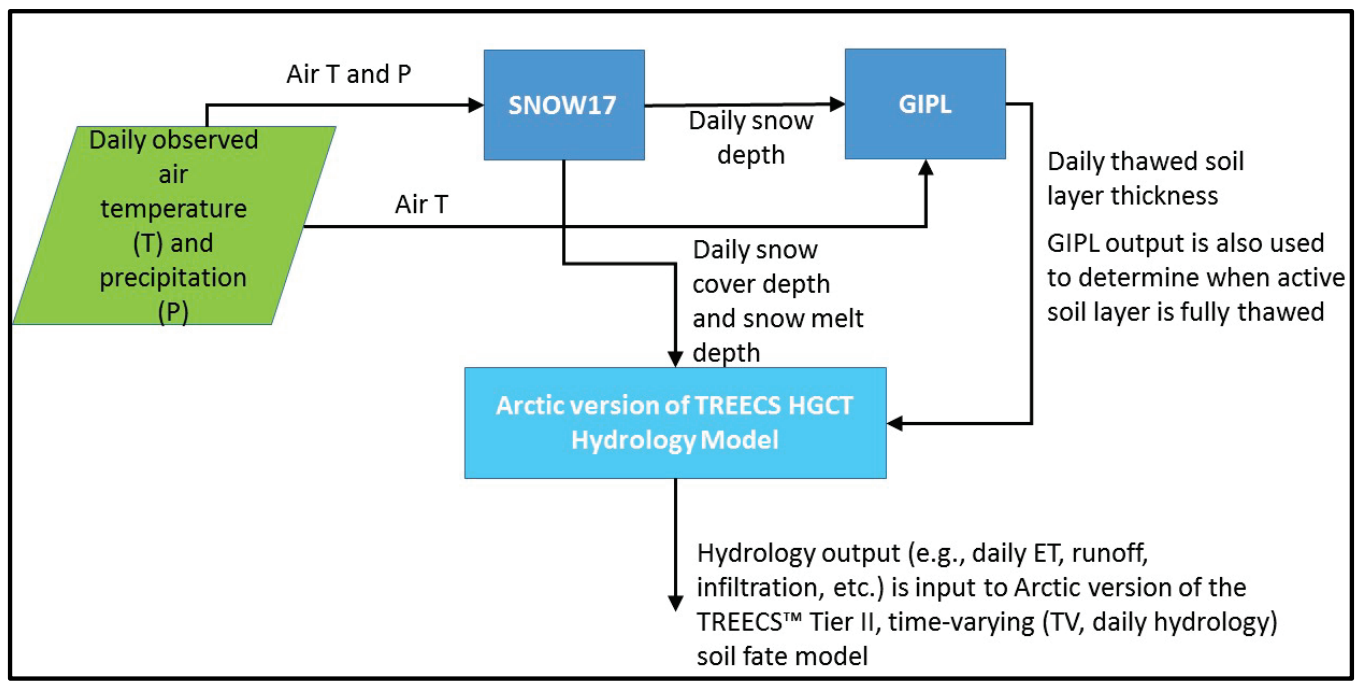

The general approach for modeling constituent $\mathrm{F} / \mathrm{T}$ for Arctic conditions is shown by the schematic in Figure 24. The surface soil and surface water media can be modeled in TREECS ${ }^{\mathrm{TM}}$ using either annual average (AA) or time-varying (TV) hydrologic drivers. The groundwater media are modeled only with AA hydrology since the MEPAS groundwater models can use only AA hydrologic drivers, and these models are presently the only options available within TREECS ${ }^{\mathrm{TM}}$ Tier II for groundwater. The use of AA hydrology for groundwater is usually adequate given the long response 
times for $\mathrm{F} / \mathrm{T}$ in that media. For Arctic conditions, AA hydrology is inadequate for the surface soil medium since the thawed layer thickness varies daily and freeze/thaw occurs seasonally with runoff and soil erosion occurring only during the thaw period. Thus, it is necessary to use TV hydrology for surface soil F/T modeling, and the model described in Chapter 7 was developed for this purpose. It is noted that the TV hydrology is daily-varying, but the time step and outputs for the TV Arctic soil fate model may not be exactly a day depending on the time-stepping option and time step size specified by the user.

Figure 24. Schematic of TREECS ${ }^{\mathrm{TM}}$ application methodology for Arctic regions.

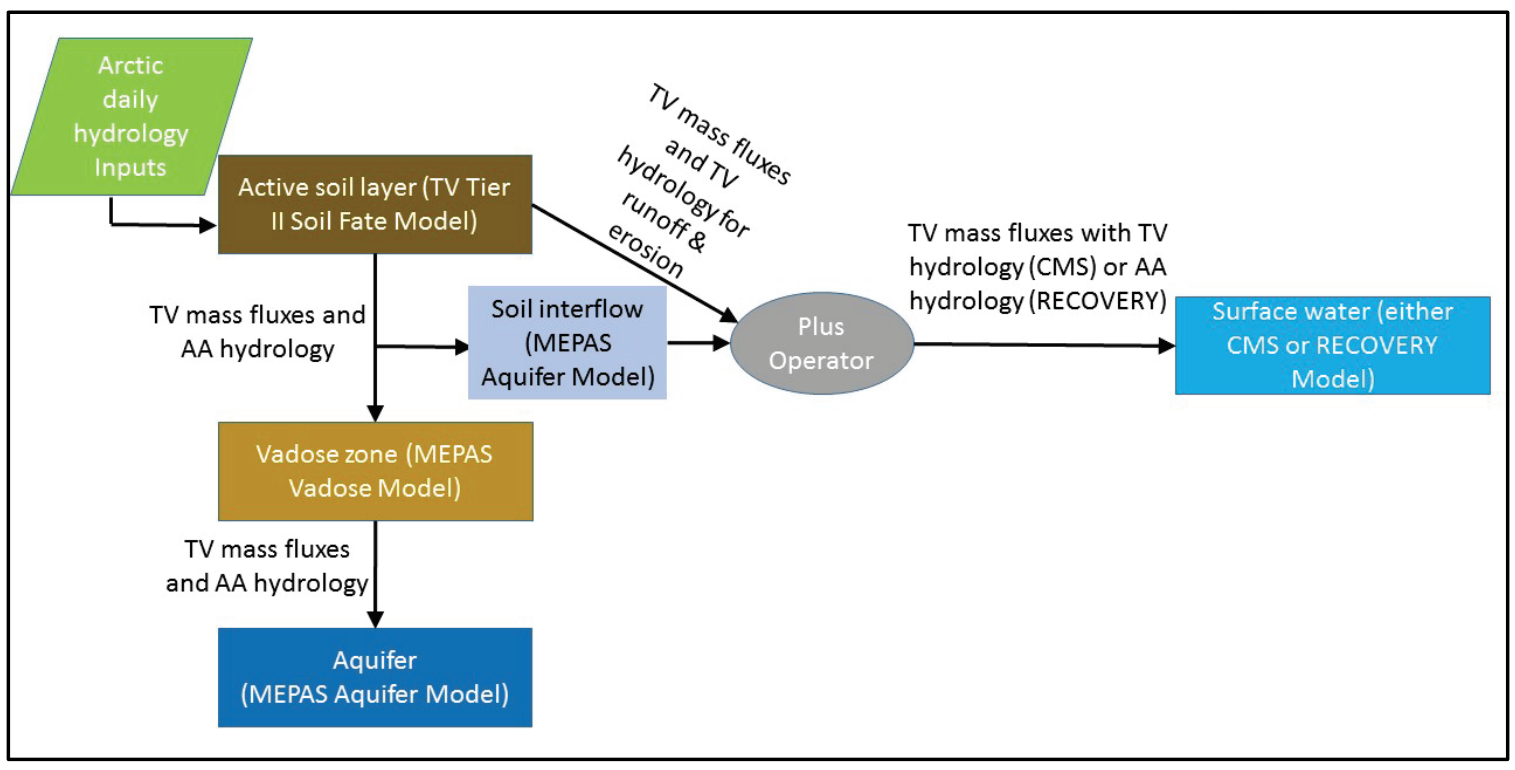

There are presently two models within TREECS ${ }^{\mathrm{TM}}$ that can be used for modeling surface water media, the Contaminant Model for Streams, CMS (Fant and Dortch 2007), and the RECOVERY model (Ruiz and Gerald 2001). The CMS is better suited for modeling flowing streams and rivers since it is $1 \mathrm{D}$ longitudinal along the stream flow axis. The RECOVERY model is better suited for modeling standing surface water, such as lakes and ponds. RECOVERY treats the water column as fully mixed, but the benthic sediments are modeled with multiple layers (1D vertical). The CMS can accept and use either AA or TV hydrology, but RECOVERY presently uses only a constant flow through rate as specified or determined based on model UI inputs provided by the user. Thus, the CMS is fully compatible with output from the surface soil fate model when it is run with TV hydrology. However, the TV hydrology is not used by the RECOVERY model, although it accepts TV constituent mass fluxes and computes TV concentrations. The assumption of constant flow rate in the RECOVERY 
model is less of a concern when the surface water residence time (i.e., water volume divided by water flow rate) is large.

Although TV soil interflow constituent mass fluxes will be computed, the AA water flow rate (volume/time, $\mathrm{m}^{3} / \mathrm{yr}$ ) for soil interflow must be used in the MEPAS aquifer model, which is used to compute soil interflow mass fluxes exported to surface water (see section 2.3). As stated previously, the MEPAS groundwater models (vadose and aquifer) use only constant AA water flow rates. The constant flow rate limitation for soil interflow mass fate is acceptable since the transport time of constituent mass in soil interflow can be quite prolonged due to low flow velocities in porous media and constituent adsorption partitioning to soil. Thus, similar to groundwater, the use of AA water flow is not considered a serious flaw for soil interflow F/T. Time-varying constituent mass fluxes feed into the MEPAS vadose and aquifer models, as well as the RECOVERY model, without any problems or required modifications. It is noted that all of the Tier II F/T models in TREECS ${ }^{\mathrm{TM}}$ utilize and produce TV mass fluxes (and concentrations), even when using AA hydrology.

Both the Tier II soil fate model, and MEPAS aquifer model, have their own unique time-stepping methods which results in temporal steps of mass flux output that can be different. Also, the water fluxes are time-varying and constant over time for the surface soil model and soil interflow model, respectively. The time series of water and constituent mass fluxes associated with runoff and erosion from surface soil must be combined with the time series of soil interflow water and constituent mass fluxes (from the MEPAS aquifer model) for loading to the receiving surface water model. A special module, referred to as the Plus Operator, exists within TREECS $^{\mathrm{TM}}$ for performing these combinations such that two time series with different temporal steps can be combined into one time series for use by the receiving model.

\subsection{TREECS $^{\text {TM }}$ application methodology}

To preclude having to make substantial changes to TREECS ${ }^{\mathrm{TM}}$, the required transport pathways shown in Figure 24 can be readily modeled with few modifications by using the Advanced Tier II option. Advanced Tier II involves using the Framework for Risk Analysis in Multimedia Environmental Systems (FRAMES). FRAMES (Whelan et al. 1997) (http://mepas.pnnl.gov/FramesV1/index.stm) is an object-oriented model linkage system within TREECS ${ }^{\mathrm{TM}}$ where disparate modules or models can be 
linked together in various ways. The details of how to use FRAMES is not covered in this TR since this information can be found in the TREECS ${ }^{\mathrm{TM}}$ user manual (Gerald et al. 2012) and the FRAMES Help screens accessible within the UI.

FRAMES provides the means to model complicated transport and exposure pathways that are not available with the preconfigured TREECS $^{\text {TM }}$ templates (i.e., not Advanced Tier II). An Advanced Tier II example case for Arctic conditions was developed to facilitate such applications and is provided in the TREECS ${ }^{\mathrm{TM}}$ install directory. To use the TREECS ${ }^{\mathrm{TM}}$ Arctic example case, the user should launch TREECS ${ }^{\mathrm{TM}}$ and open the case ArcCase.trp, which can be found in the path $\mathrm{C}: \backslash$ Prog Files $\backslash$ Treecs $\backslash$. After opening the example case, the user should resave the opened case using another name so that the original example case will be preserved for later use if needed. It is best to save this new case in another directory related to the project study.

The FRAMES workspace for the example case ArcCase.trp is shown in Figure 25. This example case is a variation of the demonstration applications presented in Chapter 9 for the Stuart Creek Impact Area of the Yukon Training Area near Fairbanks, AK. The contaminant of concern for this example is RDX, and there are pathways from soil to surface water via soil interflow and surface runoff, and erosion from soil to groundwater. The fraction of AOI underlain by permafrost was set to 0.5 for this case. The lines with arrows in Figure 25 show the FRAMES mass and water flux pathways.

The soil model selected for the AOI impact area soil is the Arctic Tier II soil fate model that is discussed in Chapter 7. As explained previously in Section 7.2, the UI/post-processor for the Arctic soil fate model splits the interflow water and mass fluxes from other surface soil fluxes in the Water Flux File (WFF), whereas the non-Arctic soil fate model UI/post-processor combines surface and interflow fluxes for transfer to surface water. The non-Arctic soil fate model UI/post-processor can be modified at some future time to do the same thing as the Arctic version (i.e., split the fluxes for interflow). 
Figure 25. FRAMES work space within TREECS ${ }^{\mathrm{TM}}$ for case ArcCase . trp.

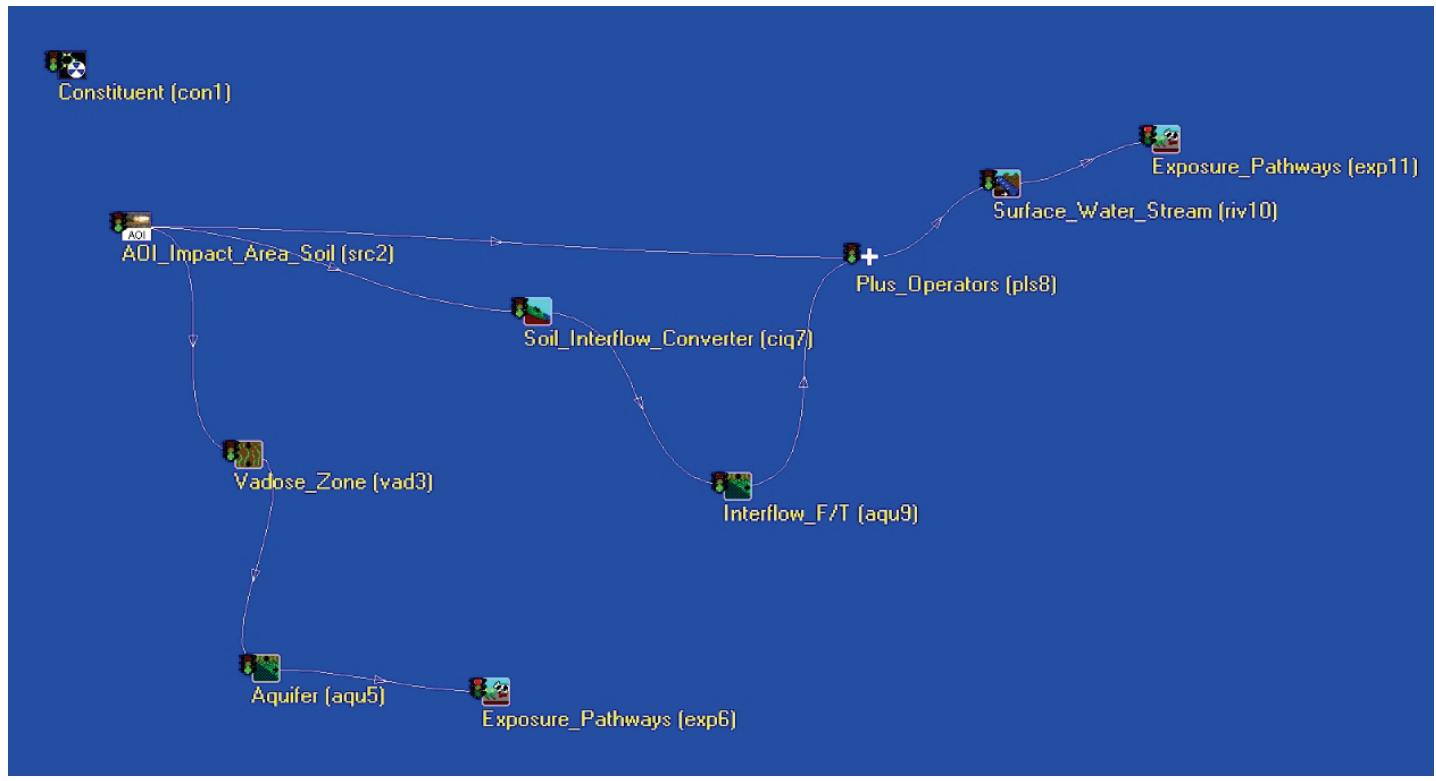

A new module was developed, referred to as the WFF Interflow to WFF Aquifer Converter. This converter, shown as Soil Interflow Converter in Figure 25, takes the soil interflow water flow rate $\left(Q_{i f}, \mathrm{~m}^{3} / \mathrm{yr}\right)$, and TV interflow mass fluxes in the WFF section for soil fate model output, and writes them into the aquifer section of the WFF for use by the MEPAS aquifer model for interflow (shown as Interflow_F/T (aqu9) in Figure 25). The Plus Operator shown in Figure 25, is needed to combine the water and mass fluxes for surface soil output (i.e., runoff and erosion), and interflow $\mathrm{F} / \mathrm{T}$ output for delivery to surface water as explained in section 8.1.

The MEPAS aquifer model UI requires input by the user for Darcy velocity (length/time). For modeling soil interflow F/T, the Darcy velocity represents the soil interflow background velocity as discussed in section 2.3. The user must estimate this velocity and input the value into the MEPAS aquifer model UI when setting inputs for the soil interflow F/T modeling. As explained in section 2.3, this value can be estimated by dividing the AA soil interflow water flow rate $\left(Q_{i f}, \mathrm{~m} 3 / \mathrm{yr}\right)$ by the AOI cross-sectional area for soil interflow. As stated previously, this cross-sectional area is the product of the soil interflow thickness, and the width of the AOI site, perpendicular to the flow path from the AOI to the receiving surface water (Figure 2). The user must estimate the AOI site width. The interflow thickness is essentially the AAALT for thawed surface soil (Section 7.2). The user can obtain the AAALT from the Arctic soil fate model UI, and multiply it by the AOI site width, to calculate the AOI soil interflow cross-sectional area. The value of $Q_{i f}$ can be 
obtained by the user viewing the WFF text output file for the WFF Interflow to WFF Aquifer Converter. This viewing is performed by right clicking the Soil Interflow Converter object in the FRAMES workspace, and then selecting View/Print Module Output/WFF Text View. The value of $Q_{i f}$ can be found near the top of the file in the line just after the line " $y r ", " m \wedge 3 / y r$,, 2. This line contains the year o followed by a comma, which is followed by the $Q_{i f}$ flow rate in $\mathrm{m}^{3} / \mathrm{yr}$.

The default surface water model in the example case is the CMS, however, the RECOVERY model can be easily substituted for the CMS if desired. As noted previously, the RECOVERY model only uses AA hydrology based on user inputs specified within the model UI for three of the four input variables of water surface area, mean water depth, flow through rate ( $\mathrm{m}^{3} / \mathrm{yr}$ ), or residence time (year); the RECOVERY model UI computes the fourth variable. Usually, surface area, depth, and flow through rate are specified, and the residence time is computed. With this arrangement, water fluxes (i.e., flow rates) available from an upstream module, which is the Plus Operator (Figure 25), are not used by the RECOVERY model since the flow rate is provided by the UI based on user input. The TV mass fluxes from the upstream module are used within the RECOVERY model for mass loading inputs.

Additional pathways and media can be added within FRAMES, such as groundwater discharging to surface water, or multiple surface water bodies like a stream flowing into a lake. The example case includes one vadose zone model representing mineral soils in vadose below the highly organic peat surface soil (represented by the soil fate model). If the peat layer for a site extends deeper, then another vadose zone model can be added, where the upper model represents the organic vadose soils and the lower one represents the deeper mineral vadose soils. Fluxes from an upper vadose zone model feed into a lower vadose zone model. The vadose zone feeds into the aquifer (Figure 25). As explained previously, the MEPAS vadose and aquifer models are used.

The TREECS ${ }^{\mathrm{TM}} /$ FRAMES modifications that were required to support the Arctic example case shown in Figure 25, consisted primarily of developing the WFF Interflow to WFF Aquifer Converter module discussed above. This module does not require any input by the user. Also, some minor effort was expended for development of the FRAMES module Description (DES) files required for the Arctic Tier II soil fate model, and the WFF 
Interflow to WFF Aquifer Converter module. The other modifications required of TREECS ${ }^{\mathrm{TM}}$ for the Arctic were those previously discussed for the HGCT (Chapter 6) and the Arctic soil fate model UI (section 7.2). 


\section{Demonstration Applications}

\subsection{General study plan}

Demonstration applications of TREECS ${ }^{\mathrm{TM}}$ for Arctic conditions were conducted to evaluate the new features and assess how they affect model results. The first task for these applications was to select an appropriate study site. The primary needs for the study site were that it should be an Army training area in Alaska (AK) where there is permafrost. Impact areas for live fire, medium and large caliber projectiles, such as artillery and mortars, commonly experience a low percentage of partial (low-order) detonations that potentially expose HE residue. Thus, artillery and mortar impact areas received preference for the study site area of interest (AOI).

U.S. Army Alaska is composed of two posts, Forts Wainwright and Richardson. Fort Wainwright was selected because of the availability of permafrost. Major training areas associated with Fort Wainwright include the Donnelly Training Area (DTA), the Yukon Training Area (YTA), and the Tanana Flats Training Area (TFTA), which are shown on the map of Figure 26. Of these three training areas, YTA is the farthest north and also includes artillery and mortar impact areas, thus, making it a viable study site candidate.

Ideally, it would be beneficial to be able to validate TREECS ${ }^{\mathrm{TM}}$ for Arctic conditions from the three following aspects: surface soil hydrology, contaminant $\mathrm{F} / \mathrm{T}$ in surface soil with observed surface soil concentrations, and contaminant $\mathrm{F} / \mathrm{T}$ in receiving media (i.e., groundwater and surface water/sediment) with observed concentrations in the receiving media. Unfortunately, suitable data was not found for validating TREECS ${ }^{\mathrm{TM}}$ for Arctic conditions for these three aspects. Surface soil MC concentrations have been measured within DTA (https://energetics.erdc.dren.mil/FW.html), but DTA is farther south than YTA with less permafrost.

Given the needs of these applications and the available sites, the YTA was selected. Specifically, the Stuart Creek Impact area with YTA was chosen for the study site. 
Figure 26. Map of Alaska showing Forts Wainwright and Richardson and associated training areas (from CSU 2004b).

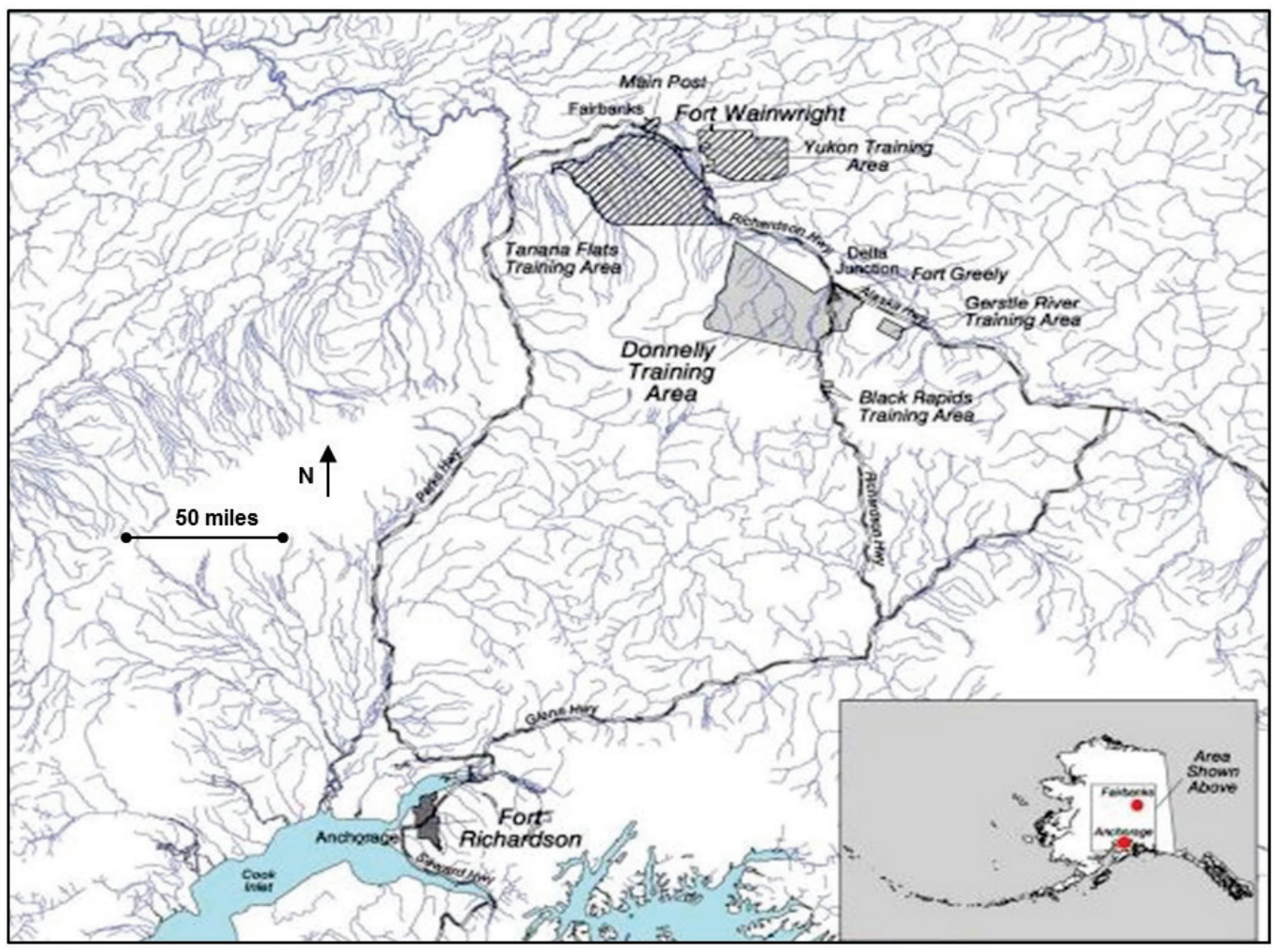

\subsection{Selection of AOI and site description}

The YTA comprises approximately 248,000 acres (CSU 1999, 2004a). The YTA is adjacent to Eielson Air Force Base and lies east of the Tanana River between the Chena and Salcha Rivers, and northeast of the Richardson Highway. The Stuart Creek Impact Area (SCIA) of YTA (Figure 27) comprises approximately 25,000 acres (CSU 1999, 2004a) and is designated as a dudded impact area where Army live fire and Air Force bombing occur.

As shown in Figure 28, streams of the northern and eastern YTA drain into the Chena River. The Chena River is north of YTA and drains into the Tanana River at Fairbanks. The Tanana River is south of YTA. Major tributaries of YTA that drain into the Chena River include South Fork Chena River, Hunts Creek, and Horner Creek. Tributaries of South Fork Chena River include Stuart Creek, Globe Creek, and Beaver Creek. All of the streams of YTA originate in rolling, glacier-free terrain of the Yukon Tanana upland with elevations of less than 2,000 $\mathrm{ft}$. 
Figure 27. SCIA of the YTA (modified from CSU 2004b).

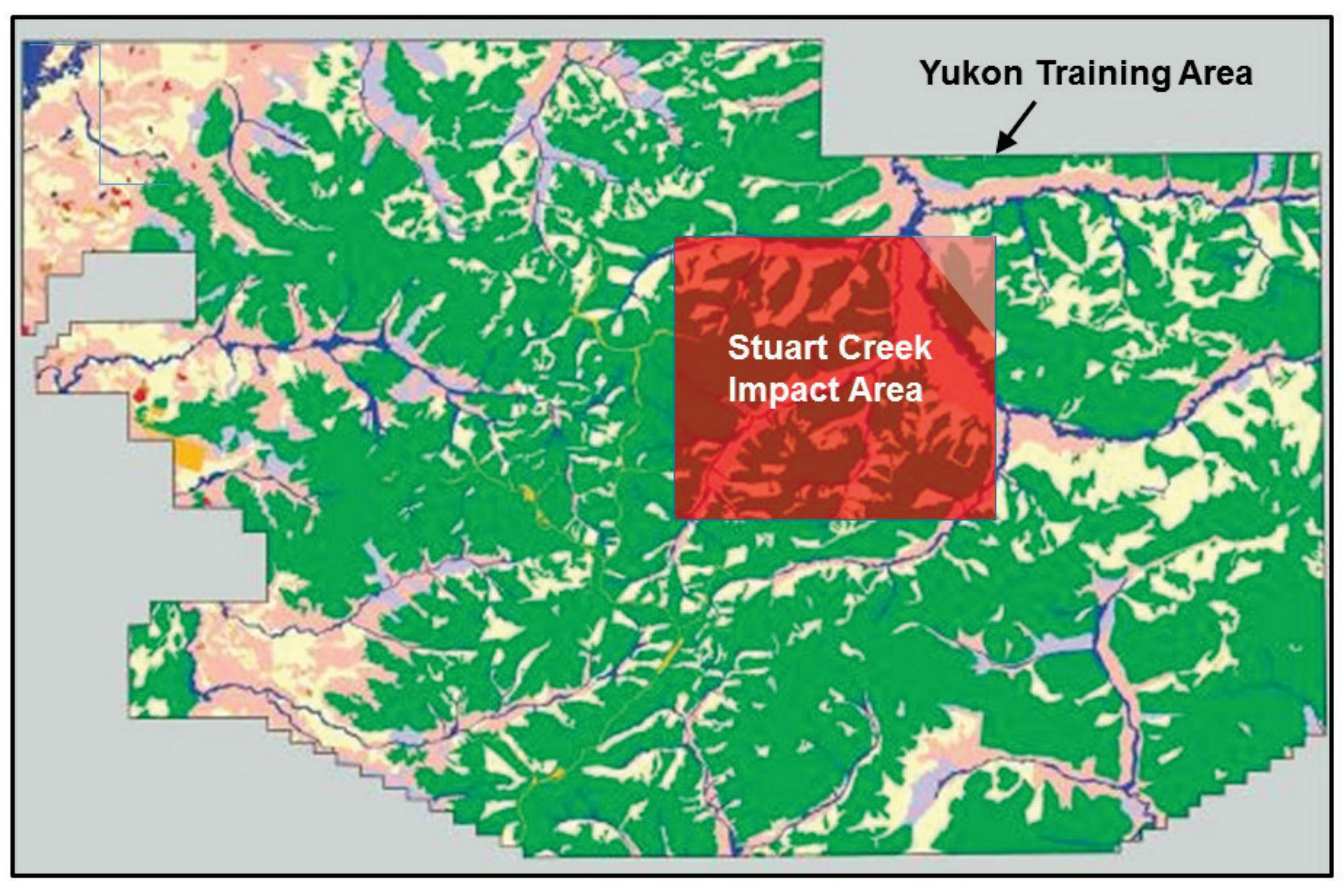

Figure 28. Streams of YTA (modified from CSU 2004b).

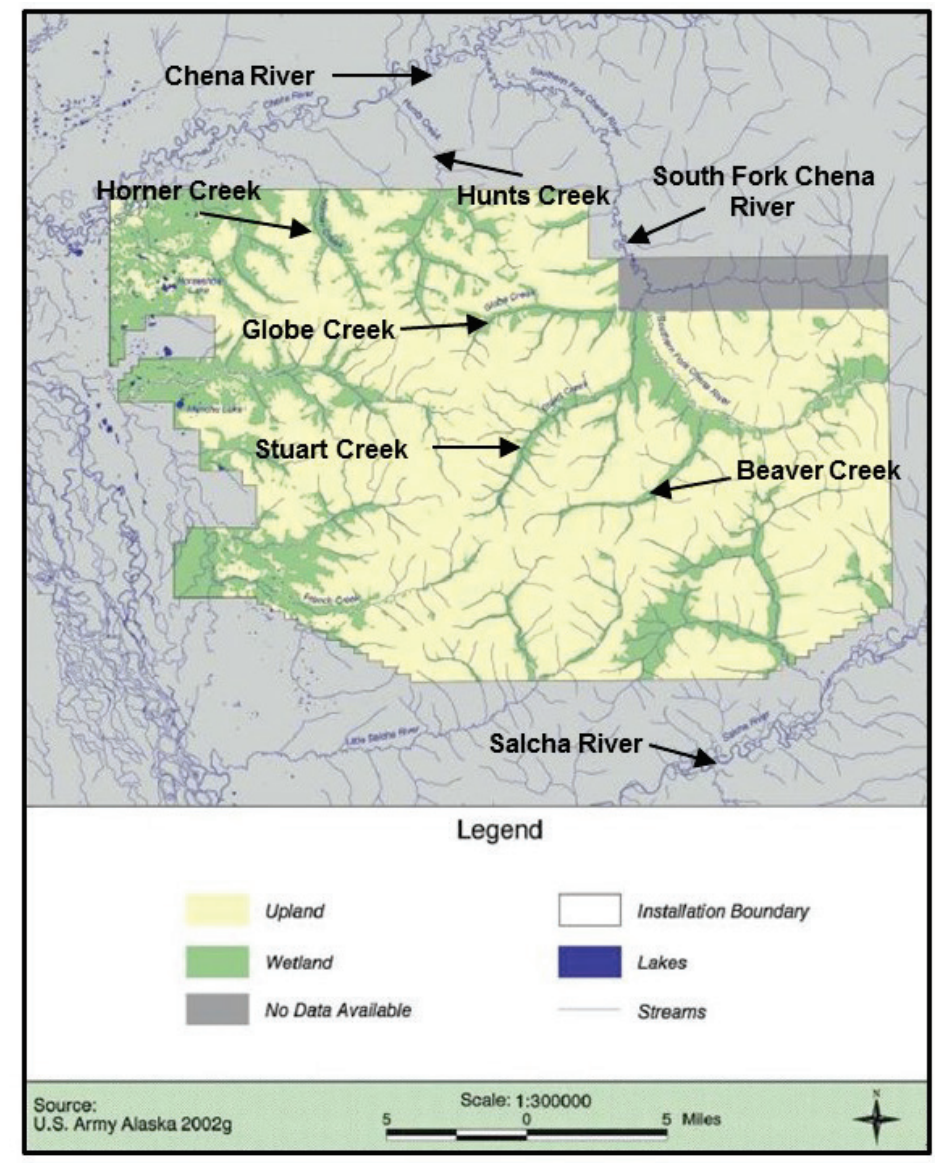


Information was provided from Fort Wainwright personnel ${ }^{2}$ pertaining to the location of target areas within the SCIA. There are multiple target areas within SCIA used by the U.S. Army and U.S. Air Force. The Army's primary artillery target area was denoted in the information and is shown in Figure 29 as the SCIA. These demonstration applications were focused on the artillery impact area of the SCIA, which lies along Stuart Creek (Figure 29). Thus, this artillery impact area serves as the AOI for these demonstration applications.

Figure 29. Artillery impact area of the SCIA (from rendering in Google Earth Pro ${ }^{\odot}$ ).

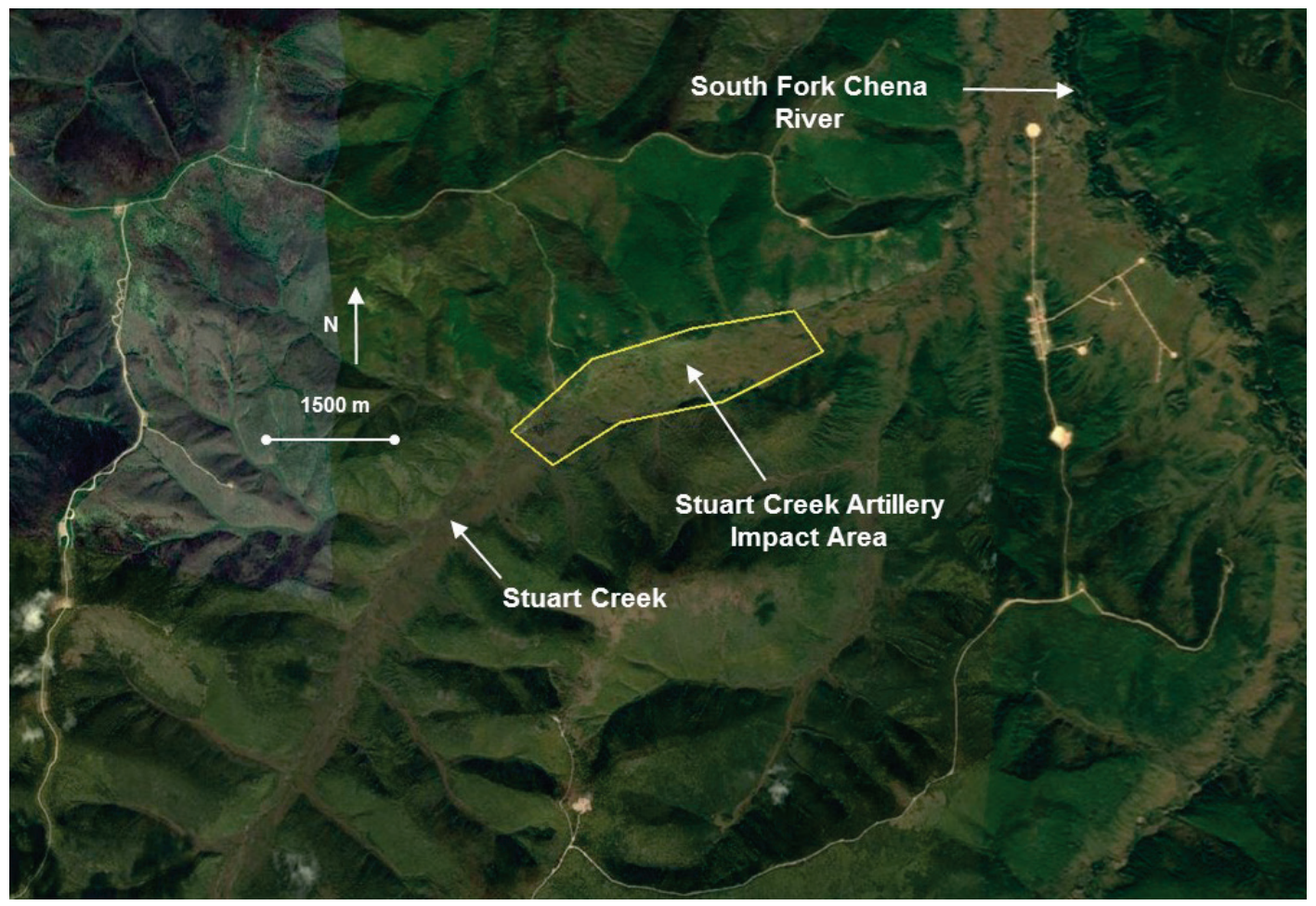

The AOI resides mostly along the floodplain of Stuart Creek where the soils are classified as Goldstream Histels complex according to Web Soil Survey (WSS) https://websoilsurvey.sc.egov.usda.gov/App/HomePage.htm). These soils are described as mucky, hydric peat with a highly organic layer overlaying loess (CSU 2004a) with $0-3 \%$ slope. The top $40 \mathrm{~cm}$ of soil has an organic matter content of about $53 \%$ with the loess consisting of approximately $75 \%$ silt, $17 \%$ sand, and $8 \%$ clay (WSS). These percentages result in a mixed content of $53 \%$ organic matter, $35 \%$ silt, $8 \%$ sand, and $4 \%$ clay. The depth to water table varies from zero to about eight inches during June -

\footnotetext{
2 Personal communication with Mr. Joshua Buzby, ITAM Coordinator, Fort Wainwright, AK, joshua.v.buzby.civ@mail.mil
} 
September, and the depth to permafrost varies from about 14-24 inches3. Permafrost of the alluvium is shown to be continuous (CSU 2004b), but adjacent, more elevated terrain is shown as permafrost free. The AOI can be characterized as shrub, alluvium wetlands (CSU 2004a).

Information regarding types and numbers of munitions items fired into the AOI were provided by Fort Wainwright personnel4. RDX was chosen as the $\mathrm{MC}$ of interest for the demonstration applications. From the firing information, it was determined that the biggest contributions of RDX residue is from firing of $155 \mathrm{~mm}$ artillery rounds. Based on the firing rates provided for 2014-2017, the average number of $155 \mathrm{~mm}$ live rounds fired per year was determined to be 1895 . Rounding this value up to 2000 rounds per year, assuming $1.3 \%$ and $1.2 \%$ dud and low order rates, respectively, with $10 \%$ of duds sympathetically detonated by other, high order rounds, assuming yields for low order and sympathetic detonations of 50\%, and assuming high order yield of $99.999995 \%$, the RDX unexploded residue mass loading rate was computed by the TREECS ${ }^{\mathrm{TM}}$ $\mathrm{MC}$ mass loading module to be $55.7 \mathrm{~kg} / \mathrm{yr}$. This value was provided to the soil fate model inputs. The assumed values listed above were based on best available information for $155 \mathrm{~mm}$ artillery rounds within the TREECS ${ }^{\mathrm{TM}}$ help sections of the MC AOI loading module.

\subsection{Application inputs}

Input values were set for each module. The modules included the $H G C T$ utility, the Arctic Tier II soil fate model (shown as AOI Impact Area Soil in Figure 25), the vadose zone model, the aquifer model, the soil interflow converter, interflow $\mathrm{F} / \mathrm{T}$, the plus operator, and the surface water model for streams. Only one vadose zone module is used in this application, whereas two are shown in Figure 25. In this application, the organic vadose layer is left out since the organic muck layer of the AOI is about the same thickness as the surface soil thickness, which is modeled by the soil fate model. The vadose layer in this application corresponds to the mineral silt loam soils beneath the organic muck.

\footnotetext{
3 U.S. Department of Agriculture, Natural Resources Conservation Service, Soil Survey of Greater Fairbanks Area, Alaska. 2004

4 Personal communication with Mr. Joshua Buzby, ITAM Coordinator, Fort Wainwright, AK, joshua.v.buzby.civ@mail.mil
} 
The exposure pathways module is a required downstream component for surface water and aquifer models, but inputs for it are not required to run those models and examine their output. The soil interflow converter has no input requirements other than the system files passed to it by the soil fate model. The description of inputs for each module are presented below.

\subsubsection{HGCT inputs}

Study of various literature provided the soil characteristics of peat required for the modeling. In general, peat has a high organic matter content with correspondingly low soil dry bulk density (DBD). For an organic matter content of $53 \%$, the DBD was estimated to vary between about 0.35 and $0.40 \mathrm{~g} / \mathrm{cm}^{3}$ using the published regression relationships of Hossain et al. (2015). A value of DBD of $0.37 \mathrm{~g} / \mathrm{cm}^{3}$ was used in the modeling. The porosity of soil with peat and mineral mixture is quite high, ranging from about $75 \%$ to $88 \%$ (Walczak et al. 2002). A soil porosity $85 \%$ was used in the modeling. The soil field capacity was set to $56 \%$ based on information found through various searches, and the residual water content was set to $18 \%$ based on information presented by Hallema et al. (2015). The saturated hydraulic conductivity for AOI soil was determined from WSS as $55 \mu \mathrm{m} / \mathrm{sec}(20 \mathrm{~cm} / \mathrm{hr})$. WSS classified the soil as poorly drained and hydrologic soil group D. The Soil Conservation Service runoff curve number for the AOI soil was estimated to be about 60 based on information presented by Menberu et al. (2015).

The Arctic soil hydrology model was run with the above inputs and using the precipitation and air temperature data from Fairbanks International Airport for 2010-2017. Additionally, output from the Snow17 and GIPL models was used for the hydrology model application. Snow17 was run with the inputs described in section 3.5.3. The GIPL model was run with the inputs described in section 4.1. The soil hydrology model yielded an average annual soil water content of 0.24 or $24 \%$ for the seven years, which seems reasonable for a normal, partially saturated soil condition. However, as stated previously, these alluvium soils are nearly saturated most of the time due to the steady supply of water from Stuart creek. Thus, the decision was made to alter the soil hydrology model inputs to better represent this special case of nearly saturated soil. The field capacity was changed to $80 \%$, the residual water content was changed to $79 \%$, and saturation was assumed to be $82 \%$. A maximum soil layer thickness of $40 \mathrm{~cm}$ was used. These inputs resulted in nearly saturated soil with average annual values of $79 \%$ soil water content, 3.85 inches (0.0978 m) of 
total runoff (rain and snow melt), 3.56 inches (0.0904 m) of net infiltration, and 5.28 inches (0.134 m) of ET.

The inputs for soil erosion included the following: rainfall factor of 20 for Alaska from HGCT help menu, soil erodibility K factor of 0.37 based on $H G C T$ help menu for silt loam with high organic content, slope of $2 \%$ from WSS, crop management factor .07 from HGCT help menu using low brush with about $50 \%$ coverage, conservation practice factor of 1 , AOI surface area of 0.88 square miles based on AOI polygon area of impact area using Google Earth Pro ${ }^{\circledR}$, AOI water course length of $3.2 \mathrm{~km}$ measured from upstream to downstream extent of AOI as measured in Google Earth Pro ${ }^{\odot}$, AOI runoff surface roughness factor of 0.2, which is the default fault value, AOI ponding factor for more than $5 \%$ ponding coverage, rainfall distribution type I for AK, and soil loss type option without $S D R$, which means the sediment delivery ratio is not used to account for basin trapping of sediment. These inputs yielded an average annual soil loss due to erosion of 5.07E-5 m/yr (0.084 metric tons/acre/yr) from the MUSLE model in HGCT.

\subsubsection{Soil fate model inputs}

Using Google Earth Pro ${ }^{\odot}$, the AOI dimensions were set to 3,200 m, $525 \mathrm{~m}$, and 2,273,000 $\mathrm{m}^{2}$ for length, width, and surface area, respectively. The AAALT computed by the GIPL model post-processor was $0.4 \mathrm{~m}$. The maximum active soil layer thickness was set to $0.4 \mathrm{~m}$. The fraction of AOI surface area that is underlain by permafrost was set to 1.o. The average annual soil-water matrix temperature during thaw periods was computed to be $2{ }^{\circ} \mathrm{C}$ by the GIPL model postprocessor. The RDX residue mass loading was computed by the MC mass loading module to be $55.7 \mathrm{~kg} / \mathrm{yr}$ based on the firing inputs as described in Section 9.2.

Soil properties described above in Section 9.3.1 as used in the HGCT were auto-loaded into the soil fate model UI. The HGCT hydrology output files dailyoutput. out and hourlyRainfall. out and the GIPL model output file SoilLayerThickness. txt residing within the application folder SCIA were selected on the Hydrology screen of the soil fate model UI. The soil interflow option to compute interflow based on soil saturated hydraulic conductivity was selected, and a value of $1,734 \mathrm{~m} / \mathrm{yr}$ for saturated hydraulic conductivity was entered. This value is the WSS value of $55 \mu \mathrm{m} / \mathrm{sec}$ stated above after converting to $\mathrm{m} / \mathrm{yr}$. 
The parameters entered on the Fate/Transport Parameters screen of the soil fate model UI included the following. The soil-water partitioning coefficient for RDX was set $4.07 \mathrm{~L} / \mathrm{kg}$, which was estimated based on the RDX organic carbon distribution coefficient of $13.2 \mathrm{~L} / \mathrm{kg}$ and percentages of organic matter, sand, silt, and clay of $53,8,35$, and 4 , respectively, from section 9.2. The RDX degradation half-lives were set to large numbers (1.oE20 years) to represent no degradation. The initial average particle size of RDX residue was set to $1,000 \mu \mathrm{m}$ based on TREECS ${ }^{\mathrm{TM}}$ help menu information. The volatilization rate for RDX was computed by the UI to be $0.0587 \mathrm{~m} / \mathrm{yr}$. Default values were used for other parameters on this input screen.

RDX properties on the Chemical-Specific Properties screen of the soil fate model UI were auto-populated from the Army Range Constituent Database within TREECS ${ }^{\mathrm{TM}}$. The value for RDX solubility was computed by the soil fate model UI as $14.94 \mathrm{mg} / \mathrm{L}$ based on $2{ }^{\circ} \mathrm{C}$, which is the average annual soil-water matrix temperature during thaw season as computed by the GIPL model post-processor and passed to the soil fate model UI. The auto-time-stepping options was selected in the model UI.

\subsubsection{Vadose zone and aquifer model inputs}

The inputs for the vadose zone and aquifer models are not really important when there is continuous permafrost $\left(f_{P F}=1.0\right)$, since there is no percolation to vadose and aquifer. However, inputs were provided to allow evaluation of scenarios with discontinuous permafrost.

The vadose zone was assumed to be mostly mineral soils with $5 \%$ organic matter. The percentages of sand, silt, and clay were set to 15,75 , and 5 , respectively. The total porosity, field capacity, saturated hydraulic conductivity, and dry bulk density were determined by the vadose zone model UI as $46.3 \%, 27.5 \%, 17.28 \mathrm{~cm} /$ day, and $1.42 \mathrm{~g} / \mathrm{cm}^{3}$, respectively, based on setting the soil class texture to silty loam. The thickness of the vadose zone (depth to reach aquifer) was assumed to be $3 \mathrm{~m}$. The soilwater partitioning distribution coefficient was computed as $0.43 \mathrm{~mL} / \mathrm{g}$ by the UI. The solubility of RDX was set to $14.9 \mathrm{mg} / \mathrm{L}$, same as for the soil fate model. No degradation of RDX was assumed; thus, the RDX half-life was set to a very large number (1E20 days).

Silty loam texture was assumed for the aquifer with composition percentages of 20,65, 13, and 2 percent for sand, silt, clay, and organic 
matter, respectively. The UI computed values were used for total porosity and dry bulk density, or $46.3 \%$ and $1.42 \mathrm{~g} / \mathrm{cm}^{3}$, respectively. The effective porosity was assumed to be $42 \%$. The Darcy velocity was set to 1.73 $\mathrm{cm} /$ day based on a saturated hydraulic conductivity of $17.3 \mathrm{~cm} /$ day for silty loam and an assumed hydraulic gradient of $0.1 \mathrm{~m} / \mathrm{m}$, which accounts for the transition for the sloping hills surrounding the AOI. The aquifer was assumed to be $10 \mathrm{~m}$ thick. A hypothetical groundwater well was assumed to be located $1 \mathrm{~km}$ from the AOI and laying along the AOI groundwater plume centerline. Dispersivity values were estimated using a utility built within the aquifer model UI. The same values used in the vadose zone model for RDX solubility and half-life were used for the aquifer model. The value for the RDX soil-water partitioning coefficient computed by the aquifer model UI was $0.22 \mathrm{~mL} / \mathrm{g}$.

\subsubsection{Soil interflow fate/transport model inputs}

As stated previously, the MEPAS aquifer model was used to simulate the fate and transport of soil interflow contaminants, thus, its inputs are similar to those of the aquifer model discussed in section 9.3.3. The soil class texture and composition were set to the same values as for the soil fate model (i.e., silty loam with composition of 8, 35, 4, and 53 percent for sand, silt, clay, and organic matter, respectively). The total porosity was set to $85 \%$, same as for the soil fate model. The effective porosity was assumed to be the same as saturation, or $82 \%$.

The Darcy velocity was set to $977 \mathrm{~m} / \mathrm{yr}$, which was computed by dividing the average annual soil interflow water flow rate $Q_{i f}$ of 205,100 m3/yr by the interflow cross-sectional flow area of $210 \mathrm{~m}^{2}$. The value of $Q_{i f}$ is approximately equal to the average annual net infiltration flow rate since there is no percolation due to continuous permafrost. The average annual net infiltration flow rate is the product of the average annual net infiltration rate of $0.0904 \mathrm{~m} / \mathrm{yr}$ times the AOI surface area of $2.27 \mathrm{E} 6 \mathrm{~m}^{2}$. The interflow cross-sectional flow area is the product of the interflow thickness of $0.4 \mathrm{~m}$ and the AOI width of $525 \mathrm{~m}$. The interflow thickness is assumed to equal the AAALT, which is computed by the GIPL model postprocessor and displayed in the Arctic soil fate model UI.

The aquifer thickness was set to $0.4 \mathrm{~m}$, which is the interflow thickness and the AAALT. The dry bulk density was set to $1.0 \mathrm{~g} / \mathrm{cm}^{3}$ rather than 0.37 $\mathrm{g} / \mathrm{cm}^{3}$ as used in the soil fate model since the MEPAS aquifer model UI will not accept a value less than 1.0. 
The flux usage location distance is the longitudinal distance along the groundwater flow path from the AOI to the receiving surface water where soil interflow would be expected to resurface. This distance was set to 500 $\mathrm{m}$, which is the approximate distance from the center of the AOI to the middle of Stuart Creek as determined from Google Earth Pro ${ }^{\odot}$. The dispersivity values were estimated using the UI utility.

The soil-water partitioning distribution coefficient for RDX was set to $4.07 \mathrm{~mL} / \mathrm{g}$, same as for the soil fate model. Likewise as for the soil fate model, the RDX solubility and half-life were set to $14.94 \mathrm{mg} / \mathrm{L}$ and 1E2O days, respectively.

\subsubsection{Plus Operator model inputs}

The Plus Operator is designed to combine multiple time series of water and mass fluxes that have different time scales into a single time series of mass fluxes for consumption by a downstream module. In this case, the Plus Operator combines TV fluxes associated with surface runoff and erosion with AA fluxes associated with soil interflow producing an output file of TV fluxes that are used by the CMS surface water model for streams.

There is only one input for the Plus Operator, which is the groundwater flow to surface water. In this case, the groundwater flow is the water flow rate existing the aquifer model which represents soil interflow water discharge rate into surface water. This flow rate can be found by right clicking the Plus Operator object, and clicking View/Print module Output/WFF Text View. This will bring up the text view of the WFF file. The water flow rate from groundwater to surface water can be found near the top of the file in the line under the line starting with " $\mathrm{yr}^{\prime}, \mathrm{m}^{\wedge} 3 / \mathrm{yr}^{\prime}$. The first number is for time, which is 0 , followed by a comma, which is then followed by the flow rate 304,500 . Thus, this input was set to $304,500 \mathrm{~m} 3 / \mathrm{yr}$, which assumes all of the soil interflow discharges into surface water. This assumption is not required if the user has better information.

\subsubsection{CMS surface water model inputs}

The number of computational nodes was set to 20, the time step was set to 0.2 day, and the simulation time was set to seven years. Typical default values were set for most of the input parameters. The stream dispersion was set to $1 \mathrm{~m}^{2} / \mathrm{sec}$. The total suspended solids concentration was assumed 
to be $20 \mathrm{mg} / \mathrm{L}$. The active sediment layer depth was set to $0.2 \mathrm{~m}$. The dry sediment bulk density was set to $1.0 \mathrm{~kg} / \mathrm{L}$, and the sediment porosity was set to 0.9. The fraction of organic carbon in suspended solids and benthic solids was assumed to be 0.02 and 0.05 , respectively. The temperature was set to $1^{\circ} \mathrm{C}$, and the wind speed was set to $5 \mathrm{~m} / \mathrm{sec}$.

The stream usage location was assumed to be the confluence of Stuart Creek with South Fork Chena River. The distance from Stuart Creek at the AOI to the confluence was estimated in Google Earth Pro ${ }^{\odot}$ to be about $6200 \mathrm{~m}$ along the stream path. The width and depth of the model stream (Stuart Creek) were assumed, respectively, to be 5 and $0.2 \mathrm{~m}$. The stream background flow rate, where the AOI water flow and mass fluxes enter, was set to $0.365 \mathrm{~m}^{3} / \mathrm{sec}$, which is an estimate based on the average annual runoff depth of $0.0978 \mathrm{~m}$ (3.85 inches) multiplied by the Stuart Creek watershed area of $54 \mathrm{~km}^{2}\left(5.4 \mathrm{E} 7 \mathrm{~m}^{2}\right)$ as estimated using Google Earth Pro ${ }^{\odot}$, and then distributed over a five-month flow season rather than 12 months. With this flow rate and stream dimensions, the stream velocity is $0.365 \mathrm{~m} / \mathrm{sec}(1.2 \mathrm{ft} / \mathrm{sec})$. It is noted that this stream velocity is associated with background flow in the thaw season. The runoff flow from the AOI during snow melt and rainfall events is an additional water flow imposed on the stream that includes RDX mass fluxes from the AOI.

The sediment-water partitioning distribution coefficients, the volatilization rate, and the sediment pore-water - water column mass transfer velocity were computed by utilities built within the CMS UI. Zero sediment burial rate was assumed, the suspended solids settling rate was set to $0.2 \mathrm{~m} /$ day, and the resuspension rate was computed to be $4 \mathrm{E}-5$ $\mathrm{m}$ /day based on benthic sediment equilibrium.

\subsection{Model results for base case scenario}

The base case scenario consists of the input conditions described in the previous section 9.3. These conditions can best and most simply be described as SCIA with continuous permafrost. Such conditions result in no RDX transmission to the groundwater, rather all RDX mass flux from the AOI is transferred to surface water.

The base conditions were run with one minor change, which was to set the initial soil RDX concentrations to a value greater than zero. An initial base condition run was made with zero initial RDX concentrations in the AOI soils. This run showed that it takes several years for RDX concentrations 
to build up enough in AOI soils to cause noticeable mass fluxes to surface water. Thus, the computed AOI soil RDX concentrations after seven years for the initial run were used to set the initial RDX concentrations for the following base case run (referred to as scenario 1 or SCIA 1 in terms of file names). Scenario 2 is discussed in section 9.5. The initial soil concentrations of RDX were $1.157 \mathrm{mg} / \mathrm{kg}$ of solid-phase RDX and 0.003 $\mathrm{mg} / \mathrm{kg}$ of non-solid-phase RDX. Non-solid-phase refers to the RDX mass that has been dissolved by water and can partition as dissolved in porewater, adsorbed to soil particles, and vapor within soil air. This slightly revised base case is more representative of what would be expected when a site has been in use for some time.

The initial stream sediment concentration of RDX was set to $2.6 \mathrm{E}-4 \mathrm{mg} / \mathrm{kg}$ in the CMS for the base case; this concentration was the final stream sediment concentration of RDX computed by CMS after seven years for the initial base case run. Base case results, in terms of computed concentrations and mass fluxes, are discussed below for each media except vadose zone and groundwater since there were no fluxes to these media due to continuous permafrost.

\subsubsection{Soil AOI concentrations and fluxes}

Computed total and dissolved (in soil pore-water) RDX concentrations in AOI soil are plotted vs. year in Figure 30 and Figure 31, respectively. Total RDX concentration includes solid-phase RDX and RDX that has dissolved and adsorbed to soil particles, where the concentration of the former is about 100 times greater than the latter. Solid-phase RDX concentration increases linearly with time due to imposing constant munitions firing rates. Thus, with solid-phase RDX concentration being much larger than dissolved and adsorbed RDX concentration, total concentration of RDX increases linearly with time. The pore-water dissolved RDX concentration increases with time, but exhibits seasonal variability associated with freeze-thaw conditions and the associated effects on surface soil hydrology. There are two interesting dips in dissolved RDX concentration early in the 2014 thaw season and late in the 2015 thaw season. Rainfall rate, which causes dissolution but also causes flushing and/or dilution of dissolved RDX in soil pore water, was much higher than usual during the early 2014 thaw season, while rainfall was higher during the late 2015 thaw season compared with early 2015 thaw season (Figure 32). Also, cumulative rainfall (Figure 33) was greater during 2014 and 2015 
compared with the previous years. These rainfall conditions could explain the rapid flushing and/or dilution of soil pore-water concentrations.

Water that enters the surface soil is either lost to ET or soil interflow for the base case. The average annual precipitation water depth transferred via soil interflow was nearly the same as that transferred via runoff (3.56 versus 3.85 inches, respectively).

Computed mass fluxes of adsorbed and dissolved RDX from AOI soil to surface water are plotted vs. year in Figure 34 and Figure 35, respectively. Adsorbed RDX flux is associated with soil erosion. Dissolved RDX flux is associated with rainfall impact with pore-water extrusion that is exported in rainfall runoff. These plots show that export from surface soil associated with erosion and runoff is sporadic and occurs during substantial summer rainfall events. It can also be observed that export flux due to rainfall runoff is about 100 times greater than that associated with erosion for this site.

Computed mass fluxes of RDX from AOI soil to soil interflow are plotted vs. year in Figure 36. These fluxes are dissolved since only dissolved constituents can move through the soil pore-water medium in the model. This plot shows that interflow flux occurs fairly consistently every summer. The interflow fluxes are the same order of magnitude as the runoff fluxes, but they occur more often since infiltrating water has no place to go except to interflow due to the continuous permafrost. The cumulative mass of RDX transferred from the AOI to soil interflow for the seven years was 2,047 $\mathrm{g}$ compared with $893 \mathrm{~g}$ transferred to surface water via erosion and runoff. Although the amount of water transferred from the AOI to surface water via runoff was about the same as that transferred via soil interflow, about 2.3 times more RDX mass is transferred by interflow than by runoff. 
Figure 30. Computed RDX total concentration vs. year in AOI soil, base case (SCIA1) (continuous permafrost).

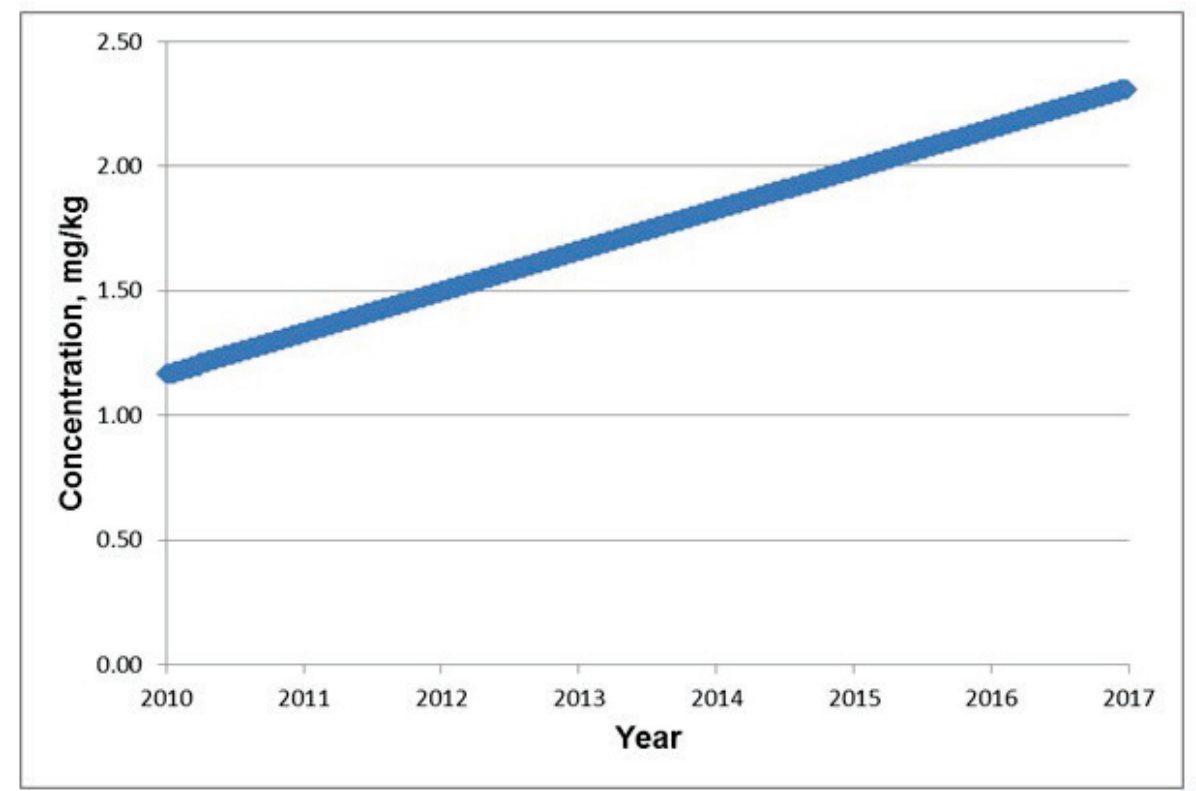

Figure 31. Computed RDX pore-water dissolved concentration vs. year in AOI soil, base case (SCIA1) (continuous permafrost).

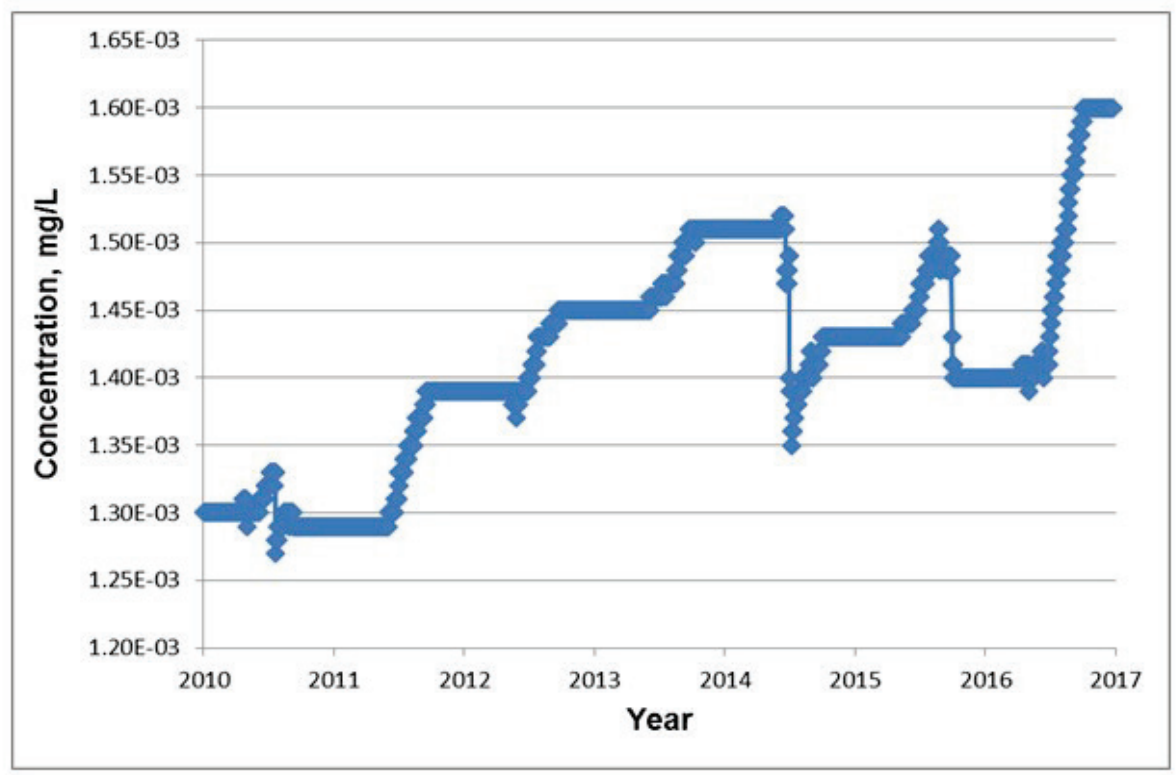


Figure 32. Rainfall rate vs. year, Fairbanks International Airport, AK.

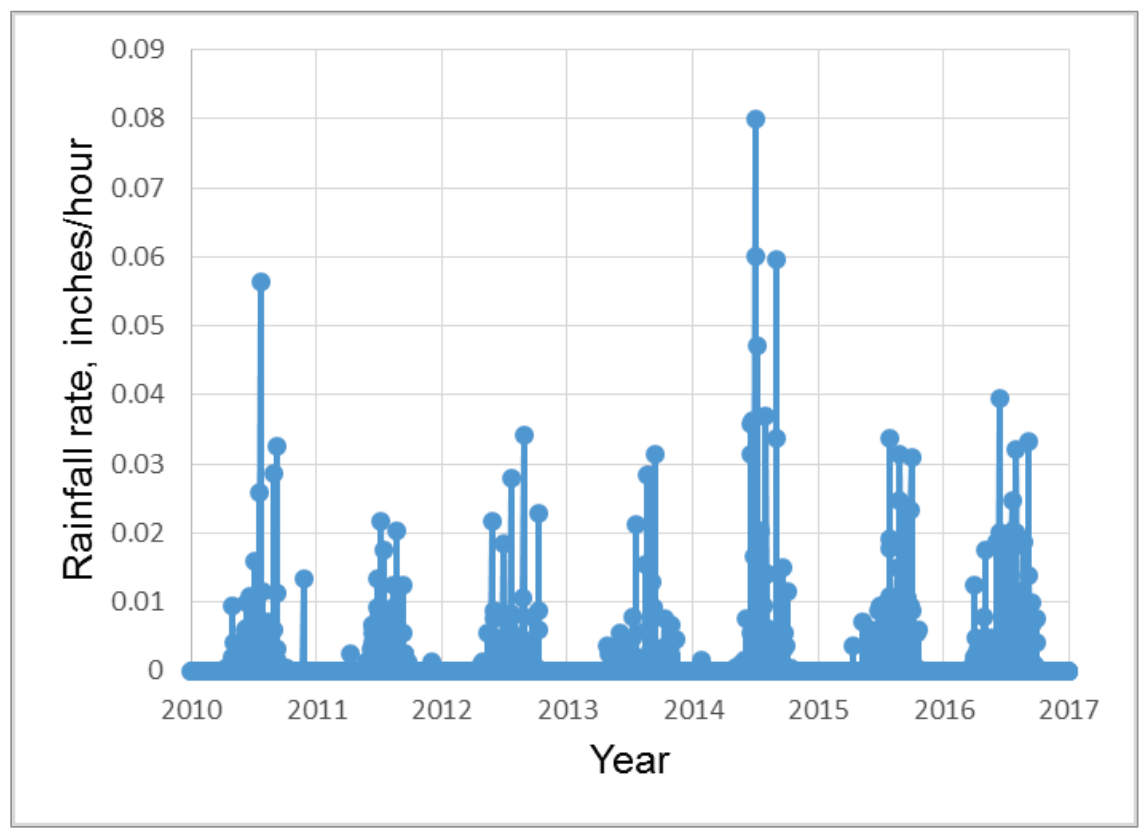

Figure 33. Cumulative rainfall vs. year, Fairbanks International Airport, AK.

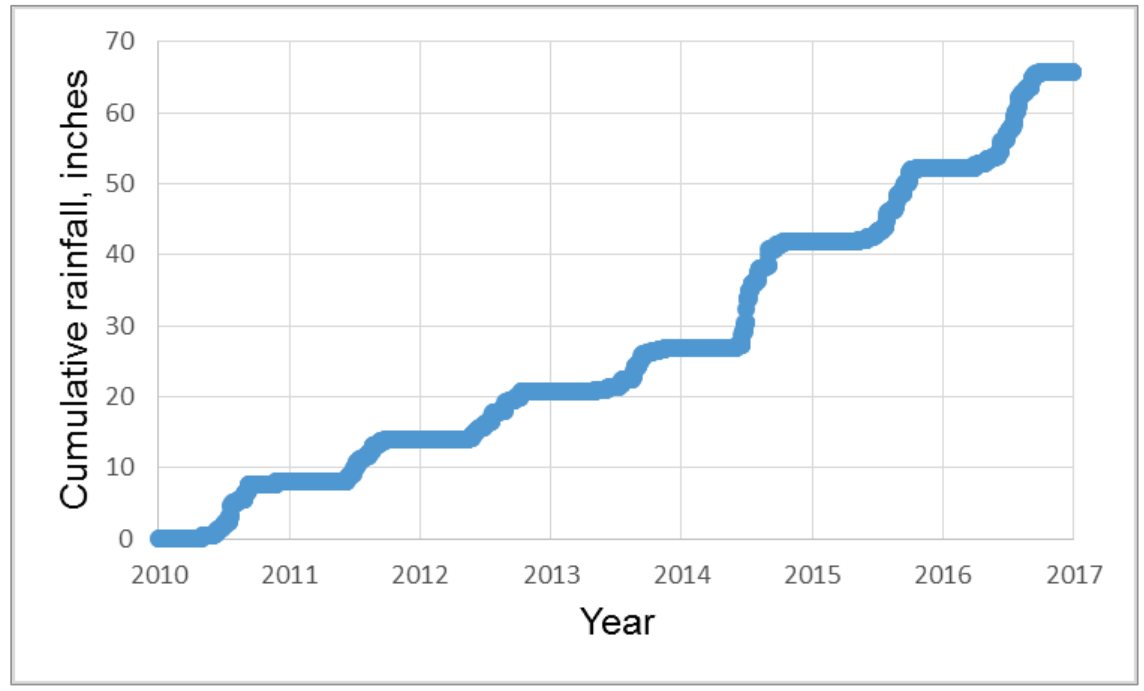


Figure 34. Computed RDX adsorbed mass flux from AOI soil to surface water (due to soil erosion) vs. year, base case (SCIA1) (continuous permafrost).

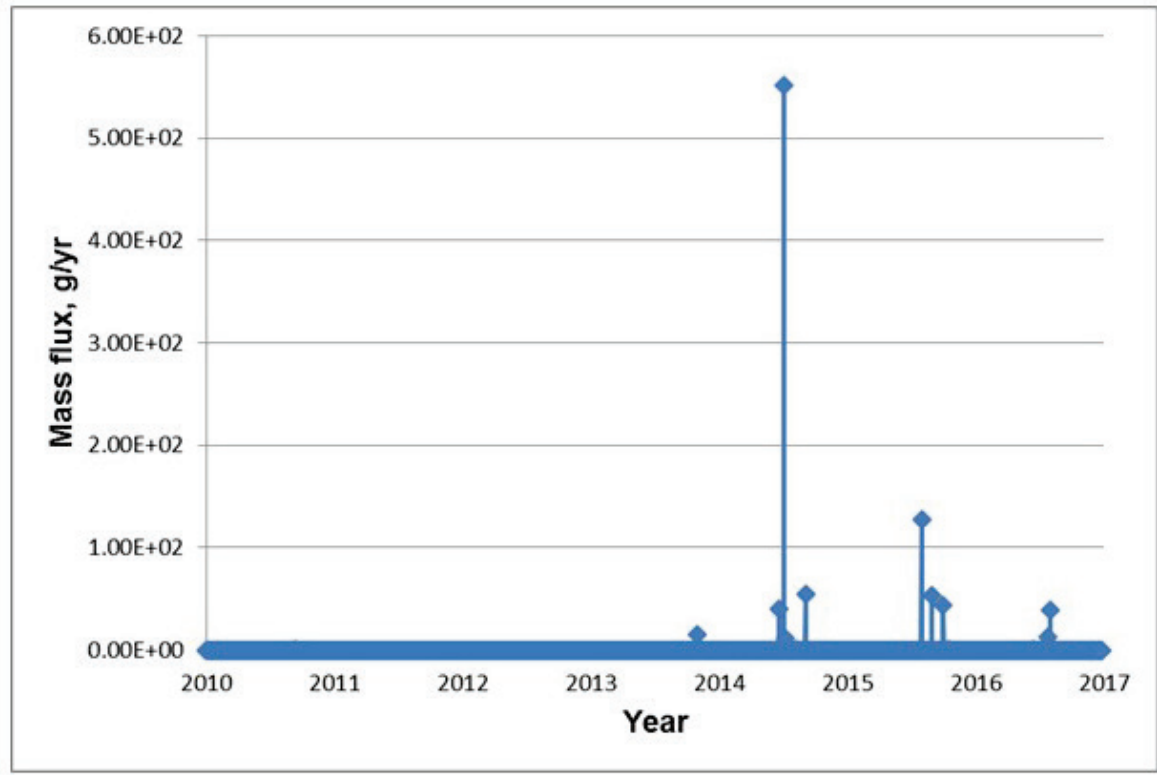

Figure 35. Computed RDX dissolved mass flux from AOI soil to surface water (due to rainfall impact and runoff) vs. year, base case (SCIA1) (continuous permafrost).

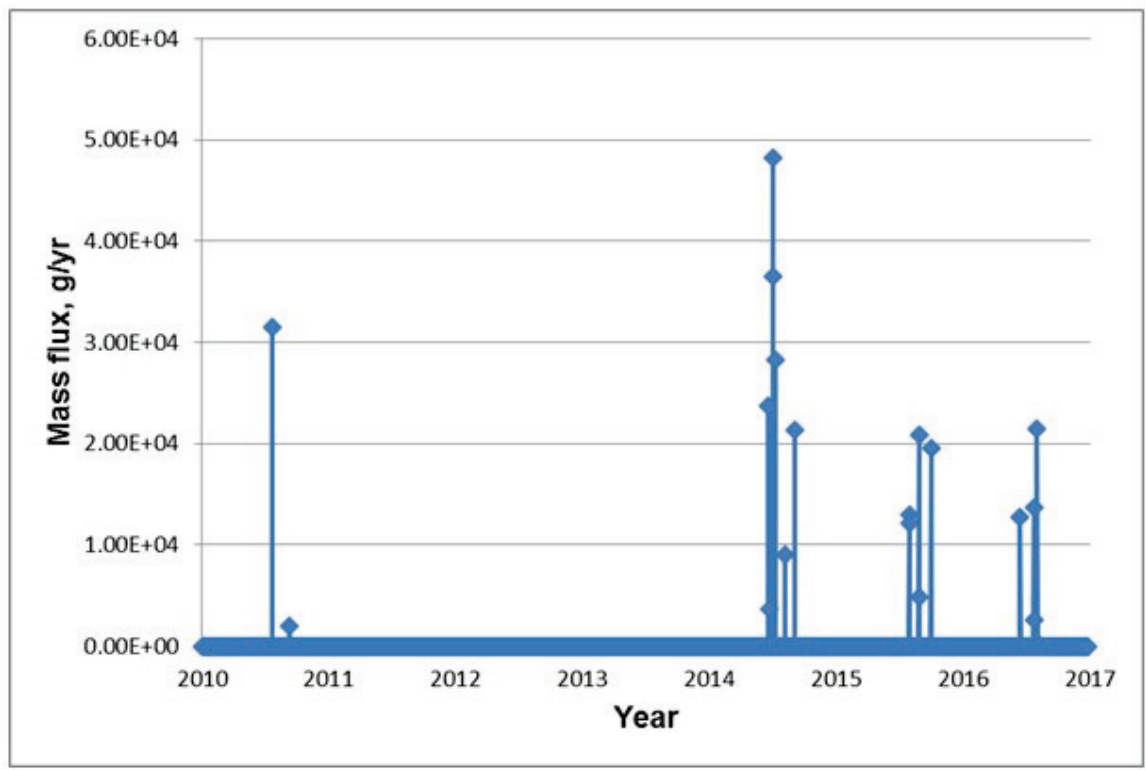


Figure 36. Computed RDX dissolved mass flux from AOI soil to soil interflow vs. year, base case (SCIA1) (continuous permafrost).

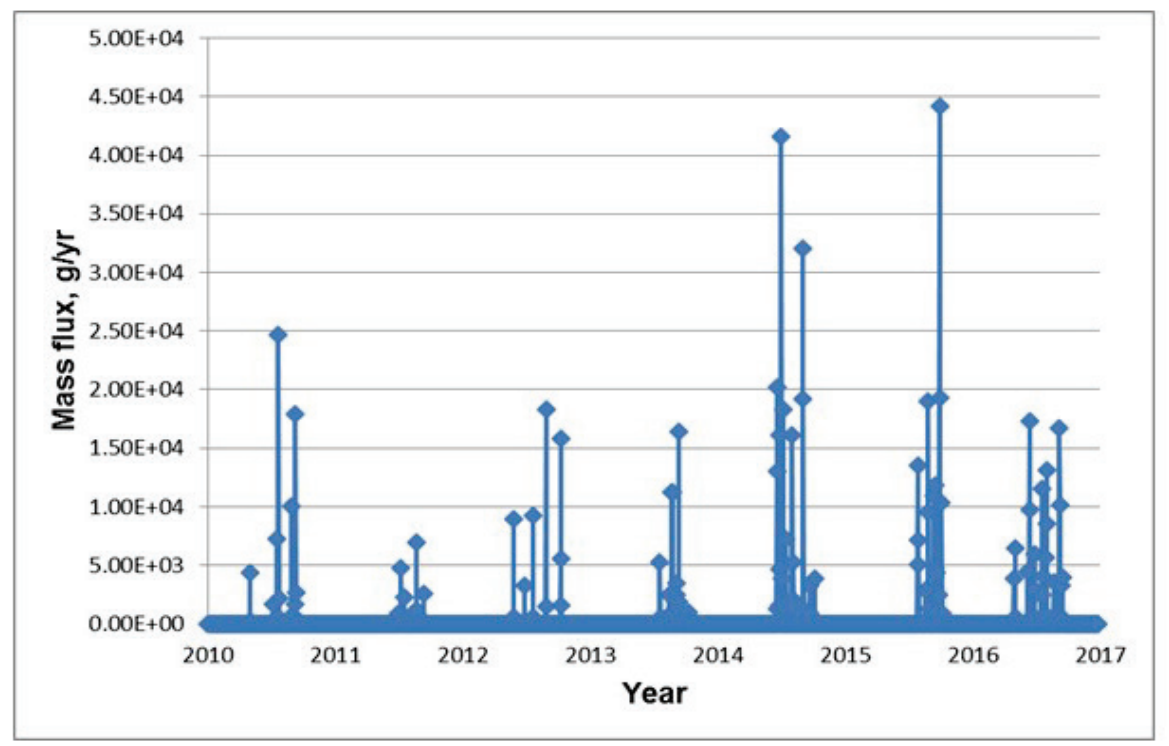

\subsubsection{Soil interflow mass fluxes to surface water}

The mass fluxes shown in Figure 36 are inputs to the soil interflow fate/transport model, which is the MEPAS aquifer model with the inputs described in section 9.3.4. These fluxes move through surface soil until exiting at the surface water stream, which is Stuart Creek. As explained previously, the aquifer model uses average annual water flow rates. Following dilution with background Darcy flow, as well as adsorption and dispersion, the resulting RDX mass fluxes exiting from soil interflow to surface water are shown in Figure 37. These fluxes are the same order of magnitude as the erosion fluxes and about 100 times less than the AOI runoff fluxes and the AOI fluxes to soil interflow due to attenuation associated with sorption and dilution. However, the interflow fluxes to surface water are much more continuous. There are up and down flux trends before 2018, but fluxes peak and decrease continually after that. This is due to the fact that AOI loadings, as well as computed fluxes from the AOI, cease at the end of 2016. Soil interflow attenuation causes the delay in the peak exit flux until 2018 followed by the gradual drop due to cessation of input fluxes. A more realistic portrayal of declining interflow exit fluxes could have been rendered by running the soil model longer (such as to 2024) with range firings ending after 2016. Also, fluxes are computed continually over time by the aquifer model without any regard to freeze/thaw periods. In reality, soil interflow fluxes should occur only during thaw season. To capture this aspect, a more comprehensive groundwater model would be required in which flow conditions vary daily. 
Figure 37. Computed RDX dissolved mass flux from soil interflow to surface water vs. year, base case (SCIA1) (continuous permafrost).

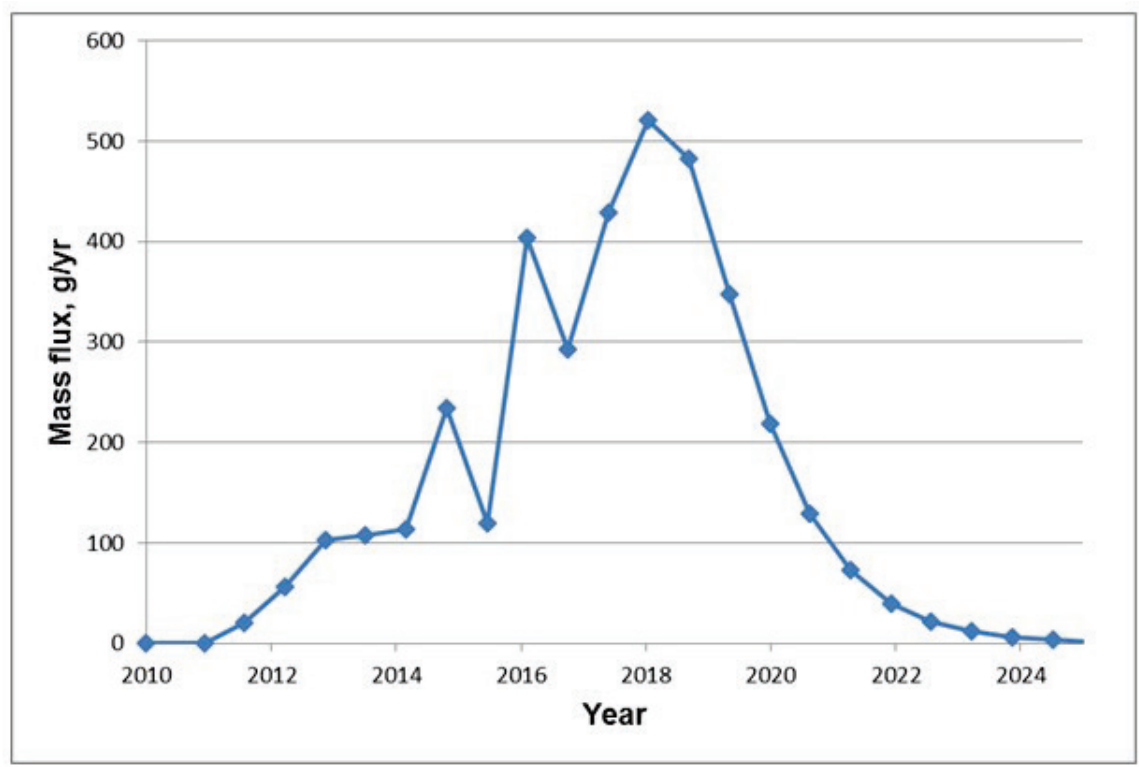

\subsubsection{Combined mass fluxes to surface water}

The computed, combined, total (adsorbed and dissolved) mass flux of RDX to surface water vs. time, as provided by the Plus Operator, is plotted in Figure 38. The vertical axis in Figure 38 is converted to $\log 10$ so that both large and small values can be easily seen in the same plot. Figure 38 shows the mass fluxes delivered to surface water associated with AOI soil erosion, runoff, and soil interflow following fate/transport. Fluxes associated with soil erosion and runoff are transferred directly to surface water without any fate/transport processes. The combined fluxes exhibit a continuous and gradual increase and decrease due to soil interflow with infrequent spikes associated with runoff events, which are the same as those shown in Figure 35.

In reality, the plot in Figure 38 should exhibit dips to zero flux during periods when the ground is frozen. However, as explained in the previous section and prior sections to that, the MEPAS aquifer model uses average annual water flow rates for AOI recharge and background Darcy flow. A more comprehensive, variable flow model is required to capture freeze/thaw flow conditions. 
Figure 38. Computed, combined, total (adsorbed and dissolved) RDX mass flux to surface water (from Plus Operator output) vs. year, base case or SCIA1 (continuous permafrost).

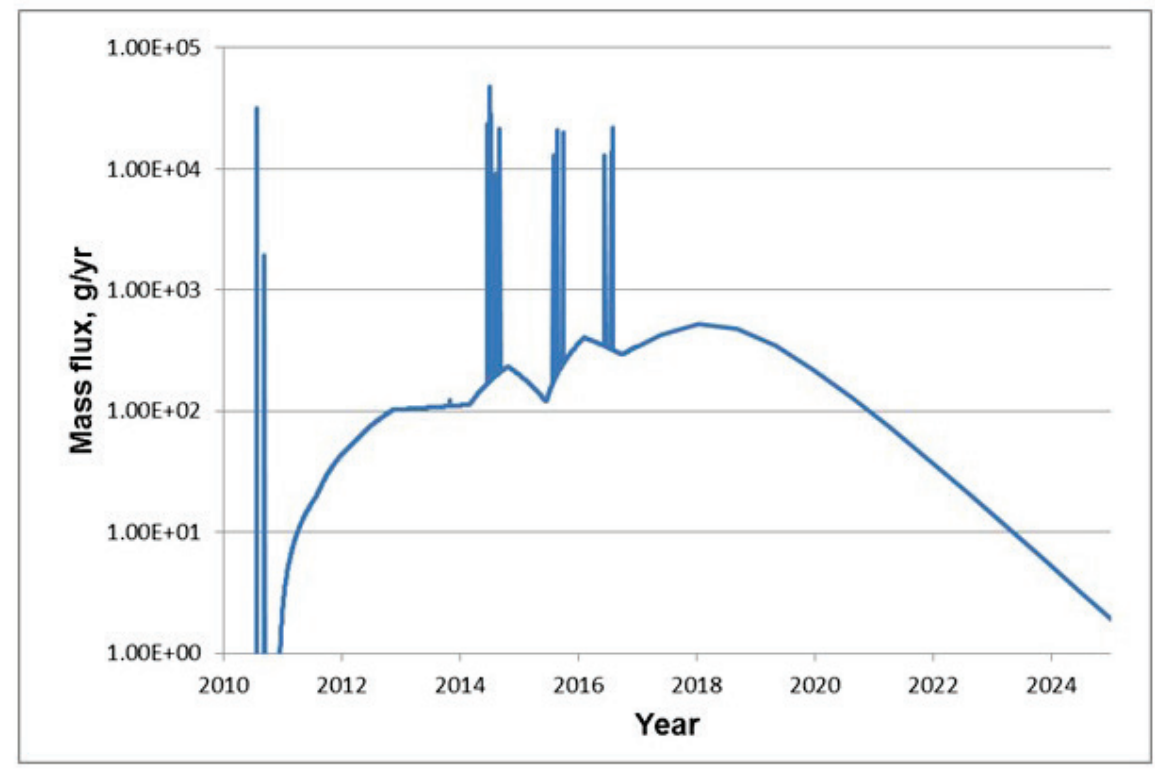

\subsubsection{Surface water and sediment concentrations}

Although the CMS can handle time-varying water flow rates, a constant background water flow velocity of $0.365 \mathrm{~m} / \mathrm{sec}$ is imposed as explained in section 9.3.6 to account for other drainage into Stuart Creek from the surrounding watershed, including additional drainage from the AOI. One of the limitations of the CMS is that the background water flow rate is constant. In reality, background water flow should be zero when frozen conditions exist. Thus, two runs were made with the CMS, one with a background flow of $0.365 \mathrm{~m} / \mathrm{sec}$, and one with essentially zero background flow (a very small flow of $0.0001 \mathrm{~m} / \mathrm{sec}$ ).

Results with a background flow are shown first. RDX total (adsorbed and dissolved) sediment concentrations in Stuart Creek at the confluence with South Fork Chena River are plotted vs. year in Figure 39. Most of the time, the sediment concentrations are very small except during major rainfall runoff events. RDX partitions weakly to sediments resulting in depletion of sediment concentrations due to stream flushing following loading spikes. Sediment dissolved pore-water concentrations are an order of magnitude lower than particulate (adsorbed) concentrations. 
Figure 39. Computed total RDX concentration in sediment vs. year in Stuart Creek at the confluence with South Fork Chena River, base case

(SCIA1) (continuous permafrost) with background flow.

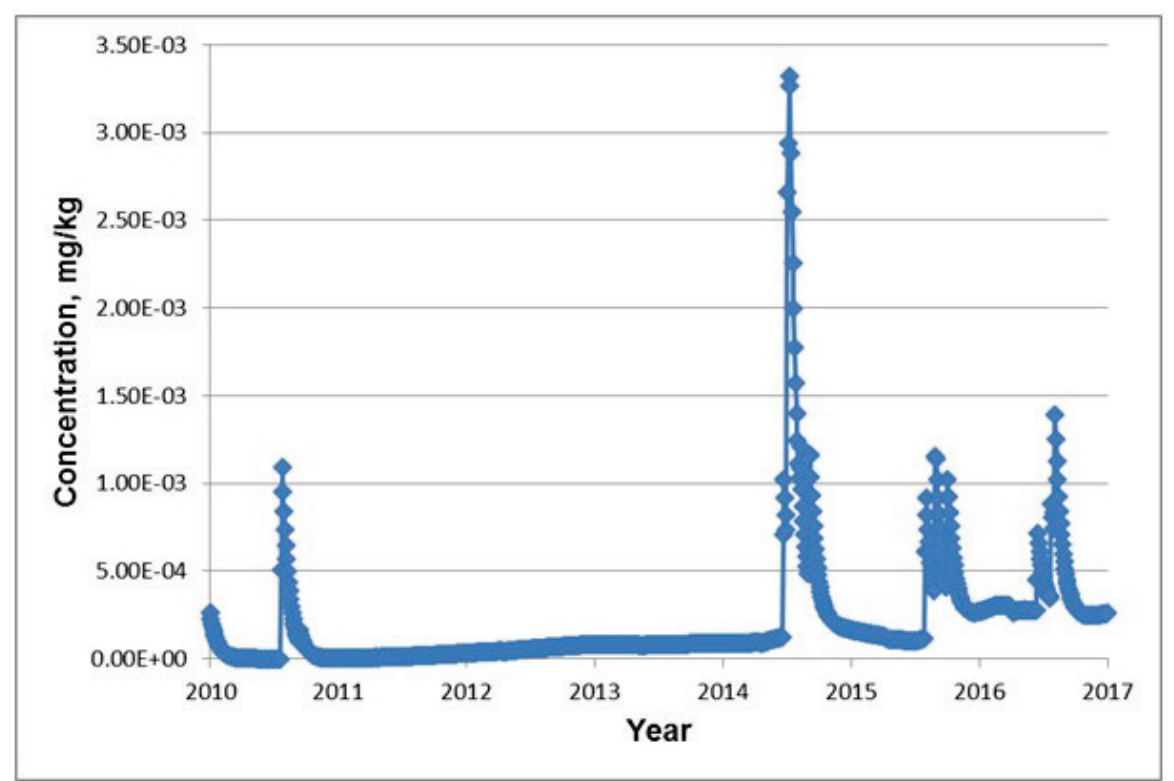

RDX total (adsorbed and dissolved) water column concentrations in Stuart Creek at the confluence with South Fork Chena River are plotted vs. year in Figure 40. The total concentrations are approximately the same as the dissolved concentrations for the water column due to low TSS concentrations and weak partitioning of RDX to TSS. Water concentrations are essentially zero, except during major runoff events. 
Figure 40. Computed total RDX concentration in water column vs. year in Stuart Creek at the confluence with South Fork Chena River, base case (SCIA1) (continuous permafrost) with background flow.

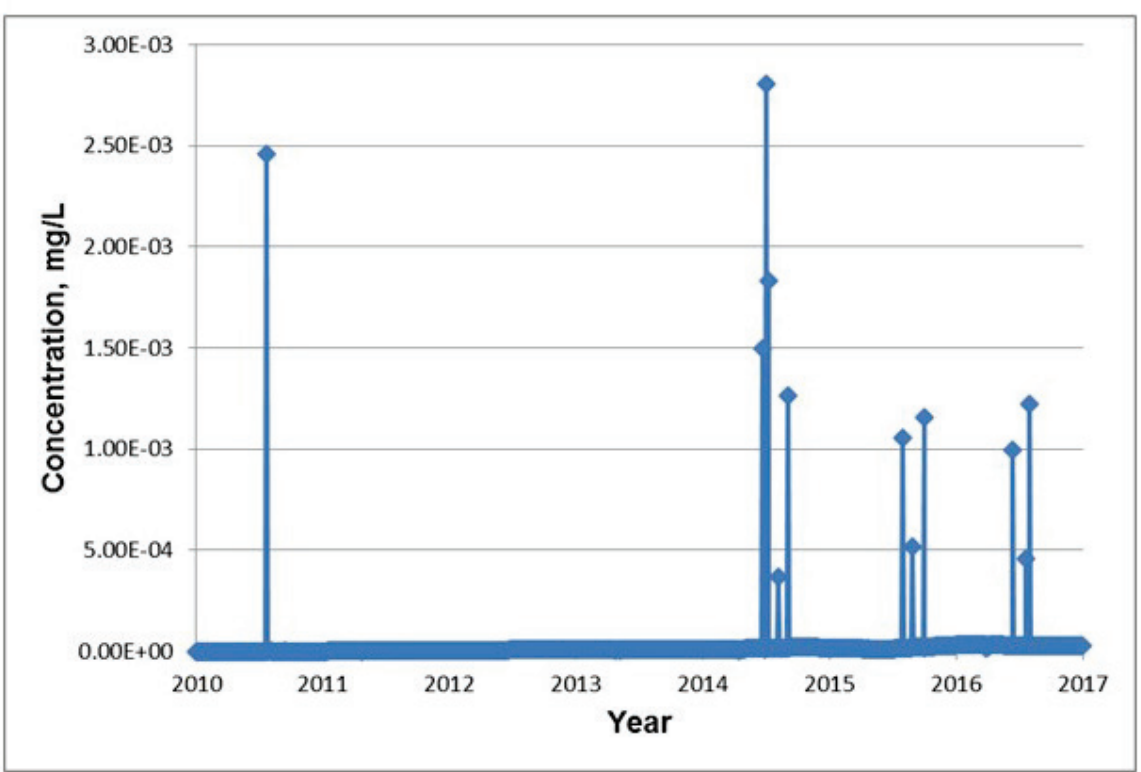

RDX total sediment concentrations in Stuart Creek at the confluence with South Fork Chena River are plotted vs. year in Figure 41 for conditions without background flow. These results resemble those of Figure 39 (with background flow), except that the concentrations are higher due to less dilution without the background flow. The most reasonable result should be between those of Figure 39 and Figure 41, with lower concentrations in thaw season due to presence of background flow (Figure 39), and higher concentrations in frozen season with absence of background flow (Figure 41).

RDX total water column concentrations in Stuart Creek at the confluence with South Fork Chena River are plotted vs. year in Figure 42 for conditions without background flow. These results show similarity to those with background flow of Figure 40, except that concentrations are greater without background flow due to the absence of flow dilution. Also, the relative peak concentrations are changed, some due to the effects of background flow. Concentrations are two orders of magnitude lower for frozen season compared with thaw season without background flow. 
Figure 41. Computed total RDX concentration in sediment vs. year in Stuart Creek at the confluence with South Fork Chena River, base case (SCIA1) (continuous permafrost) without background flow.

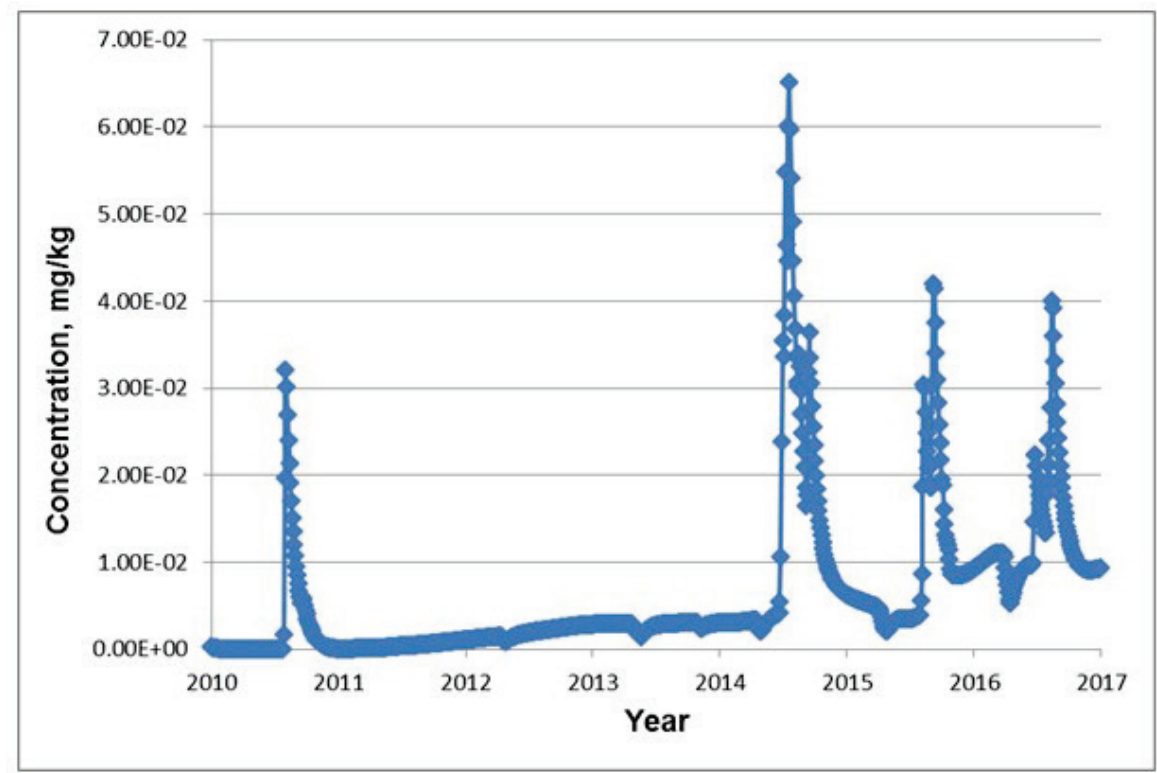

Figure 42. Computed total RDX concentration in water column vs. year in Stuart Creek at the confluence with South Fork Chena River, base case (SCIA1) (continuous permafrost) without background flow.

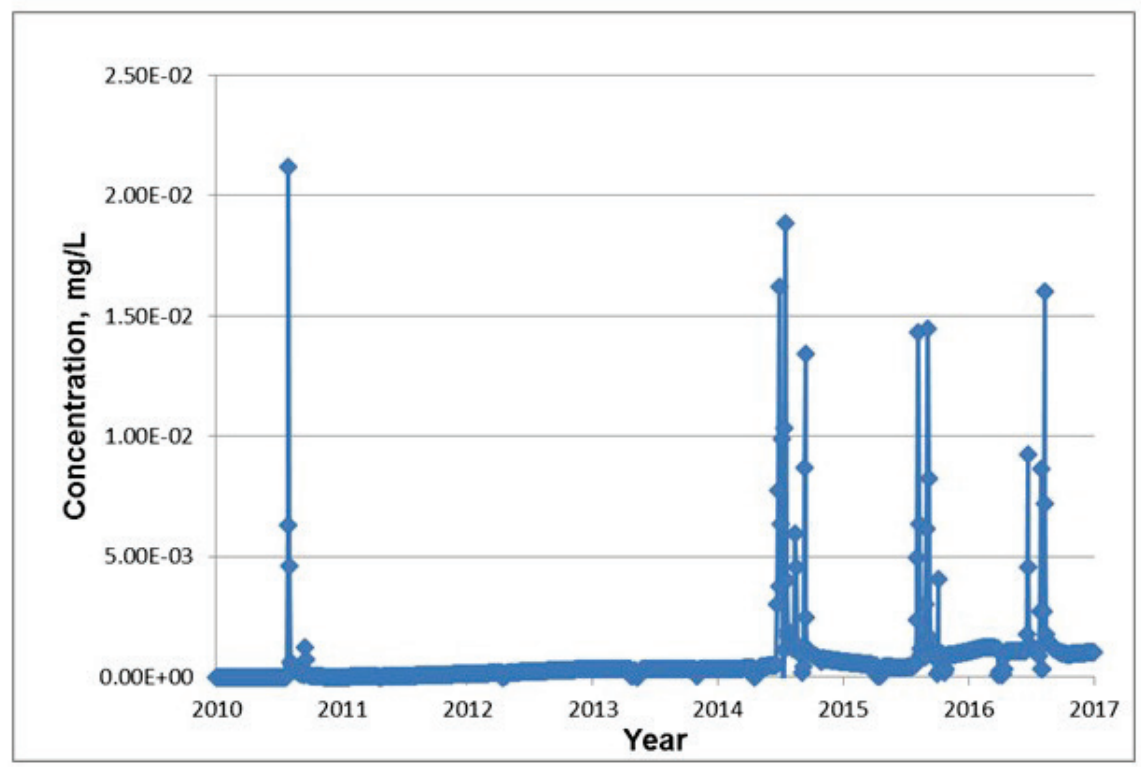

As for the sediments, the most appropriate results for the water column could be a mix of results from Figure 40 and Figure 42 (i.e., lower concentration in thaw season due to background flow, and higher concentrations in frozen season without background flow). The water 
column is frozen during the frozen season, thus making results during that season somewhat irrelevant.

\subsection{Model results for scenario 2}

Scenario 2 consists of the same conditions as the base scenario, including the same initial soil and sediment RDX concentrations, with the exception that the fraction of AOI underlain by permafrost was changed from 1.0 to o.o (i.e., no permafrost). Thus, water and RDX mass can move vertically into the vadose zone and groundwater with less transferred to surface water as occurs with permafrost. With more water moving to groundwater, the average annual flow rate to soil interflow $Q_{i f}$ was $52,533 \mathrm{~m} 3 / \mathrm{yr}$, which is considerably less than the flow of $205,100 \mathrm{~m}^{3} / \mathrm{yr}$ for the base case with continuous permafrost. Using the flow of $52,533 \mathrm{~m}^{3} / \mathrm{yr}$ and the interflow cross section of $524 \mathrm{~m}$ by $0.4 \mathrm{~m}$, the Darcy velocity was computed to be $250 \mathrm{~m} / \mathrm{yr}$, which was the value set in the aquifer model for soil interflow. With these flows, the exit water flow rate to surface water from interflow was computed by the interflow aquifer model to be $67,260 \mathrm{~m} 3 / \mathrm{yr}$, which was set in the Plus Operator module input.

The WFF output file revealed that the average annual water flow rate for percolation through the soil to the vadose zone was $152,800 \mathrm{~m} 3 / \mathrm{yr}$.

Subtracting this value from the average annual net infiltration flow to soil of $205,479 \mathrm{~m}^{3} / \mathrm{yr}$ leaves $52,679 \mathrm{~m} 3 / \mathrm{yr}$ available for interflow $Q_{i f}$, which compares closely to the value of $52,533 \mathrm{~m}^{3} / \mathrm{yr}$ as provided in the WFF output for the soil interflow converter module.

\subsubsection{Soil AOI concentrations and fluxes}

The AOI soil concentrations of RDX were practically identical to those shown in Figure 30 and Figure 31, so those plots are not repeated for scenario 2. Additionally, the AOI soil fluxes to surface water via erosion and rainfall runoff were also practically identical to those shown in Figure 34 and Figure 35, respectively, so those plots are not repeated for scenario 2. The AOI soil fluxes to soil interflow were quite different from those shown in Figure 36, so these fluxes for scenario 2 are plotted in Figure 43. Although the order of magnitude of the fluxes to interflow are about the same for the base case and scenario 2, there are far fewer instances of interflow flux for scenario 2 due to water being transferred to the vadose zone rather than soil interflow. The cumulative RDX mass transferred from the AOI by runoff was the same as with the base case ( $893 \mathrm{~g}$ ), but the 
cumulative RDX mass transferred from the AOI by soil interflow was a factor of 4.35 lower, or $471 \mathrm{~g}$, which is about half of that transferred by runoff. The remaining cumulative mass transferred from the AOI was 1576 $\mathrm{g}$, which was transferred by percolation to groundwater. The AOI soil fluxes to the vadose zone are plotted vs. year in Figure 44. This plot illustrates that mass flux that went to interflow for the base case is now diverted to the vadose zone for scenario 2 .

Figure 43. Computed RDX dissolved mass flux from AOI soil to soil interflow vs. year for scenario 2 (SCIA2) (no permafrost).

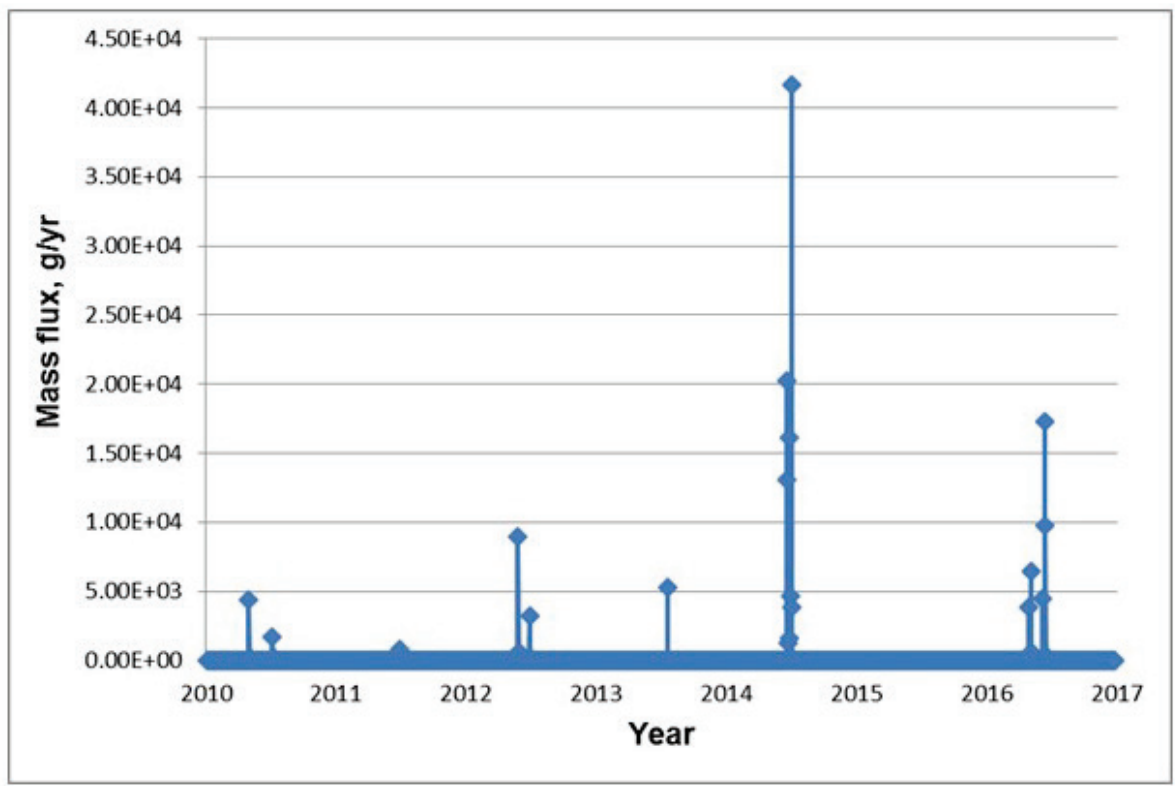

\subsubsection{Vadose zone fluxes and aquifer concentrations}

For scenario 2, water and RDX mass fluxes are able to percolate from AOI soil to groundwater. The computed RDX mass fluxes through the vadose zone and entering the aquifer are plotted vs. year in Figure 45. These fluxes continuously increase and decrease due to the constant percolating water flow rate constraint of the model. The constant flow also causes the magnitude of the pulsating fluxes entering the vadose zone to be greatly dampened after passing through the vadose zone. The retardation of transport through the vadose zone is evident by the delay of about 20 years to reach peak mass flux. The flux decreases after reaching the peak due to the cessation of RDX mass loading into the AOI and cessation of the soil fate model output after seven years. 
Figure 44. Computed RDX dissolved mass flux from AOI soil to vadose zone vs. year, scenario 2 (SCIA2) (no permafrost).

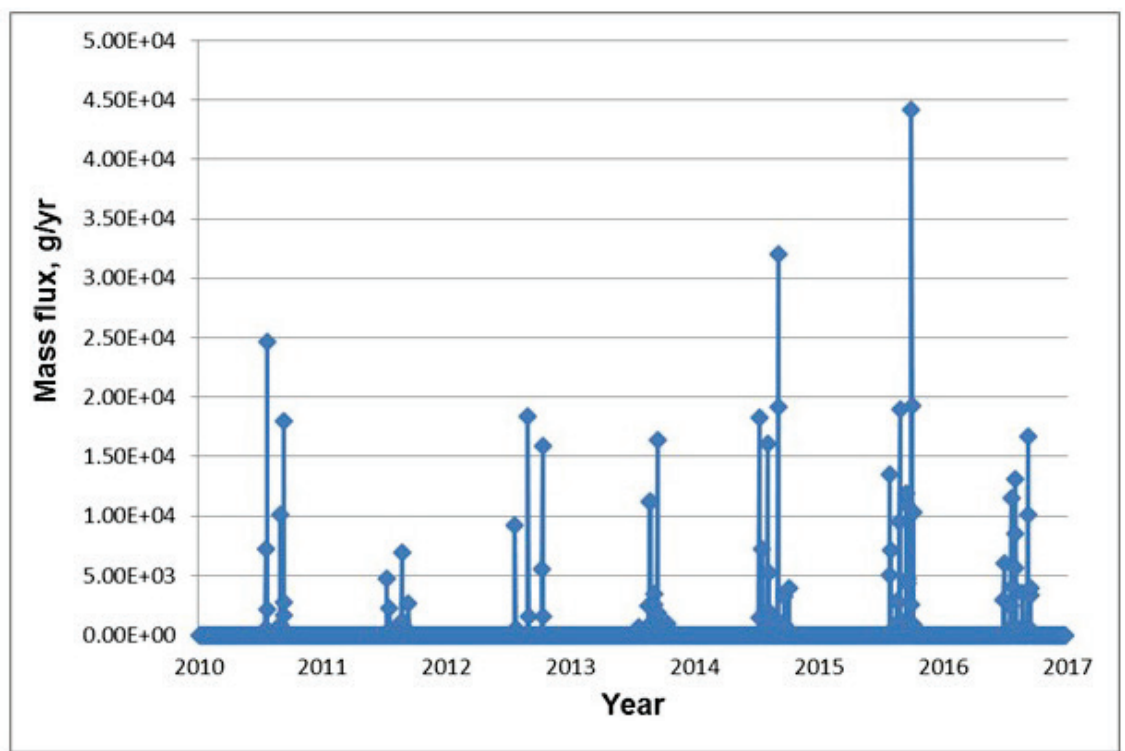

Figure 45. Computed RDX dissolved mass flux through the vadose zone and entering the aquifer vs. year, scenario 2 (SCIA2) (no permafrost).

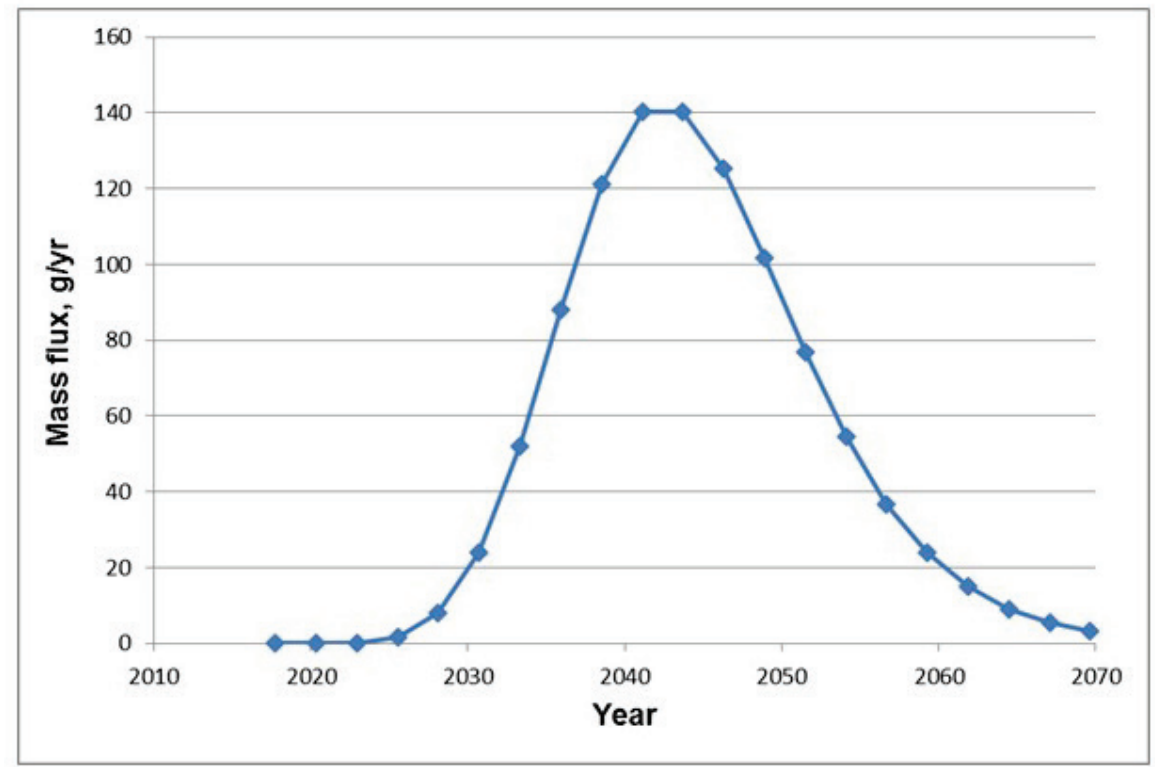

The resulting aquifer RDX concentrations at a hypothetical groundwater well located $1 \mathrm{~km}$ down-gradient of the AOI are plotted vs. year in Figure 46. There is about a fifty-year delay before RDX concentrations peak at the well, and concentrations are quite low due to dilution and transport attenuation. These low concentrations should not be interpreted as what would be always expected. Groundwater concentrations can be substantially higher for different loading conditions and site characteristics. 
Figure 46. Computed RDX dissolved concentration at groundwater well vs. year, scenario 2 (SCIA2) (no permafrost).

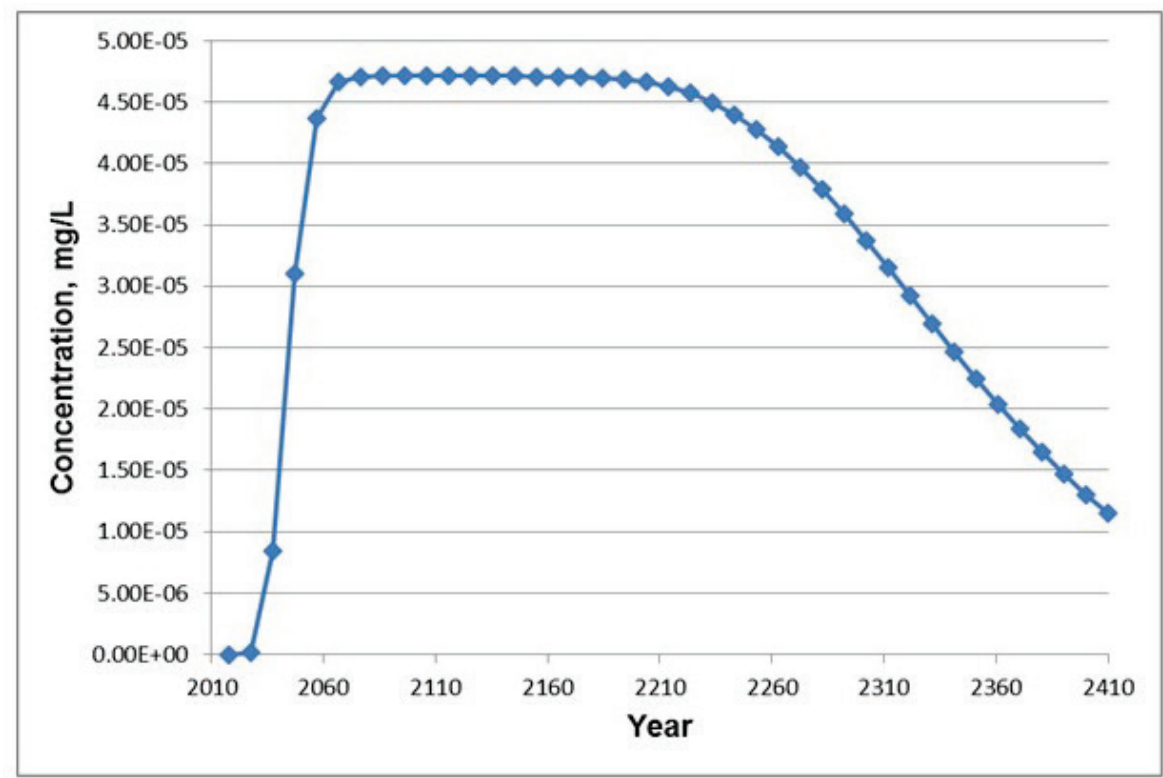

\subsubsection{Soil interflow mass fluxes to surface water}

The computed RDX mass flux from soil interflow to surface water is plotted vs. year in Figure 47 for scenario 2. Comparison of this figure to Figure 37 reveals that these fluxes are about 10 times lower for scenario 2 due to water and mass transported to the vadose zone rather than soil interflow.

\subsubsection{Combined mass fluxes to surface water}

The computed, combined, total (adsorbed and dissolved) mass flux of RDX to surface water vs. time as provided by the Plus Operator is plotted in Figure 48 for scenario 2. The vertical axis in Figure 48 is converted to log 10, so that both large and small values can be easily seen in the same plot. Figure 48 shows the mass fluxes delivered to surface water associated with AOI soil erosion, runoff, and soil interflow following fate/transport. These results are similar to those shown in Figure 38 with the primary difference being that the base fluxes due to interflow are lower for scenario 2. 
Figure 47. Computed RDX dissolved mass flux from soil interflow to surface water vs. year, scenario 2 (SCIA2) (no permafrost).

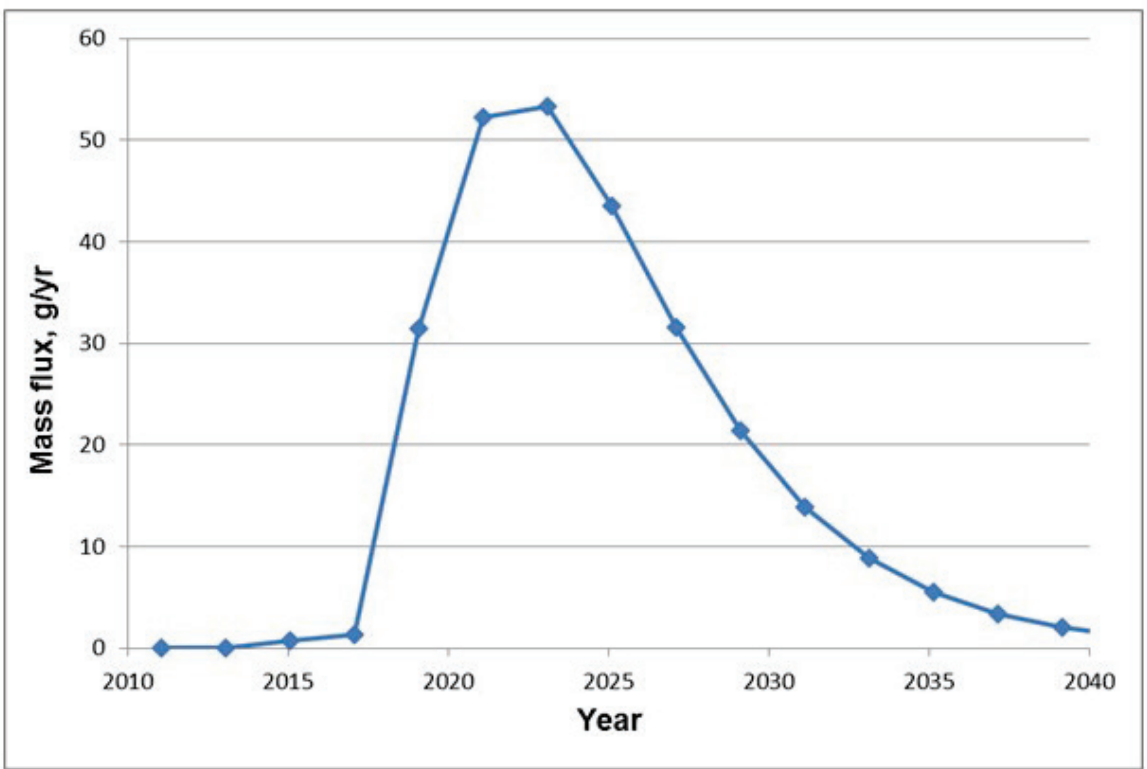

Figure 48. Computed, combined, total (adsorbed and dissolved) RDX mass flux to surface water (from Plus Operator output) vs. year, scenario 2 (SCIA2) (no permafrost).

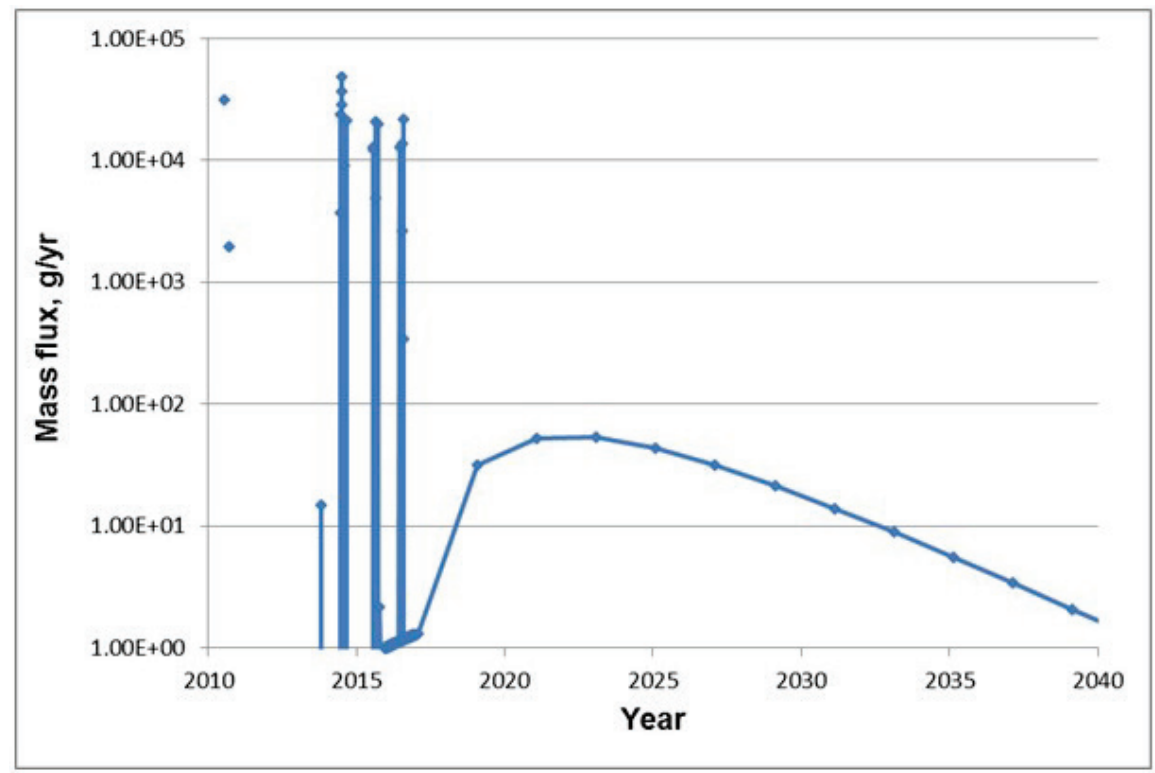

\subsubsection{Surface water and sediment concentrations}

RDX total (adsorbed and dissolved) sediment concentrations in Stuart Creek at the confluence with South Fork Chena River are plotted vs. year in Figure 49 for scenario 2. These results were obtained with background flow. Most of the time, the sediment concentrations are very near zero 
except during the thaw season when there are major rainfall - runoff events. RDX partitions weakly to sediments resulting in depletion of sediment concentrations due to stream flushing following loading spikes. Sediment dissolved pore-water concentrations are an order of magnitude lower than particulate (adsorbed) concentrations.

Comparison of Figure 49 with Figure 39 reveals that the sediment concentrations for scenario 2 are very similar to those of the base case. The reason for this is that the major contributor to the sediment concentrations is AOI surface export associated with rainfall - runoff. These exports were not impacted by the absence of permafrost.

Figure 49. Computed total RDX concentration in sediment vs. year in Stuart Creek at the confluence with South Fork Chena River, scenario 2 (SCIA2) (no permafrost) with background flow.

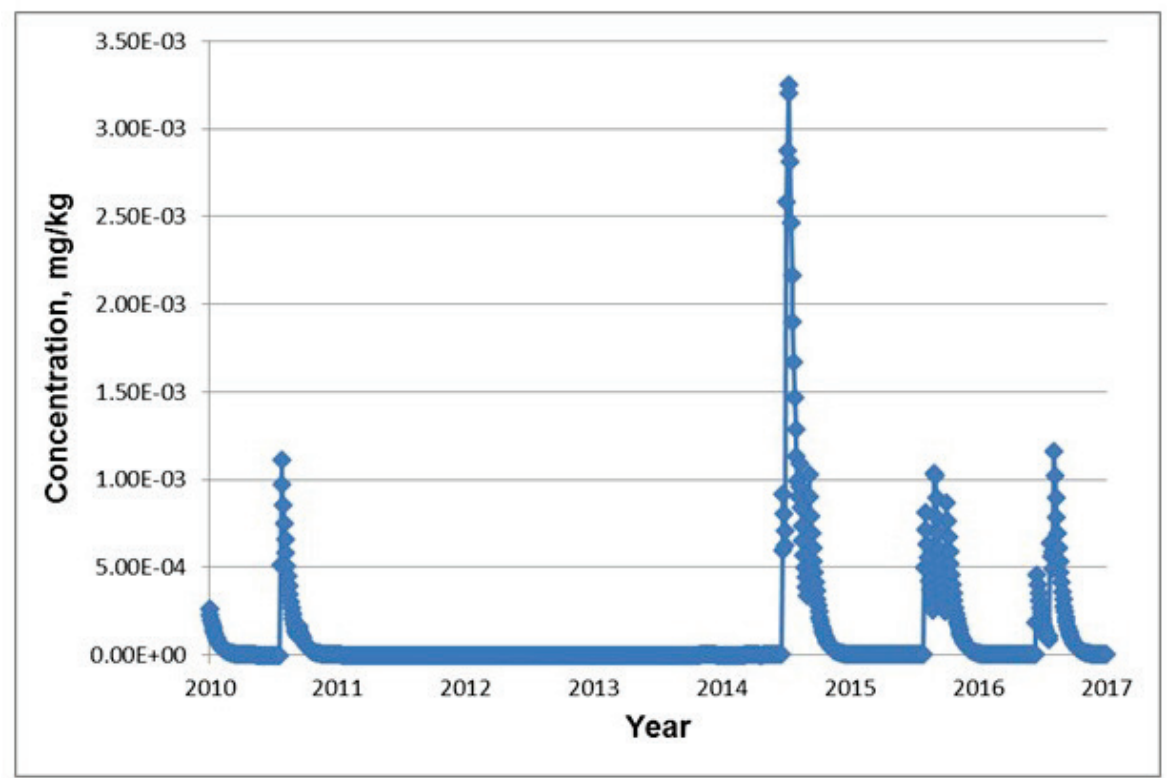

RDX total water column concentrations in Stuart Creek at the confluence with South Fork Chena River are plotted vs. year in for scenario 2. These results were obtained with background flow. Most of the time, the water column concentrations are very near zero except during the thaw season when there are major rainfall - runoff events. Comparison of Figure 50 with Figure 40 reveals that water column concentrations for scenario 2 are about the same as for the base case. The reason for this is the same as for the sediment concentrations. 
Figure 50. Computed total RDX concentration in water column vs. year in Stuart Creek at the confluence with South Fork Chena River, scenario 2 (SCIA2) (no permafrost) with background flow.

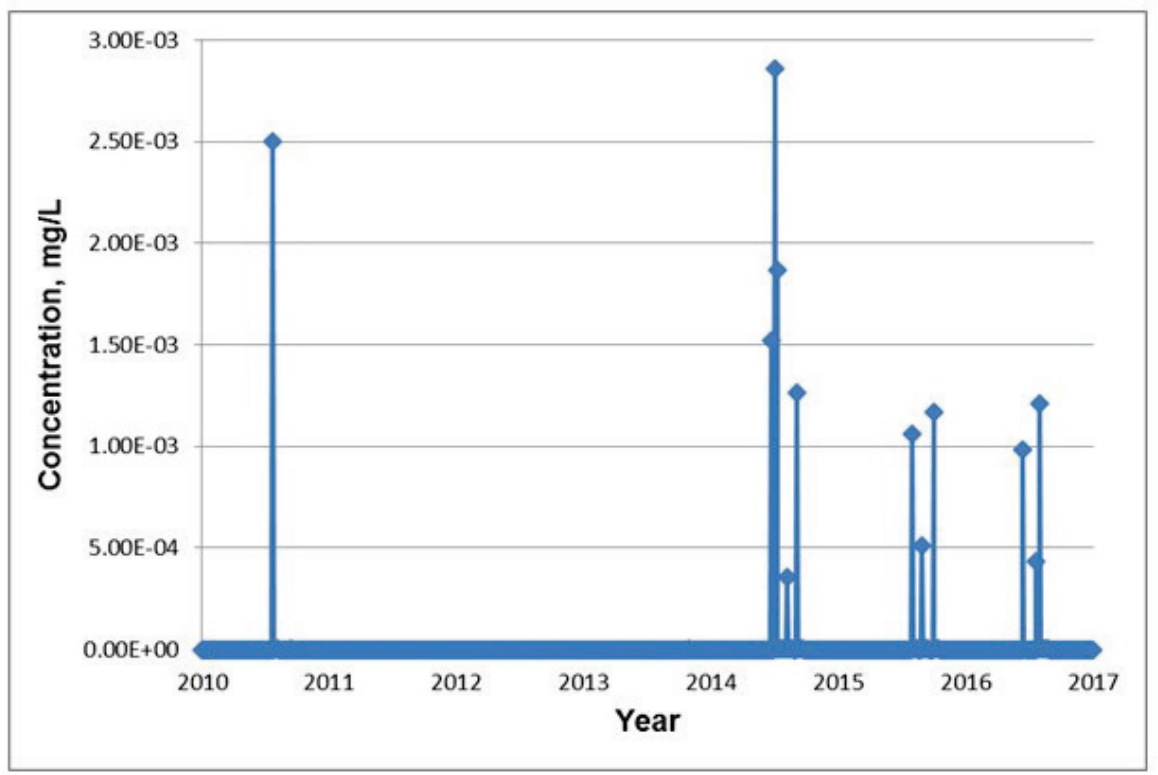




\section{Summary and Recommendations}

The TREECS ${ }^{\mathrm{TM}}$ was modified during this project to allow more realistic applications for Arctic conditions that are characterized by freeze/thaw seasons with the presence of permafrost. Modifications involved adding preprocessing models for simulating snow accumulation and melt (the Snow17 model) and soil thermal regime including daily variations in the freeze/thaw active layer thickness and depth to permafrost (the GIPL model). Output from these two models is used by the TREECS ${ }^{\mathrm{TM}}$ surface soil hydrology model, which was also modified for Arctic conditions. The soil contaminant fate model was modified to provide an Arctic version suitable for freeze/thaw seasons and varying active layer thickness. Other modifications were made to TREECS ${ }^{\mathrm{TM}}$ to accommodate applications to the Arctic including development of the WFF Interflow to WFF Aquifer Converter and modifications to the HGCT.

Arctic applications of TREECS ${ }^{\mathrm{TM}}$ should be conducted with the Advanced Tier II option. The example case ArcCase . trp, which is provided on the TREECS ${ }^{\mathrm{TM}}$ Website (https://treecs.el.erdc.dren.mil/), should be opened and resaved using another directory and name chosen by the user to preserve the example template case. This example case is a copy of the base case SCIA1.trp presented in section 9.4.

The Arctic version of TREECS ${ }^{\mathrm{TM}}$ was applied to the Stuart Creek impact area (SCIA) of the Yukon Training Area, which is part of Fort Wainwright, AK. The primary artillery impact area of SCIA was selected as the area of interest (AOI), and the HE RDX was the MC of concern. This study site is fairly unique because it resides within the alluvial plain of Stuart Creek, and as a result, the site soils are nearly saturated most of the time. TREECS $^{\mathrm{TM}}$ was applied for two conditions (Scenarios 1 and 2). Scenario 1 was applied with continuous permafrost, which is believed to be the natural condition. Scenario 2 was applied with no permafrost.

The application to SCIA confirmed preconceptions pertaining to the effects of permafrost on hydrology and transport. The presence of permafrost for the base condition forced water and $\mathrm{MC}$ mass (RDX for this application) from the AOI to surface water (Stuart Creek) with no percolation to groundwater. These results verified that the model performed as intended. There are no observations available to validate model accuracy for this 
study site. In the absence of permafrost, water and $\mathrm{MC}$ mass are able to percolate to groundwater with less available for transfer to surface water.

Precipitation either enters surface soil or runs off the AOI. With permafrost, water that enters the surface soil is either lost to ET or soil interflow. For SCIA and with permafrost, the average annual precipitation water depth transferred via soil interflow was nearly the same as that transferred via runoff ( 3.56 vs. 3.85 inches, respectively). However, the amount of RDX mass transferred by interflow was about 2.3 times greater than that transferred by runoff.

Without permafrost, the amount of average annual precipitation depth transferred to interflow was reduced by almost a factor of four to 0.91 inches, with the remainder (2.65 inches) transferred to groundwater. The cumulative mass of RDX transferred from the AOI to runoff was the same with no permafrost as with permafrost, but the RDX mass transferred from the AOI to soil interflow was a factor of 4.35 lower, or $471 \mathrm{~g}$, which is about half of that transferred by runoff. The remaining cumulative RDX mass transferred from the AOI was $1576 \mathrm{~g}$, which was transferred by percolation to groundwater.

Overall, the Arctic version of TREECS ${ }^{\mathrm{TM}}$ appeared to perform as expected with reasonable results. There were two recommendations that would improve performance. One improvement involves including new vadose zone and aquifer models that allow time-varying daily water flow rate rather than constant, average annual flow as required in the MEPAS models. A variable flow feature would result in seasonally-varying (i.e., freeze/thaw) pulses of percolating water and mass, thus, resulting in potentially more realistic groundwater concentrations. Also, since the aquifer model is used for fate and transport of soil interflow, a variable flow model should greatly improve the reasonableness of mass export to surface water by providing freeze/thaw pulses.

The second recommendation is to modify the CMS to allow variable background water flow, which would more accurately represent freeze/thaw, seasonal pulses of watershed water runoff into the receiving stream. Variable background flow would provide more accurate calculations for sediment and water column MC concentrations. Both of these recommendations would improve accuracy for non-Arctic applications as well. 
Another obvious recommendation is the collection of field data that can be used to validate the Arctic version of TREECS ${ }^{\mathrm{TM}}$. This data should include measurement of $\mathrm{MC}$ concentrations in groundwater and receiving surface water and sediment over time. Given the difficulty of measuring AOI soil $\mathrm{MC}$ concentrations due to range access, as well as MC heterogeneities in soil, long-term firing records are required to estimate $\mathrm{MC}$ loadings to the AOI soil.

The primary, overall conclusion from the site application is that recession of permafrost will promote $\mathrm{MC}$ migration to groundwater with less migration to surface water. The impact of these changes to target receptors cannot be stated since such impacts are tightly connected to site-specific conditions that can and should be included in the modeling. 


\section{References}

Anderson, E. A. 1973. National Weather Service River Forecast System Snow Accumulation and Ablation Model. NOAA Technical Memo. NWS HYDro-17. Silver Spring, MD: U.S. Department Of Commerce.

Anderson, E. A. 1976. A Point Energy and Mass Balance Model of a Snow Cover. NOAA Technical Report 19. Silver Spring, MD: U.S. Department Of Commerce.

Anderson, E. A. 2002. Calibration of conceptual hydrologic models for use in river forecasting. National Weather Service Hydrology Laboratory http://www.nws.noaa.gov/oh/hrl/calb/calbmain.htm. Accessed 24 January 2018.

Anderson, E. A. 2006. Snow accumulation and ablation model-SNOW-17, NWSRFS User Documentation, and U.S. National Weather Service. http://www.nws.noaa.gov/oh/hrl/nwsrfs/users_manual/part2/_pdf/22snow17.pdf.

Brock, T. D. 1981. Calculating solar radiation for ecological studies. Ecological Model 14: 1-19.

Buck, J. W., G. Whelan, J. G., Droppo, Jr., D. L. Strenge, K. J. Castleton, J. P. McDonald, C. Sato, and G. P. Streile. 1995. Multimedia Environmental Pollutant Assessment System (MEPAS) application guidance, guidelines for evaluating MEPAS input parameters for version 3.1. PNL-10395. Richland, WA: Pacific Northwest Laboratory.

Clapp, R.B., and G.M. Hornberger. 1978. Empirical equations for some soil hydraulic properties. Water Resources Research 14(4):601-604.

Colorado State University (CSU). 1999. Alaska Army lands withdrawal renewal final legislative environmental impact statement, Prepared for United States Army Alaska by the Center for Ecological Management of Military Lands, Fort Collins, CO: Colorado State University (CSU).

Colorado State University (CSU). 2004a. Transformation of U.S. Army Alaska, final environmental impact statement, Volume I, Prepared for United States Army Alaska by the Center for Environmental Management of Military Lands, Fort Collins, CO: Colorado State University (CSU).

Colorado State University (CSU). 2004b. Transformation of U.S. Army Alaska, final environmental impact statement, Appendix A, Maps, Prepared for United States Army Alaska by the Center for Environmental Management of Military Lands, Fort Collins, CO: Colorado State University (CSU).

Dortch, M. S., B. E. Johnson, Z. Zhang, and J. A. Gerald. 2011. Methods for Tier 2 modeling within the Training Range Environmental Evaluation and Characterization System. ERDC/EL TR-11-2. Vicksburg, MS: U.S. Army Engineer Research and Development Center.

Dortch, M. S. 2012. Validation applications of the Training Range Environmental Evaluation and Characterization System (TREECS ${ }^{\mathrm{TM}}$ ). ERDC/EL TR-12-3. Vicksburg, MS: U.S. Army Engineer Research and Development Center. 
Dortch, M. S., B.E. Johnson, and J.A. Gerald. 2012. Extension of capabilities for the Tier 1 and Tier 2 approaches within the Training Range Environmental Evaluation and Characterization System (TREECS ${ }^{\mathrm{TM}}$ ). ERDC/EL TR-12-11. Vicksburg, MS: U.S. Army Engineer Research and Development Center.

Dortch, M. S., B. E. Johnson, and J. A. Gerald. 2013. Modeling fate and transport of munitions constituents on firing ranges. Soil and Sediment Contamination: An International Journal 22(6):667-688. https://doi.org/10.1080/15320383.2013.756453.

Dortch, M. S. 2014. Evaluation of time-varying hydrology within the Training Range Environmental Evaluation and Characterization System (TREECS ${ }^{\mathrm{TM}}$ ). ERDC/EL CR-14-3. Vicksburg, MS: U.S. Army Engineer Research and Development Center.

Dortch, M. S., B. E. Johnson, and E. J. Weber. 2017a. Field demonstration and validation of TREECS ${ }^{\mathrm{TM}}$ and CTS for the risk assessment of contaminants on Department of Defense (DoD) ranges. ERDC/EL TR-17-5. Vicksburg, MS: U.S. Army Engineer Research and Development Center.

Dortch, M. S., E. J. Weber, and B. E. Johnson. 2017b. User guidance for application of TREECS ${ }^{\mathrm{TM}}$ and CTS for the risk assessment of contaminants on Department of Defense (DoD) ranges. ERDC/EL TR-17-8. Vicksburg, MS: U.S. Army Engineer Research and Development Center.

Dortch, M. S. 2018. Modeling dissolution of high explosive formulations. Soil and Sediment Contamination: an International Journal 27(4):280-310.

Fant, S., and M. S. Dortch. 2007. Documentation of a one-dimensional, time-varying contaminant fate and transport model for streams. ERDC/EL TR-07-01. Vicksburg, MS: U.S. Army Engineer Research and Development Center.

Farouki, O.T. 1981. Thermal Properties of Soils. CRREL Monograph 81-1. Hanover, NH: U.S. Army Cold Regions Research and Engineering Laboratory.

Forsythe, W. C., E. J. Rykiel, Jr., R. S. Stahl, H. Wu, and R. M. Schoolfield. 1995. A model comparison for day length as a function of latitude and day of year. Ecological Modeling 80(1):87-95. https://doi.org/10.1016/0304-3800(94)00034-F.

Frampton, A., S. Painter, S. W. Lyon, and G. Destouni. 2011. Non-isothermal, three-phase simulations of near-surface flows in a model permafrost system under seasonal variability and climate change. Journal of Hydrology 403(3-4):352-359. https://doi.org/10.1016/i.jhydrol.2011.04.010.

Franz, K. J., T. S. Hogue, and S. Sorooshian. 2008. Operational snow modeling: addressing the challenges of an energy balance model for National Weather Service forecasts. Journal of Hydrology 360(1-4):48-66. https://doi.org/10.1016/j.jhydrol.2008.07.013.

Gerald, J. A., B. E. Johnson, and M. S. Dortch. 2012. User guide for applying the Training Range Environmental Evaluation and Characterization System (TREECS ${ }^{\mathrm{TM}}$ ). ERDC/EL TR-12-16. Vicksburg, MS: U.S. Army Engineer Research and Development Center. 
Hallema, D. W., Y. Périard, J. A. Lafond, S. J. Gumiere, and J. Caron. 2015. Characterization of water retention curves for a series of cultivated histosols. Vadose Zone Journal 14(6):8.

Hansson, K., J. Šimůnek, M. Mizoguchi, L.-Ch. Lundin, and M. Th. van Genuchten. 2004. Water flow and heat transport in frozen soil: Numerical solution and freeze/thaw applications. Vadose Zone Journal 3(2):693-704.

Hossain, M. F., W. Chen, and Yu Zang. 2015. Bulk density of mineral and organic soils in the Canada's arctic and sub-arctic. Information Processing in Agriculture 2:183190.

Jafarov, E. E., S. S.Marchenko, and V. E. Romanovsky. 2012. Numerical modeling of permafrost dynamics in Alaska using a high spatial resolution dataset. The Cryosphere 6:613-624.

Johnson, B. E., and M. S. Dortch. 2014. Hydrology model formulation within the Training Range Environmental Evaluation and Characterization System (TREECS ${ }^{\mathrm{TM}}$ ). ERDC/EL TR-14-2. Vicksburg, MS: U.S. Army Engineer Research and Development Center.

Joint Departments of the Army and the Air Force USA. 1987. Arctic and Subarctic Construction Calculation methods for Determination of Depths of Freeze and Thaw in Soils. TM 5-852-6/AFR 88-19, Volume 6.

Konovalov, A. A., and L. T. Roman. 1973. The thermophysical properties of peat soils. Soil Mechanics and Foundation Engineering 10(3):179-181.

Lovell, C. W. 1957. Temperature effects on phase composition and strength of partially frozen soil. Highway Research Board Bulletin 168:74-95.

Luo D. L., H. J. Jin, S. Marchenko, and V. Romanovsky. 2014. Distribution and changes of active layer thickness (ALT) and soil temperature (TTOP) in the source area of the Yellow River using the GIPL model. China: Earth Sciences 57:1834-1845.

McKenzie, J. M., C. I. Voss, and D. I. Siegel. 2007. Groundwater flow with energy transport and water-ice phase change: Numerical simulations, benchmarks, and application to freezing in peat bogs. Advances in Water Resources 30:966-983.

Menberu, M. W., A. T. Haghighi, A. K. Ronkanen, J. Kværner, and B. Kløve. 2015. Runoff curve numbers for peat-dominated watersheds Journal of Hydrological Engineering 20(4):04014058-1-04014058-10.

Model:GIPL. Jan 4, 2016. CSDMS. Accessed on 19 July 2016. https://csdms.colorado.edu/mediawiki/index.php?title=Model:GIPL\&oldid=216660.

Mueller, K. E., D. Tillman, D. A. Fornara, and S. E. Hobbie. 2013. Root depth distribution and the diversity-productivity relationship in a long-term grassland experiment. Ecology 94(4):787-793.

Mulligan, D., 2004. Soil Survey of the Greater Fairbanks Area, Alaska. Available for download from the Natural Resources Conservation Service at https://www.nrcs.usda.gov/Internet/FSE_MANUSCRIPTS/alaska/AK610/0/GreaterFairbanks.p df. 
Nicolsky, D. J., Romanovsky, V. E., and G. S. Tipenko. 2007. Using in-situ temperature measurements to estimate saturated soil thermal properties by solving a sequence of optimization problems. The Cryosphere 1:41-58.

Nippert, J. B., R. A. Wieme, T. W. Ocheltree, and J. M. Craine. 2012. Root characteristics of $\mathrm{C}_{4}$ grasses limit reliance on deep soil water in tallgrass prairie. Plant Soil 355(1-2):385-394.

Painter, S. L. 2011. Three-phase numerical model of water migration in partially frozen geological media: model formulation, validation, and applications. Computational Geosciences 15:69-85.

Ping, C. L. 1987. Soil temperature profiles of two Alaskan soils. Soil Science Society of America Journal 51:1010-1018.

Plumb, E. W., and M. R. Lilly. 1996. Snow-depth and water-equivalent data for the Fairbanks area, Alaska, spring 1995. Open-File Report 96-414. Fairbanks, AK: U.S. Geological Survey (USGS).

Rühaak, W., H. Anbergen, C. Grenier, J., McKenzie, B. L. Kurylyk, J. Molson, N. Roux, and I., Sass. 2015. Benchmarking numerical freeze/thaw models, Energy Procedia 76:301-310.

Ruiz, C. E., and T. Gerald. 2001. RECOVERY version 2.o, a mathematical model to predict the temporal response of surface water to contaminated sediments. ERDC/EL TR-01-3. Vicksburg, MS: U.S. Army Engineer Research and Development Center.

Shamir, E., and K. P. Georgakakos. 2007. Estimating snow depletion curves for American river basins using distributed snow modeling. Journal of Hydrology 334:162173. https://doi.org/10.1016/i.jhydrol.2006.10.007.

Sturm, M., J. Holmgren, and G. E. Liston. 1995. A seasonal snow cover classification for local to global application. Journal of Climate 8:1261-1283. https://doi.org/10.1175/1520-0442(1995)008<1261:ASSCCS>2.0.C0;2

Sturm, M., B. Tara, G. E., Liston, C. Derksen, T. Jonas, and J. Lea. 2010. Estimating snow water equivalent using snow depth data and climate classes. Journal of Hydrometeorology 11:1380-1394.https://doi.org/10.1175/2010JHM1202.1.

Tice, A. R., P. B. Black, and R. L. Berg. 1989. Unfrozen water contents of undisturbed and remolded Alaskan silt. Cold Regions Science and Technology 17(2):103-111. https://doi.org/10.1016/S0165-232X(89)80001-1.

Voss, C. I., and A. M. Provost. 2002. SUTRA; A model for saturated-unsaturated, variable-density ground-water flow with solute or energy transport. WaterResources Investigations Report 02-4231. Washington, DC: U.S. Geological Survey (USGS).

Walczak, R., E. Rovdan, and B. Witkowska-Walczak. 2002. Water retention characteristics of peat and sand mixtures, International Agrophysics 16:161-165. 
Watanabe, K., N. Toride, M. Sakai, and J. Šimůnek. 2007. Numerical modeling of water, heat, and solute transport during soil freezing. Journal of the Japanese Society of Soil Physics 106 21-32.

Whelan, G., J. P. McDonald, and C. Sato. 1996. Multimedia Environmental Pollutant Assessment System (MEPAS): Groundwater Pathway Formulations. PNNL10907/UC-630, Richland, WA: Pacific Northwest National Laboratory. http://mepas.pnl.gov/mapas/maqu/index.html.

Whelan, G., and K. J. Castleton. 2006. Groundwater modeling system linkage with the frame-work for risk analysis in multimedia environmental systems. PNNL15654. Report to U.S. Nuclear Regulatory Commission. Richland, WA: Pacific Northwest National Laboratory.

Whelan, G., K. J. Castleton, J. W. Buck, B. L. Hoopes, M. A. Pelton, D. L. Strenge, G. M. Gelston, and R. N. Kickert. 1997. Concepts of a Framework for Risk Analysis in Multimedia Environmental Systems. PNNL-11748. Richland, WA: Pacific Northwest National Laboratory. 


\section{Appendix A: GIPL Input and Output files}

Figure A-1. Example of GIPL input file used as the control file for TREECSTM GIPL, gipl_config.cfg.

\begin{tabular}{|c|}
\hline 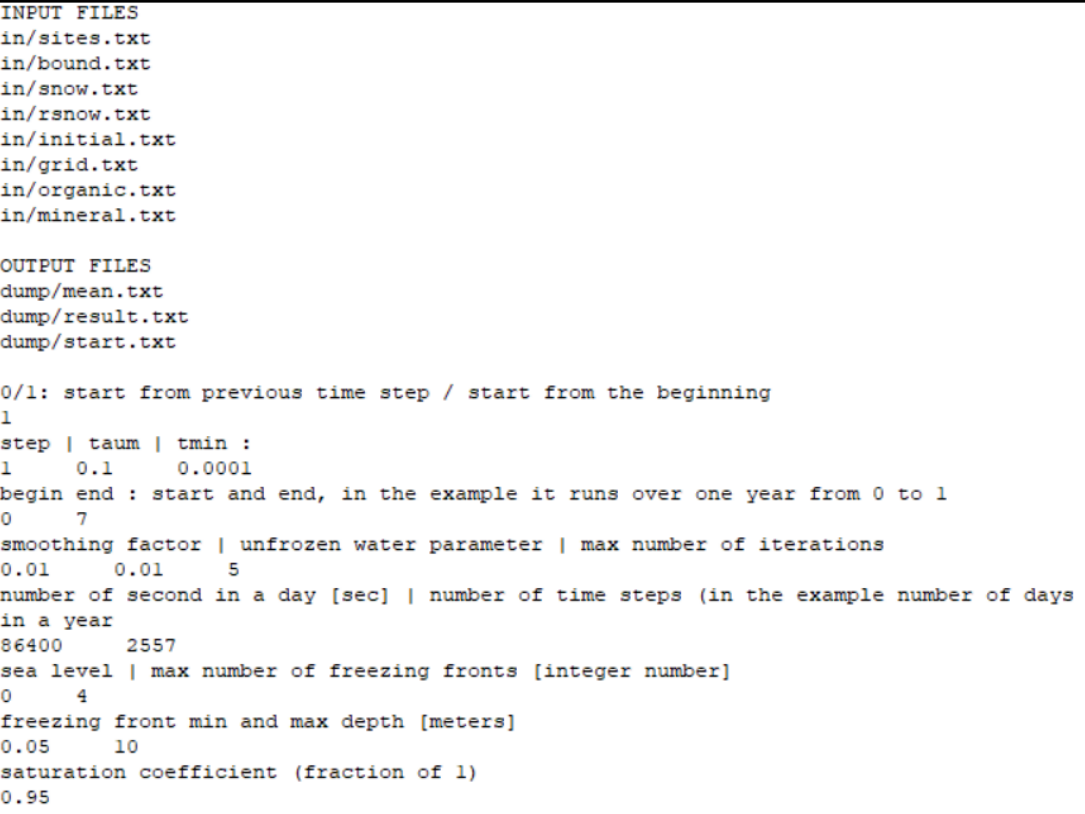 \\
\hline
\end{tabular}

Figure A-2. Example of sites input file used by TREECSTM GIPL, in/sites.txt.

\begin{tabular}{|llllll|}
\hline 1 & & & & & \\
1 & 246 & 1 & 1 & 1 & -0.2021 \\
& & & & & \\
\hline
\end{tabular}


Figure A-3. Example of grid input file used by TREECSTM GIPL, in/grid.txt. a) listing of selected grid nodes, b) listing of nodes selected for output.

\begin{tabular}{|l|}
\hline 176 \\
-1.5 \\
-1.45 \\
-1.4 \\
-1.35 \\
-1.3 \\
-1.25 \\
-1.2 \\
-1.15 \\
-1.1 \\
-1.05 \\
-1 \\
-0.95 \\
-0.9 \\
-0.85 \\
-0.8 \\
-0.75 \\
-0.7 \\
-0.65 \\
-0.6 \\
-0.55 \\
-0.5 \\
-0.45 \\
-0.4 \\
-0.35 \\
-0.3 \\
-0.25 \\
-0.2 \\
\hline
\end{tabular}




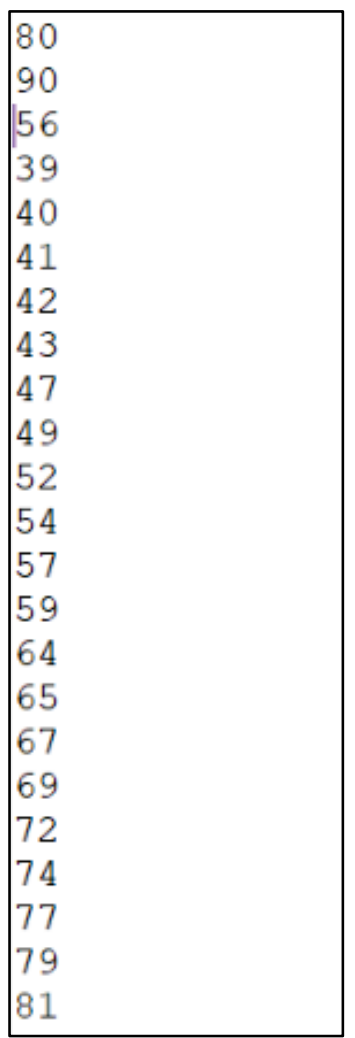

Figure A-4. Example of mineral input file used by TREECSTM GIPL, in/mineral.txt.

\begin{tabular}{|c|c|c|c|c|c|c|c|}
\hline \multicolumn{8}{|l|}{1} \\
\hline 1 & & & & & & & \\
\hline 0.4 & 0.07 & -0.19 & 2000000 & 1600000 & 1.9 & 3.11 & 0.5 \\
\hline 0.485 & 0.001 & -0.9 & 2400000 & 2300000 & 3.08 & 3.29 & 20 \\
\hline
\end{tabular}

Figure A-5. Example of organic input file used by TREECSTM GIPL, in/organic.txt.

\begin{tabular}{|c|c|c|c|c|c|c|c|}
\hline \multicolumn{8}{|l|}{1} \\
\hline 1 & & & & & & & \\
\hline 0.85 & 0.07 & -0.019 & 2000000 & 1600000 & 0.1 & 0.6 & 0.3 \\
\hline
\end{tabular}


Figure A-6. Example of bound input file used by TREECSTM GIPL, in/bound.txt

\begin{tabular}{|ll|}
\hline \multicolumn{2}{||}{2557} \\
1 & -30.6 \\
2 & -35 \\
3 & -33.9 \\
4 & -27.2 \\
5 & -19.5 \\
6 & -14.2 \\
7 & -16.1 \\
8 & -21.4 \\
9 & -23.9 \\
10 & -29.5 \\
11 & -34.7 \\
12 & -36.7 \\
13 & -30.3 \\
14 & -29.5 \\
15 & -32.3 \\
16 & -27.5 \\
17 & -23.4 \\
18 & -26.4 \\
19 & -28.9 \\
20 & -29.2 \\
21 & -26.7 \\
22 & -22 \\
23 & -26.7 \\
\hline
\end{tabular}

Figure A-7. Example of rsnow input file used by TREECSTM GIPL, in/rsnow.txt.

\begin{tabular}{|ll|}
\hline 1 & 0.1 \\
2 & 0.1 \\
3 & 0.1 \\
4 & 0.1 \\
5 & 0.1 \\
6 & 0.1 \\
7 & 0.1 \\
8 & 0.1 \\
9 & 0.1 \\
10 & 0.1 \\
11 & 0.1 \\
12 & 0.1 \\
13 & 0.1 \\
14 & 0.1 \\
15 & 0.1 \\
\hline
\end{tabular}


Figure A-8. Example of snow input file used by TREECS'M GIPL, in/snow.txt

\begin{tabular}{|ll|}
\hline \multicolumn{2}{|c|}{2557} \\
1 & 0.254 \\
2 & 0.254 \\
3 & 0.254 \\
4 & 0.254 \\
5 & 0.254 \\
6 & 0.254 \\
7 & 0.254 \\
8 & 0.254 \\
9 & 0.254 \\
10 & 0.254 \\
11 & 0.254 \\
12 & 0.254 \\
13 & 0.254 \\
14 & 0.254 \\
15 & 0.254 \\
\hline
\end{tabular}

Figure A-9. Example of initial input file used by TREECS ${ }^{\top M}$ GIPL, in/initial.txt

\begin{tabular}{|lc|}
\hline 1 & 19 \\
DEPTH & TEMP \\
-1.5 & -12.6 \\
0.01 & -4.612 \\
0.02 & -4.6081 \\
0.1 & -3.9004 \\
0.16 & -3.4188 \\
0.24 & -3.0496 \\
0.32 & -2.6052 \\
0.4 & -2.286 \\
0.48 & -1.9465 \\
0.56 & -1.5635 \\
0.7 & -0.7951 \\
0.86 & -0.2021 \\
1.05 & -0.2021 \\
1.5 & -0.2021 \\
2 & -0.2021 \\
2.5 & -0.2021 \\
3 & -0.2021 \\
10 & -0.2021 \\
90 & -0.2021 \\
\hline
\end{tabular}


The dump/results . txt file (Figure A-10) is the source of the GIPL output on the GIPL_output tab within the TREECS Arctic pre- and postprocessor. The first column is the site designated in the in/sites.txt file. The second column is the time step counter. In TREECSTM this will always be in days. Column \#3 is the upper boundary temperature specified in the in/bound. txt input file. Column \#4 is the snow depth specified in the in/snow. txt input file. The remaining columns correspond to the nodes specified for output beginning at the upper end of the profile and progressing deeper toward the right of the file. Figure A-10 shows 2 columns of node temperature output but the file does extend for 54 more columns to the right of what is shown.

Figure A-10. Example of output file dump/result. txt used by GIPL_output tab.

\begin{tabular}{|lrllll|}
\hline 1 & 1.000 & -30.600000000000 & 0.254000000000 & -4.664900662252 & -4.659610596026 \\
1 & 2.000 & -35.000000000000 & 0.254000000000 & -4.270102714679 & -4.262513459983 \\
1 & 3.000 & -33.900000000000 & 0.254000000000 & -5.023808062561 & -5.010437915258 \\
1 & 4.000 & -27.200000000000 & 0.254000000000 & -5.693884580086 & -5.678856990621 \\
1 & 5.000 & -19.500000000000 & 0.254000000000 & -5.907109676928 & -5.893433297266 \\
1 & 6.000 & -14.200000000000 & 0.254000000000 & -5.669915288965 & -5.658936310453 \\
1 & 7.000 & -16.100000000000 & 0.254000000000 & -5.222600826564 & -5.213852219096 \\
1 & 8.000 & -21.400000000000 & 0.254000000000 & -4.926212517185 & -4.917749272643 \\
1 & 9.000 & -23.900000000000 & 0.254000000000 & -4.944991154392 & -4.935358494173 \\
1 & 10.000 & -29.500000000000 & 0.254000000000 & -5.184555663478 & -5.173393267796 \\
1 & 11.000 & -34.700000000000 & 0.254000000000 & -5.640153832606 & -5.626827507291 \\
1 & 12.000 & -36.700000000000 & 0.254000000000 & -6.253472070360 & -6.237950269238 \\
1 & 13.000 & -30.300000000000 & 0.254000000000 & -6.814172730536 & -6.797735463094 \\
\hline
\end{tabular}

The dump / mean . txt file (Figure A-11) is created to summarize the large dump/result.txt file. Column \#1 is the site number designated in in/sites.txt. Column \#2 is the mean time. Column \# 3 is the average upper boundary temperature. Column \#4 is the average snow depth. Beginning with column \#5, there is one average temperature per node. Two average node temperature columns are shown in Figure A-11. Three columns follow the average node temperature columns (part b, Figure A11). The third column from the right is the mean depth of the freezing front. The second column from the right is the freeze-up date within the current year and the final column is the global freeze up date. 
Figure A-11. Example of output file dump/mean . txt created by the GIPL model: a) The left side columns \#1-\#6. b) The final columns \#55-\#59.

\begin{tabular}{|rrrrrr|}
\hline 1 & 1279.000 & -1.665 & 0.164 & 3.329 & 3.293 \\
1 & 3836.000 & -0.300 & 0.745 & -0.987 & -0.987 \\
1 & 6393.000 & -0.300 & 0.745 & -0.515 & -0.515 \\
1 & 8950.000 & -0.300 & 0.745 & -0.426 & -0.427 \\
1 & 11507.000 & -0.300 & 0.745 & -0.386 & -0.386 \\
1 & 14064.000 & -0.300 & 0.745 & -0.362 & -0.362 \\
1 & 16621.000 & -0.300 & 0.745 & -0.346 & -0.346 \\
\hline
\end{tabular}

\begin{tabular}{|lrr|}
\hline 0.000 & 2501.000 & 2501.000 \\
0.000 & -7777.000 & -7777.000 \\
0.000 & -7777.000 & -7777.000 \\
0.000 & -7777.000 & -7777.000 \\
0.000 & -7777.000 & -7777.000 \\
0.000 & -7777.000 & -7777.000 \\
0.000 & -7777.000 & -7777.000 \\
\hline
\end{tabular}

The start file (Figure A-12) is a hot-start file so that the output of a previous model run can be used as the initial condition for a new model run. The data in the start file corresponds to the node temperatures in the last row of the dump/results . txt file.

Figure A-12. Example of output file dump/start.txt created by the GIPL model.

\begin{tabular}{|r|}
\hline 1.00000000000000 \\
-0.300000000000000 \\
-0.300000026542650 \\
-0.300000053085300 \\
-0.300000079627950 \\
-0.300000106170600 \\
-0.300000132713250 \\
-0.300000159255899 \\
-0.300000185798549 \\
-0.300000212341199 \\
-0.300000238883848 \\
-0.300000265426498 \\
-0.300000291969147 \\
-0.300000318511797 \\
\hline
\end{tabular}




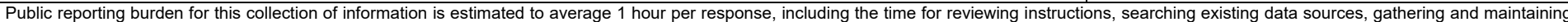

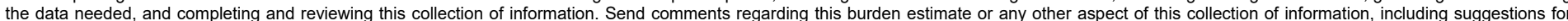

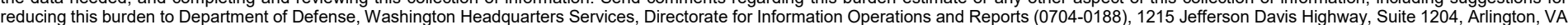

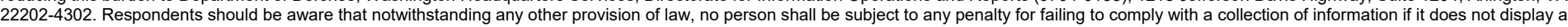
currently valid OMB control number. PLEASE DO NOT RETURN YOUR FORM TO THE ABOVE ADDRESS.
1. REPORT DATE (DD-MM-YYYY)
2. REPORT TYPE
Final report
September 2019

\section{TITLE AND SUBTITLE}

Development and Testing of the Training Range Environmental Evaluation and Characterization System (TREECS ${ }^{\mathrm{TM}}$ ) for Arctic/Sub-Arctic Conditions

3. DATES COVERED (From - To)

5a. CONTRACT NUMBER

5b. GRANT NUMBER

5c. PROGRAM ELEMENT NUMBER

\section{AUTHOR(S)}

Mark S. Dortch, Jodi L. Ryder, Jeffrey A. Gerald, and Billy E. Johnson

5d. PROJECT NUMBER

ER-201435

5e. TASK NUMBER

5f. WORK UNIT NUMBER

8. PERFORMING ORGANIZATION REPORT NUMBER

ERDC/EL TR-19-12

U.S. Army Engineer Research and Development Center

Environmental Laboratory

3909 Halls Ferry Road

Vicksburg, MS 39180-6199

9. SPONSORING / MONITORING AGENCY NAME(S) AND ADDRESS(ES)

Headquarters, U.S. Army Corps of Engineers

Washington, DC 20314-1000
10. SPONSOR/MONITOR'S ACRONYM(S)

11. SPONSOR/MONITOR'S REPORT

NUMBER(S)

\section{DISTRIBUTION / AVAILABILITY STATEMENT}

Approved for public release; unlimited distribution.

13. SUPPLEMENTARY NOTES

\section{ABSRACT}

The Training Range Environmental Evaluation and Characterization System (TREECS ${ }^{\mathrm{TM}}$ ) was developed for the Army to forecast the fate of and risk from munitions constituents (MC), such as high explosives and metals, within and transported from firing/training ranges to surface water and groundwater. The military footprint of the United States (U.S.) in the Arctic region falls within the state of Alaska, where the U.S. Army manages approximately 10\% of all active Army training lands worldwide. Primary recalcitrant contaminants of concern at active and previously-used training ranges include energetics, high explosives, and heavy metals. There are limited management tools for assessing contaminant fate \& transport and identifying risks in Arctic environments. TREECS ${ }^{\mathrm{TM}}$ can handle a wide variety of site conditions and has been applied to a variety of temperate sites. However, previous versions had limitations for application to Arctic conditions. The work reported herein was conducted to overcome these limitations. This report describes the changes implemented in TREECS ${ }^{\mathrm{TM}}$ for handling Arctic conditions as well as application test results.

\section{SUBJECT TERMS}

Fate/transport modeling

16. SECURITY CLASSIFICATION OF:

\begin{tabular}{|l|l|}
\hline a. REPORT & b. ABSTRACT \\
UNCLASSIFIED & UNCLASSIFIED
\end{tabular}

Multi-media

Freeze/thaw conditions

c. THIS PAGE
UNCLASSIFIED

Permafrost
17. LIMITATION OF ABSTRACT
18. NUMBER OF PAGES

136 19a. NAME OF RESPONSIBLE PERSON

19b. TELEPHONE NUMBER (include

